\title{
Therapy development for spinal muscular atrophy: perspectives for muscular dystrophies and neurodegenerative disorders
}

Sibylle Jablonka* ${ }^{*}$, Luisa Hennlein and Michael Sendtner ${ }^{*}$

\begin{abstract}
Background: Major efforts have been made in the last decade to develop and improve therapies for proximal spinal muscular atrophy (SMA). The introduction of Nusinersen/Spinraza ${ }^{\mathrm{TM}}$ as an antisense oligonucleotide therapy, Onasemnogene abeparvovec/Zolgensma ${ }^{\mathrm{TM}}$ as an AAV9-based gene therapy and Risdiplam/Evrysdi ${ }^{\mathrm{TM}}$ as a small molecule modifier of pre-mRNA splicing have set new standards for interference with neurodegeneration.

Main body: Therapies for SMA are designed to interfere with the cellular basis of the disease by modifying premRNA splicing and enhancing expression of the Survival Motor Neuron (SMN) protein, which is only expressed at low levels in this disorder. The corresponding strategies also can be applied to other disease mechanisms caused by loss of function or toxic gain of function mutations. The development of therapies for SMA was based on the use of cell culture systems and mouse models, as well as innovative clinical trials that included readouts that had originally been introduced and optimized in preclinical studies. This is summarized in the first part of this review. The second part discusses current developments and perspectives for amyotrophic lateral sclerosis, muscular dystrophies, Parkinson's and Alzheimer's disease, as well as the obstacles that need to be overcome to introduce RNA-based therapies and gene therapies for these disorders.
\end{abstract}

Conclusion: RNA-based therapies offer chances for therapy development of complex neurodegenerative disorders such as amyotrophic lateral sclerosis, muscular dystrophies, Parkinson's and Alzheimer's disease. The experiences made with these new drugs for SMA, and also the experiences in AAV gene therapies could help to broaden the spectrum of current approaches to interfere with pathophysiological mechanisms in neurodegeneration.

Keywords: Motoneuron disease, Neurodegenerative disease, Muscular disease, Spinal muscular atrophy, Amyotrophic lateral sclerosis, Muscular dystrophy, Alzheimer disease, Parkinson disease, Clinical trial, Gene therapy

\section{Background}

Spinal muscular atrophy (SMA) is the most common form of a lethal pediatric neuromuscular disorder with autosomal recessive inheritance. It is caused by homozygous loss of function (LOF) mutations of the Survival Motor Neuron 1 (SMN1) gene [170] on human chromosome 5(5q13.2). Thus, therapeutic approaches so far have

*Correspondence: jablonka_s@ukw.de; sendtner_m@ukw.de Institute of Clinical Neurobiology, University Hospital of Wuerzburg, Versbacher Str. 5, 97078 Wuerzburg, Germany focused on restoration of SMN expression. The specific architecture on human chromosome 5 with a second $S M N$ gene (SMN2) is responsible for the cellular production of low levels of SMN protein that are not sufficient to maintain structure and function of motoneurons. SMN2 differs from SMN1 by a single C to T transition in exon 7, leading to increased skipping of exon 7 [180, 206]. Thus, approaches to suppress alternative splicing of this exon and an AAV9-based gene therapy for enhanced expression of the SMN protein in motoneurons have led 
to success in treating degeneration of motoneurons in this disease.

Restoration of protein expression is also a central goal for therapy development in Duchenne-and Becker-type muscular dystrophies [52, 72, 155]. Thus, oligonucleotide-based therapies as well as gene therapies are currently tested in these disorders. Experience with such therapies is rapidly progressing, and this also has impact on therapy development for other neurodegenerative disorders such as amyotrophic lateral sclerosis (ALS). Oligonucleotide therapies do not exclusively offer the chance to increase expression of proteins such as SMN, but also to repress expression of mutant proteins with pathological function in other neurodegenerative disorders. This offers further technical opportunities for interference with other neurodegenerative mechanisms.

Our review summarizes the development of antisenseoligonucleotide (ASO) and gene therapy for SMA, based on the literature search via PubMed.gov and released data from https://clinicaltrials.gov. The second part addresses opportunities and challenges associated with further development of these approaches for treatment of other neurodegenerative disorders and muscular dystrophies.

\section{Spinal muscular atrophy (SMA): disease mechanisms and identification of targets for therapy}

\section{Disease presentation and classification of spinal muscular} atrophy (SMA)

The severe form of proximal spinal muscular atrophy, also called Werdnig-Hoffmann disease [122, 123, 316], is the most common monogenetic lethal pediatric neuromuscular disorder. A milder form of proximal spinal muscular atrophy also exists that originally has been considered as a distinct neurological disease [160]. However, after the identification of the underlying gene defect [170], it became apparent that both diseases are caused by homozygous deletion of the Survival Motor Neuron 1 (SMN1) gene on human chromosome 5q13.2. All forms of 5q-SMA (type 1-4) have an incidence of 1/600010,000 world-wide [77, 229, 231, 305]. SMA follows autosomal recessive inheritance. Dysfunction and loss of spinal motoneurons is the most prominent pathological feature causing weakness and atrophy, notably in proximal muscle groups, and respiratory failure.

Depending on disease onset and severity, SMA is classified into four types ranging from the most severe type 1 to intermediate type 2 and milder types 3 and 4 (with adult onset) $[69,70,78,230]$. This classification mainly focuses on achieved motor milestones with the disadvantage of frequent overlap between different types. Thus, an additional classification has been introduced to cover dynamic changes in the clinical phenotype after therapy as well. This new classification distinguishes non-sitters (type 1-2), sitters (type 2-3) and walkers (type 3-4) [197], summarized in Table 1.

\section{SMA genetics}

The two survival motor neuron genes: SMN1 and SMN2

Humans carry two $S M N$ genes (SMN1 and SMN2) within a duplicated region on chromosome 5q. Homozygous loss or mutations of SMN1 cause SMA, whereas loss of SMN2 is usually not associated with the disease. During evolution, the duplication of the SMN gene occurred at the stage of non-human primates [251]. In laboratory mice and other rodents, the Smn gene is not duplicated [263, 264]. SMN1 and SMN2 differ only in a few nucleotides. Of particular importance is the $\mathrm{C}$ to $\mathrm{T}$ transition in exon 7 of the centromeric SMN2 which causes alternative splicing of exon 7. Most transcripts from the SMN2 gene lack exon 7-encoded domains, resulting in only 5-10\% full-length SMN protein in comparison to $100 \%$ full-length SMN protein from SMN1 transcripts (Fig. 1). Therefore, SMN2 can only partially compensate for SMN1 loss [180, 206, 207]. Most SMA patients carry 2-3 SMN2 copies. This allows cellular production of approximately $10-30 \%$ full-length SMN protein in comparison to healthy controls with intact SMN1 gene copies. Thus, the SMN2 copy number is the most important genetic modifier of SMA disease severity [85, 319].

The majority of the severely affected SMA patients bear homozygous deletions of SMN1 whereas most SMA type 2 and 3 patients show a homozygous absence of SMN1 due to a gene conversion of SMN1 into SMN2 [37, 318]. Gene conversion is a common cause for $S M N 2$ gene copy number variations, increasing the SMN2 gene copy number from 2 to 3 or 4 [40]. Four copies of SMN2 usually generate sufficient functional SMN protein for a milder disease phenotype $[85,185]$ in SMA type 3 patients.

In about $5 \%$ of SMA patients, point mutations are detected in the SMN1 gene mostly in exon 6 and 7 [320]. Such cases are termed "compound heterozygotes"-with a deletion/conversion in one allele and a point mutation in the other.

Apart from 5q-SMA, other forms of spinal muscular atrophies exist which can be classified into the following categories on the basis of disease phenotype and genetic inheritance: autosomal recessive and autosomal dominant distal spinal muscular atrophies (DSMAs); autosomal dominant proximal spinal muscular atrophies; autosomal recessive non-5q spinal and bulbar muscular atrophies; X-linked recessive SMAs.

\section{Genetic modifiers in SMA}

A transcriptome-wide differential expression analysis of total RNA from lymphoblastoid cells, derived from 
Table 1 New classification of disease severity in SMA patients according to [69, 78, 230] and adapted to [70]

\begin{tabular}{|c|c|}
\hline SMA type & Phenotype \\
\hline SMA type 1 & $\begin{array}{l}\text { Severe with variations }(1.1-1.9) \text {, patients never sit at the time of diagnosis. } \\
\text { 1.1- Severe paralysis at birth with respiratory failure, bulbar paralysis and negative survival prognosis. } \\
\text { 1.5- Floppy baby just after birth, abdominal breathing but no spontaneous respiratory distress. No noticeable } \\
\text { feeding and breathing constraints. } \\
\text { 1.9- The infant is able to sit unaided, but not quite; problems in feeding and breathing are not recognizable. }\end{array}$ \\
\hline SMA type 2 & $\begin{array}{l}\text { Intermediate with variations }(2.1-2.9) \text {, patients sit independently at the time of diagnosis. } \\
\text { 2.1- The sitting position is hard to maintain. } \\
\text { 2.5- Stable sitting with good posture, but not able to stand without support. } \\
\text { 2.7- Stable sitting position, can develop the ability to walk with the aid of crutches. } \\
\text { 2.9- Sitting in a stable fashion, standing with support, or independently but not for a long time. }\end{array}$ \\
\hline SMA type 3 & $\begin{array}{l}\text { Mild with variation ( } 3.1-3.9) \text {, patients walk independently at the time of diagnosis } \\
\text { 3.1- Standing alone but only taking a few unstable steps. } \\
\text { 3.5- Steady ambulation. } \\
\text { 3.9 - Almost normal ambulation, but not able to walk fast or to hop on one leg or to run. }\end{array}$ \\
\hline SMA type 4 & Normal, patient walks independently at the time of diagnosis \\
\hline
\end{tabular}

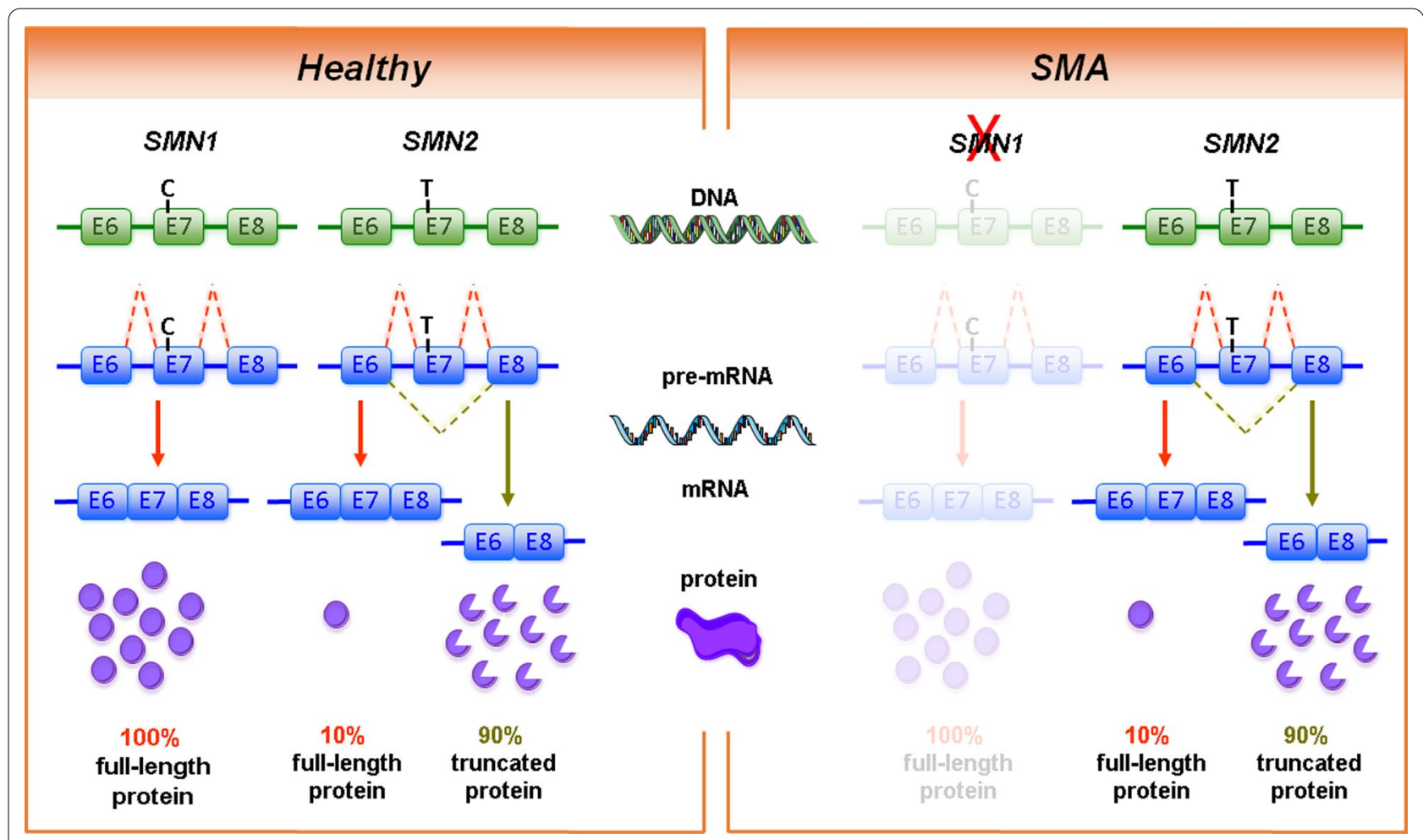

Fig. 1 Genetic cause of spinal muscular atrophy (SMA). The human survival motor neuron genes (SMN1 and SMN2) are located in an inverse duplicated region on chromosome 5q13.2. On DNA level, the two genes only differ by one functionally relevant nucleotide exchange within exon 7. This transition from C to T results in the generation of an exonic splicing silencer (ESS) site leading to exon 7 skipping on mRNA level. While SMN1 codes for the functional, full-length SMN protein, SMN2 predominantly ( 90\%) produces a truncated, non-functional version of the protein. SMA is caused by homozygous deletions of SMN1 resulting in highly reduced SMN protein levels. However, the number of SMN2 copies that determines the amount of functional SMN protein can modify disease severity 
SMN1-deficient siblings with discordant disease phenotype, revealed a significant association between disease severity and Plastin 3 (PLS3) expression [224]. PLS3 maps to Xq23 [282]. The gene is located on the X-chromosome and appears as a sex-specific modifier of SMA. Plastins are evolutionarily conserved and function as modulators of the actin cytoskeleton. Thus they play an important role in cell migration, adhesion and exo- and endocytosis [321]. Additional genetic modifiers in SMA include Neurocalcin delta (NCALD) and Calcineurin-like EF-hand Protein 1 (CHP1). Both proteins act as $\mathrm{Ca}^{2+}$-sensors and $\mathrm{Ca}^{2+}$-binding proteins $[124,143,246]$. All three SMA protective modifiers are not active in the assembly of spliceosomal snRNPs. Since they are involved in modulating various cellular processes including the rescue of impaired endocytosis in Smn-deficient cells and animal models [64, 124, 143, 246], these SMA modifiers turned into potential therapeutic targets.

\section{The cellular and molecular function of SMN}

The SMN protein is ubiquitously expressed and not only found in the nervous system especially in motoneurons. SMN acts in a protein complex that mediates spliceosomal snRNP assembly [91, 176, 194, 233]. Classical Smn gene knockout in mice causes early embryonic lethality [264], which is consistent with a fundamental role of Smn in all cell types as an essential cellular protein for pre-mRNA processing. Mice with homozygous gene knockout of endogenous Smn with 2 additional transgenic copies of human SMN2 develop severe SMA, thus mimicking SMA type 1 in humans [208]. However, mRNA levels in most organs of these mice including brain appear normal, and splicing of defined transcripts is unaffected [140]. This indicates that processing of pre-mRNAs including splicing in general is not affected in SMA. However, it cannot be excluded that few transcripts require high levels of SMN protein and SMN complex so that the levels of SMN that can be produced from up to four copies of $S M N 2$ are not sufficient in such cells. Studies in Drosophila have provided evidence that specific transcripts requiring the U11/12 minor splice complex appear more vulnerable to Smn depletion [132, 177, 181] than the majority of transcripts that are processed via the U1, 2, 4, 5, 6-dependent major spliceosome complex. However, these findings have been challenged by the observation that development of Smn-deficient flies in general is delayed and that U11/12-dependent premRNA splicing during normal development occurs only at later larval stages [98]. Thus, the lower levels of U11/12 minor splice complex-dependent mRNA modifications could reflect a delay of larval development in Smn-deficient flies. Although U11/12 as well as U2-dependent intron retention have been observed in transcripts in
Smn-deficient flies and mice, only few were reproducibly confirmed, such as TMEM41B/Stasimon and Mdm2/4 $[66,181,275,300]$. Despite the observation that the restoration of $\mathrm{Mdm} 2 / 4$ expression improved motor functions to some degree, this restoration of $\mathrm{Mdm} 2 / 4$ did not beneficially affect survival of SMA mice [300]. Beside the components of the classical SMN complex, additional SMN interaction partners have been identified; among them hnRNP R [256], TDP-43 [296], FUS [323] and HuD [82], which are involved in many neuronal functions including transcription regulation, nuclear pre-mRNA processing, nuclear export and subcellular transport of many mRNAs $[4,18,81,82,102,104,110,218,255,325$, 326]. In particular the axonal translocation of the $\beta$-actin mRNA is severely disturbed in Smn- [255], hnRNP R[102] and TDP-43- [33] deficient neurons. HnRNP R as an interaction partner of SMN is found in the nucleus and the cytosol, including axons of motoneurons [68, 256]. It is involved in subcellular transport of mRNAs and other types of RNA in axons [32, 34, 261].

\section{Regulation of SMN expression during development}

The developmental expression of SMN in mice and humans shows unique dynamic features. SMN protein levels are high during prenatal development and decline during early perinatal stages $[20,38,97,140,144,240$, 241]. In blood, higher SMN expression levels are found in young children compared to adults $[309,330]$. The median SMN protein level was 2.3 -fold higher in prenatal healthy individuals in comparison to early postnatal children younger than 3 months. This difference increases during development. SMN protein levels are about 6.5-fold reduced in human autopsy tissue samples (lumbar or thoracic spinal cord) in individuals aged 3 months through 14 years [240,241] when compared to samples from fetal stages. SMN levels are fourfold lower in human spinal cord samples from SMA patients at postnatal stages (up to 3 months of age) in comparison to healthy subjects. Downregulation of the high prenatal SMN protein levels at early postnatal stages was also observed in frontal cortex, diaphragm and skeletal muscles [240, 241].

SMN protein levels correlate only modestly with total SMN1 and SMN2 mRNA transcript levels in prenatal tissue samples. The decline in median SMN1 full-length or SMN2 mRNA levels at early postnatal stages in tissues from healthy controls is mild in comparison to the protein level $[240,241]$. This indicates that SMN protein levels decline at early postnatal stages independent from SMN promoter activity [71, 206, 207, 257] via posttranscriptional mechanisms [53, 149]. In mice, Smn protein levels decline in spinal cord between embryonic day (E) 14 and 19. This period is followed by a further decline 
between postnatal day (P) 5 and 15 [140]. At the moment, the mechanisms which regulate SMN expression at posttranscriptional and posttranslational levels are not fully resolved. Both, translational control and the regulation of Smn protein degradation could play a role. The instability of $S M N \Delta 7$ protein is mediated by a degradation signal termed degron (SMN $\triangle 7-\mathrm{DEG}$ ) which is created by the new $\mathrm{C}$-terminus in the truncated protein from the $S M N 2$ gene [45]. Inactivation of SMN $\Delta 7-D E G$ by a point mutation stabilizes SMN $\Delta 7$, which in turn is able to compensate for SMN loss in cell lines.

\section{SMA: motoneuron and neuromuscular pathology}

As stated before, relative SMN protein levels are highest at prenatal stages in humans and in mice (1 week before birth) [140, 240,241] implying a crucial role of SMN in cellular differentiation. In motoneurons, this period of high SMN protein levels coincides with the developmental stage when these neurons grow out axons and form synaptic contacts with skeletal/striated muscle fibers to establish neuromuscular endplates. These findings suggest that high amounts of SMN protein are necessary for proper development of the neuromuscular system [38, $140,141]$. During early prenatal development, about half of the postmitotic motoneurons that have been originally generated in the spinal cord undergo physiological cell death. Developmental cell death is controlled by neurotrophic factors [11, 116, 129, 234, 265, 266, 268]. In humans as well as in mice, SMN deficiency does not amplify motoneuron loss during this critical developmental period. This developmental period of physiological motoneuron death is followed by a ssynapses are eliminatedtage when supranumerary synapses are eliminated [173], so that one muscle fiber receives synaptic input only from one motoneuron. This time window of polysynaptic elimination coincides with deterioration of motor function and motoneuron degeneration at least in mouse models of SMA type 1 and 2 [103, 126, 166]. During this stage, about $17-29 \%$ motoneurons are lost in SMA type 1 mouse models in comparison to healthy littermates [208]. Motoneuron loss continues after these early postnatal stages. In heterozygous Smn mice in which only one allele of Smn is deleted, resulting in a reduction of $50 \%$ Smn protein levels, about $50 \%$ of motoneurons are lost at a stage of 12 months [140, 274]. Likewise in children with SMA type 1, severe motoneuron loss has been observed at disease endstage. At an age of 5-22 months, motoneuron loss in patients with type 1 SMA increases to more than $70 \%$ [272].

When motoneurons are isolated from embryonic $S m n^{-1-}$;SMN2 mice and cultured for periods up to 7 days, cell death is not enhanced but axon extension is markedly altered. This axonal defect $[139,156,255]$ appears as a prominent feature and is also observed in other Smn-deficient animal models such as zebrafish [192, 317]. Defective axon growth correlates with reduced actin dynamics [211, 255] and altered excitability through voltage-gated $\mathrm{Ca}^{2+}$-channels [139]. Treatment of SMA and control mice with the calcium channel modulator R-Roscovitine results in an increased number of preserved and even regenerating neuromuscular junctions (NMJs) [291]. Thus, defective presynaptic activity and reduced transmitter release apparently contribute to pathology and degeneration of neuromuscular junctions and axons in SMA.

A common and characteristic pathological feature of SMA is that proximal muscle groups appear more vulnerable than distal muscles. For example, muscle groups for finger movements appear less affected than the trapezius, deltoid, quadriceps or gastrocnemic muscles [69]. This appears on a first view counterintuitive because motoneurons with long axons are generally considered to be more vulnerable than those with shorter axons. However, motoneurons that innervate muscle groups for position control usually generate large motor units with highly branched motor axons up to several thousand terminals. In contrast, motor units for fine movements of fingers or posture are usually small. For example, the motor unit in finger muscles such as the first lumbrical muscle is in a range of 100 [84, 115]. In contrast, the gastrocnemius muscle has an innervation ratio of 1000-2000 muscle fibers per motoneuron [84]. Thus, vulnerability of motoneurons in SMA seems to correlate with the size of motor units. Axons of motoneurons contain relatively high levels of mRNAs which are transported into these distal neuronal compartments, where they are locally translated [34, 220, 261]. Transcripts encoding actin, mitochondrial proteins or components of presynaptic active zones are highly enriched in motor axons. The transport of these transcripts seems to be highly disturbed in Smndeficient motoneurons [34, 211, 261]. To some extent, defective translocation of transcripts for these proteins seems to be compensated in motoneurons with low numbers of axonal branches and corresponding low numbers of neuromuscular junctions that are served by these branches. However, in motoneurons of large motor units such compensatory processes might be limited, and then probably leading to degeneration of presynaptic compartments and retrograde degeneration of axons.

\section{Muscle pathology in SMA}

Motoneuron and skeletal muscle maturation closely correspond and depend on cellular contact between each other. Although muscle atrophy in SMA is primarily caused by denervation, there is growing evidence that muscle-autonomous alterations also occur in SMA and 
could contribute directly to disease pathogenesis. The Smn complex is localized at sarcomeric z-discs in striated myofibrils [311]. Muscle-specific Smn knockout in mice without reducing Smn expression in motoneurons results in massive muscular dystrophy [47], implying a cellular function of the Smn protein also in the skeletal muscle. Similar observations were recently reported by Kim et al. [151], as muscle-specific Smn depletion in mice induces morphological alterations in myofibers and NMJs. This correlates with reduced ex vivo force and impaired motor function by 6-7 months of age and reduced lifespan [151]. Other studies on selective restoration of Smn protein expression by $50 \%$ in muscle satellite cells showed significant improvement of the SMA phenotype in mice [219]. The hypothesis of muscle-specific disease mechanisms has also been discussed on the basis of morphometric studies of human SMN-deficient skeletal muscle samples [22, 87, 187]. Initial studies, performed more than 20 years ago, already suggested that type 1 and 2 (but not type 3) SMA patient-derived myofibers degenerate after one to three weeks in coculture with wild type fetal rat spinal cord explants [30]. This indicates that myoblasts and myofibers from type 1 and type 2 SMA patients have a higher vulnerability and propensity to undergo cell death. Abnormal expression of markers for skeletal muscle development such as slow and fast myosin [186] and defective myoblast fusion have also been reported [12, 31, 114, 190, 271]. Hence, these findings indicate that myogenesis is delayed in SMA.

Taken together, these data indicate that expression of SMN in skeletal muscles is important for proper development and maintenance, and that SMN levels should not fall below a threshold that so far is not well-defined. The data from Braun et al. [30] suggest that SMN protein levels might be sufficient in SMA type 3 but not type 1 SMA, although other studies on SMN in muscle reported contradictory effects [99, 137]. Muscle-specific overexpression of Smn in the severe $S m n^{-1-}$;SMN2 mouse model showed no beneficial phenotypic effect [99]. Second, a muscle-specific Smn knockdown-via Myf5-Cre and the Cre-loxP recombination system-on a SMN2/ $S M N \Delta 7$ background did not cause any SMA symptoms [137]. The extensor digitorum longus muscle was investigated for this study [137], a muscle which is usually not heavily denervated in the $S M N \Delta 7$ mouse model [174]. However, these findings support the hypothesis that SMN thresholds could play a crucial role in different muscle types depending on the severity of the disease. It is still unclear how the SMN expression levels change in later life. It could be that the expression level in muscle also falls below a critical threshold when SMN expression decreases during later postnatal development.
This could lead to a situation that a myopathic disease mechanism could contribute to the disease phenotype or even pre-dominate neurogenic muscle atrophy in milder SMA types. SMN protein levels in muscle in general are much lower than in spinal cord or brain [50, 138], and these levels are also expected to decrease during life time. Relevant data from SMA patients to judge the extent of altered SMN protein expression during life are missing. This raises the point that ubiquitous SMN upregulation via a therapeutic approach with a small molecule such as Risdiplam might counteract the myopathic phenotype better at higher age than a therapeutic approach delivering the drug through intrathecal administration only to spinal cord and brain.

\section{Muscle pathology in non-5q-SMA}

Spinal muscular atrophy with respiratory distress type 1 (SMARD1) also referred to as DSMA1 (distal spinal muscular atrophy type 1), is a fatal motoneuron disorder which usually starts in infancy and early childhood [23, 109]. SMARD1 is characterized by dysfunction and progressive degeneration of motoneurons in the ventral horn of the spinal cord, resulting in a neurogenic atrophy of striatal and skeletal muscle fibers [107]. In addition, diaphragm and heart muscle are primarily affected in the mouse model. This results in a mixed phenotype comprising both primary and neurogenic muscle degeneration. Muscle weakness in SMARD1 patients predominantly affects distal muscle groups, usually starting in the lower limbs. The most prominent and defining symptom of SMARD1 is a life-threatening respiratory distress due to a severe paralysis of the diaphragm $[107,108,259]$. The neuromuscular degeneration $\left(N m d^{2 J}\right)$ mouse is a model system for the juvenile form of SMARD1 [51]. The pathological features of the $\mathrm{Nmd}^{2 J}$ mouse are comparable to humans. However, muscle fiber degeneration in the diaphragm does not correlate with motor axon loss in the phrenic nerve $[106,158,307]$. That means there is a clear distinction between motoneuron degeneration and myopathy in this form of spinal muscular atrophy.

\section{Approved therapies for SMA}

Significant advances in basic research and clinical studies paved the way for FDA- (Food and Drug Administration, USA) as well as EMA- (European Medicines Agency, $\mathrm{EU})$ approved SMA therapies. All of these approved therapies focus on strategies aiming at increased SMN protein expression, either by modulation of SMN2 splicing to increase exon 7 inclusion via Antisense Oligonucleotides (ASOs: Nusinersen/Spinraza ${ }^{\mathrm{TM}}$ ) or small molecules (Risdiplam/Evrysdi ${ }^{\mathrm{TM}}$ ), or by viral gene transfer for introduction of an intact additional SMN1 cDNA copy (Onasemnogene abeparvovec/Zolgensma ${ }^{\mathrm{TM}}$ ) (Fig. 2). 


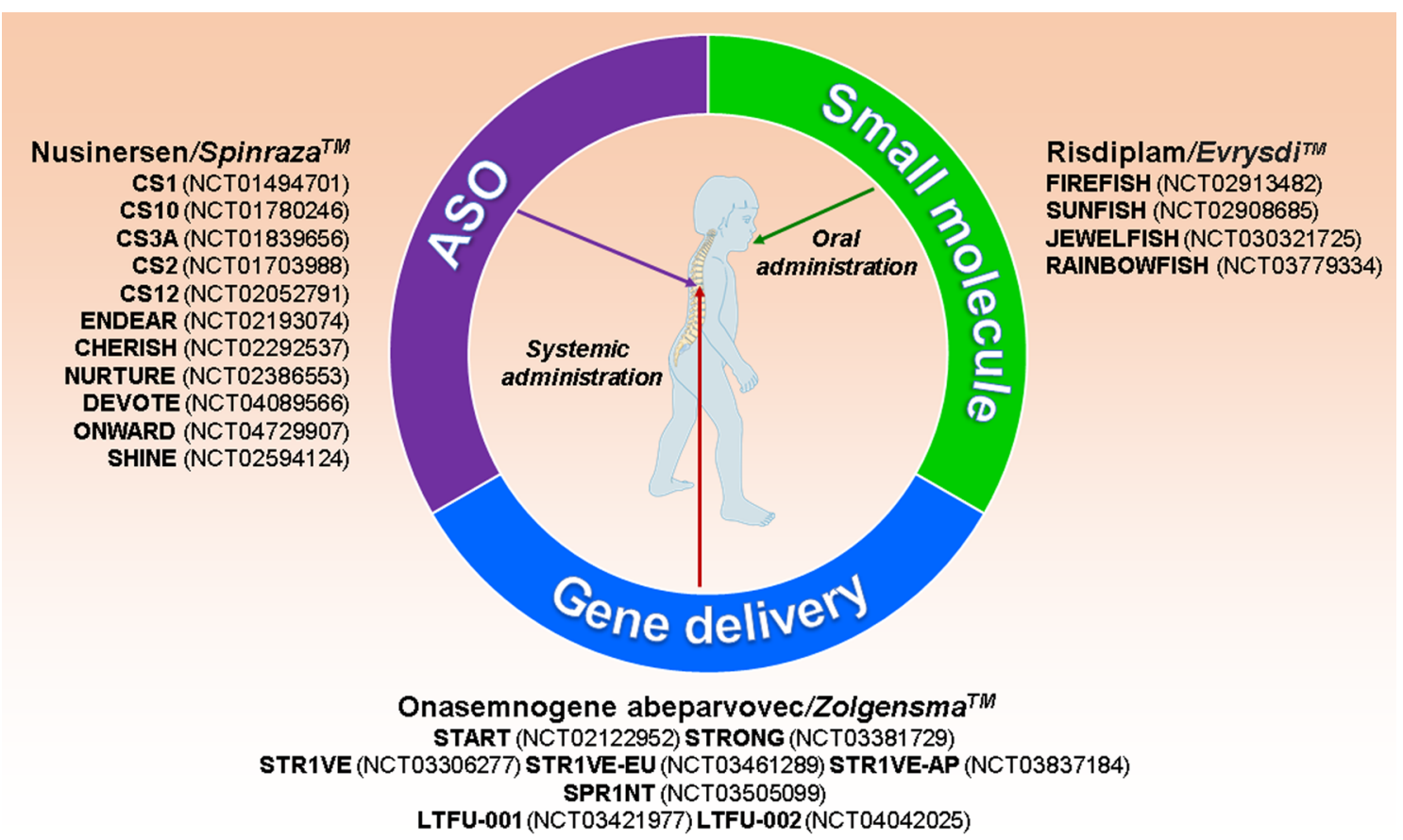

Fig. 2 Gene therapies in SMA. Overview of the currently available therapies for spinal muscular atrophy (SMA): Antisense Oligonucleotide (ASO: Nusinersen), small molecule (Risdiplam), AAV9 gene delivery approach (Onasemnogene abeparvovec) —and corresponding clinical trials

Figure 2 summarizes all studies which are described and discussed in more detail hereinafter. More information can be obtained from https://clinicaltrials.gov. All therapies have been developed in mouse models for SMA, and their efficacies have been optimized with established cell culture models. They thus stand as a success story for translational research from basic cellular and molecular neuroscience models towards new therapies for treatment of a neurodegenerative disease.

At present, there are three different therapies for SMA approved by the FDA and the EMA that use different strategies to enhance functional, full-length SMN protein levels. Antisense Oligonucleotides (ASOs), known under the name Spinraza ${ }^{\mathrm{TM}}$, are intrathecally injected and are designed to inhibit exon 7 skipping in SMN2 transcripts. Small molecules such as Evrysdi ${ }^{\mathrm{TM}}$ are applied orally and modulate exon 7 inclusion similarly to ASOs. The third treatment option is gene therapy via systemic intravenous application of a non-replicating self-complementary adeno-associated virus 9 (scAAV9) that introduces SMN1 cDNA (Zolgensma ${ }^{\mathrm{TM}}$ ) into infected cells.

\section{Antisense oligonucleotide strategies} Nusinersen/Spinraza ${ }^{\mathrm{TM}}$ : an ASO-approach

ASOs are short strands of synthetic nucleic acids which bind target-RNA by complementary base pairing to modulate RNA stability, structure and function [247].
Nusinersen is an 18-mer ASO modified by 2'-O-2-methoxyethyl phosphorothioate to protect it from rapid degradation. It was designed to block the binding of hnRNP A1 to the intronic splicing silencer N1-(ISS-N1) motif in intron 7 of the SMN2 gene. The block of hnRNP A1 binding to this domain in turn disrupts a splice inhibitor site and thus promotes exon 7 inclusion in the pre-mRNA that is derived from the SMN2 gene [128]. Due to their size, ASOs cannot cross the blood-brain barrier (BBB) and have to be applied by intrathecal administration so that they can be taken up by motoneurons from the cerebrospinal fluid (CSF).

Nusinersen was the first drug that has been approved for the treatment of SMA by the FDA in December 2016 and by the EMA in June 2017. Currently 31 clinical trials have been reported by https://clinicaltrials.gov. Herein we report a selection of studies focusing on dose finding with already disclosed data. The first phase 1 clinical trial with Nusinersen (CS1, NCT01494701 and CS10, NCT01780246) was conducted with 28 patients (2 to 14 years of age) with SMA type 2 and type 3. This study provided evidence that intrathecal delivery of a single dose of Nusinersen ( $1 \mathrm{mg}, 3 \mathrm{mg}, 6 \mathrm{mg}$, or $9 \mathrm{mg}$ ) is safe and well tolerated. Nusinersen more than doubled SMN protein levels in the CSF in the $6 \mathrm{mg}$ and $9 \mathrm{mg}$ treatment groups. This was accompanied by a significant increase in motor function illustrated by the Hammersmith 
Functional Motor Scale Expanded (HFMSE) scores in the $9 \mathrm{mg}$ group [44]. A subsequent phase 2, open-label study (CS3A; NCT01839656) with SMA type 1 patients with 2-3 SMN2 copies (3 weeks to 6 months of age) was conducted with multiple doses of Nusinersen. Four patients received ascending doses of 6 to $12 \mathrm{mg}$ and 16 patients a $12 \mathrm{mg}$ intrathecal injection. The patients in the $12 \mathrm{mg}$ group exhibited incremental achievements in developmental motor milestones on the Hammersmith Infant Neurological Examination-2 (HINE-2) score (from baseline to last visit $\mathrm{p}<0.0001$ ), improvement in Children's Hospital of Philadelphia Infant Test of Neuromuscular Disorders (CHOP INTEND) motor function scores $(p=0.0013)$ and significantly increased CMAP for abductor digiti minimus and tibialis anterior via stimulation of the ulnar nerve or the peroneal nerve. Probability of permanent ventilation-free survival was also significantly increased. Examination of post mortem tissue revealed an even distribution of Nusinersen throughout spinal cord, including motoneurons and brain that coincided with an enhanced exon 7 inclusion in SMN2 and an increase of the SMN protein [88]. Subsequent studies with Nusinersen treatment in 28 patients with SMA type 2 and type 3 (age $2-5$ years) for approximately 3 years showed a long-term benefit (CS2; NCT01703988 and CS12; NCT02052791). The patients started with ascending doses (3, 6, 9, $12 \mathrm{mg}$ over 253 days) followed by a period of treatment with $12 \mathrm{mg}$ every 6 months for more than two years (CS12) [54]. This was followed by the SHINE study (NCT02594124) via continuing $12 \mathrm{mg}$ Nusinersen applications to assess the long-term clinical effects of Nusinersen. The treatment over the first three years resulted in motor function improvements and disease activity stabilization that differed significantly from the natural disease history. Participants with later-onset SMA in CS2/CS12/SHINE displayed increases in walking distances that were not observed in natural history cohorts [210] with stabilization in fatigue and improvements of ambulatory function over the period of Nusinersen treatment ( 5.5 years) [209]. The phase $1 / 2$ results encouraged the design of two large, multicenter, randomized, sham-controlled, phase 3 studies with Nusinersen: ENDEAR (NCT02193074) in SMA type 1 patients and CHERISH (NCT02292537) in SMA type 2 patients. The ENDEAR study (NCT02193074) included 122 SMA type 1 patients at 7 months of age or younger. They were randomized to receive multiple intrathecal doses of Nusinersen or a sham procedure at a ratio of 2 to 1 [89]. In the CHERISH study (NCT02292537) 126 children were randomly assigned, in a 2:1 ratio, to receive multiple doses of $12 \mathrm{mg}$ Nusinersen or a sham procedure. The median age at study onset was 4 years (2-9 years) in the Nusinersen group and 3 years (2-7 years) in the control group [196]. In both studies, treated children showed a significant improvement in motor function compared to control groups. In the ENDEAR study the overall survival was higher in the Nusinersen-treated group than in the control group. A very striking observation was made, as infants with shorter disease duration at the study onset were more likely to benefit from Nusinersen than those with longer disease duration. The crucial timing of initiation of Nusinersen treatment for maximal therapeutic benefit is currently under investigation in a phase 2 study of pre-symptomatic patients (NURTURE, NCT02386553). The 25 included patients are still alive and do not require permanent ventilation. All patients are able to sit without support and achieved walking with or without assistance and still without ventilation support [59]. In December 2016 Nusinersen/ Spinraza $^{\mathrm{TM}}$ became available at a recommended dose of $12 \mathrm{mg}$ per treatment for all patients. Currently, safety and efficacy of higher doses are in focus of the DEVOTE study (NCT04089566). DEVOTE is subdivided into part A, B, C. Part A is an open-label study focusing on safety and tolerability of Nusinersen $(3 \times 28 \mathrm{mg}$ loading doses and $2 \times 28 \mathrm{mg}$ maintenance doses). Part B should demonstrate that higher doses improve participants' outcomes measured by CHOP INTEND and motor skill ability. This part is designed as a randomized, double-blind, active-controlled study with infants and later-onset SMA patients. Patients will receive $4 \times 12 \mathrm{mg}$ loading doses, followed by $2 \times 12 \mathrm{mg}$ maintenance doses or $2 \times 50 \mathrm{mg}$ loading doses and $2 \times 28 \mathrm{mg}$ maintenance doses. Participants receiving the FDA-approved $12 \mathrm{mg}$ of Nusinersen will serve as controls. The open-label part $\mathrm{C}$ will evaluate the safety and tolerability of transitioning patients that have already been treated with Nusinersen for at least one year. They will receive a single initial $20 \mathrm{mg}$ dose followed by two $28 \mathrm{mg}$ maintenance doses at four and eight months after therapy onset. The DEVOTE trial will then be followed by the open-label extension study ONWARD (NCT04729907) as a long-term extension.

Expanded access programs (EAPs) for Nusinersen had been initiated in several countries to verify therapeutic benefit with motor function improvements [10, 83, $100,199,232]$. Two studies on SMA patients with adult onset (mean age 16-65 and 18-72) have been recently reported by Hagenacker et al., and Maggi et al. [111, 184]. The primary outcome in both studies was an increase of the HFMSE score. Maggi et al. additionally reported that RULM (Revised Upper Limb Module) score improved significantly in sitters [184]. Both studies provide evidence of Nusinersen safety and efficacy in SMA type 2 and type 3 patients.

In some patients, hydrocephalus has been reported as a potential side effect [10,83, 100, 199, 232, 287]. The most 
commonly occurring side effects include lower respiratory infection and constipation in SMA infants whereas headache, vomiting and back pain are also observed in SMA patients with later onset (summarized in https:// www.drugs.com/sfx/nusinersen-side-effects.html).

In SMA patients with significant scoliosis or patients who had received surgical spinal fusion, the intrathecal application of Nusinersen is challenging. It usually requires the use of computer-tomography guidance, video fluorangiography, ultrasound, or alternative administration techniques such as subcutaneous intrathecal catheters [199, 283, 314]. However, such new devices for Nusinersen administration have not been approved so far by the relevant regulatory authorities.

For unknown reasons, some patients respond better to the ASO than others [54]. A problematic issue with Nusinersen/Spinraza ${ }^{\mathrm{TM}}$ is the lack of systemic availability and the potential lack of efficacy to counteract long-term adverse effects of low SMN levels in peripheral tissues. Nusinersen restores SMN expression only in the central nervous system. There are preclinical data indicating that restoration of SMN protein levels might also be important for peripheral tissues such as liver, kidney, muscle and heart $[112,127]$.

\section{The small molecule and splicing modifier Risdiplam/ Evrysdi $^{\text {TM }}$}

Another option to restore SMN protein levels through increasing exon 7 inclusion in SMN2 transcripts is via small molecules. Such small molecules appear of advantage especially when they can cross the BBB. When administered systemically, they then could act on the processing of the SMN2 gene transcript in peripheral organs. Such small molecules have also been shown to modulate SMN2 splicing. They are bioavailable after oral administration and distributed systemically, thus targeting not only the central nervous system but also the peripheral nervous system and non-neuronal organs and tissues [217, 242, 243]. A potential disadvantage of the small splice modifiers in comparison to ASO-based drugs is the higher propensity for off-target effects [28]. To bypass such unspecific effects, a high throughput screening for SMN2 splicing modifiers was performed to receive optimal candidates such as RO073406/RG7916 (Risdiplam) [217, 237, 242]. Risdiplam increases SMN protein levels not only in CNS but also in peripheral tissues in two mouse models of SMA [237]. This effect is achieved by stabilizing the U1:5'ss duplex at the 5'ss of SMN2 exon 7 $[39,227,276]$. Nevertheless, Risdiplam still produces offtarget effects on splicing of exons of several other transcripts such as those coding for STRN3, FOXM1, APLP2, MADD, SLC25A17 [242, 276]. Administration at $1 \mathrm{mg} / \mathrm{kg}$ of body weight produces a robust enhancement in SMN levels in brain and quadriceps muscle in a SMA mouse model. It counteracts NMJ pathology and reduces motoneuron loss [242, 243, 276]. Higher levels of Risdiplam (10 mg/kg body weight) improve life expectancy in SMA mouse models to the same level as for healthy littermates [217].

On the clinical level, the evaluation of safety, tolerability, and efficacy of this drug was tested in SMA patients in the FIREFISH trial (SMA type 1 patients, NCT02913482) and the SUNFISH trial (SMA type 2 and 3 patients, NCT02908685) [223]. The FIREFISH trial was designed for infantile-onset SMA as a two part non-randomized open-label study in which 41 patients (1-7 months) were enrolled and studied for one year. All patients had a homozygous deletion of SMN1 gene and two copies of SMN2. 29\% of patients were able to sit independently for at least $5 \mathrm{~s}$ after 12 months treatment, reaching relevant motor milestones, and $42 \%$ could live without permanent ventilation [55]. Treatment with Risdiplam caused an increase of SMN protein levels in blood [19]. SUNFISH is a two part trial with later-onset SMA patients ( 2 to 25 years), randomized and placebo-controlled. The first part with 51 participants is a dose-finding and safety tolerability study whereas part 2 with 180 SMA patients focusses on efficacy and safety [223]. The motor function skills of the Risdiplam-treated patients surpassed significantly those of the untreated patients after 24 months of treatment. No treatment-related adverse effects leading to withdrawal or treatment discontinuation during the 24 months trial period have been reported (Dr. Elizabeth Kichula CureSMA Meeting 2021; SUNFISH Part 2: Later-Onset SMA).

The JEWELFISH study (NCT030321725) was designed as a subsequent multicenter, open-label study primarily evaluating the safety and tolerability of once-daily oral administration of Risdiplam in SMA patients aged 6 months to 60 years who have previously enrolled in other studies including those with RG7800 (NCT02240355), Nusinersen, Olesoxime and Onasemnogene abeparvovoec [239]. The JEWELFISH population is heterogeneous with a broad spectrum of motor impairment at baseline. 174 SMA type 2 and 3 patients with 3 or 4 SMN2 copies have been enrolled, including non-sitters but also walkers, some of them with scoliosis and hip subluxation or dislocation. No serious adverse events related to the drug was reported. No ophthalmological findings attributable to Risdiplam exposure were reported [270] as in preclinical studies with cynomolgus monkeys. Retinal toxicity was observed in these monkeys consisting of photoreceptor degeneration and microcystoid macular degeneration (MMD) in the central retina after 5-6 months of daily treatment [242]. On August 7, 2020 FDA approved Risdiplam (Evrysdi ${ }^{\mathrm{TM}}$ ) under the 
fast-track designation and rare pediatric disease priority review process [223, 276]. Data across SUNFISH, FIREFISH and JEWELFISH suggest that Risdiplam has a favorable safety profile. In accordance to this safety profile, the RAINBOWFISH trial (NCT03779334) focusing on pre-symptomatic SMA patients has been started but the enrollment of the patients is still ongoing. It is a multicenter open-label study to analyze efficacy, safety, and pharmacokinetics/dynamics of Risdiplam in infants aged from birth to 6 weeks. Risdiplam is orally administered once daily for 2 years followed by an open-label extension (OLE) phase of at least 3 years. A follow-up of at least 5 years for each participant enrolled will finalize the RAINBOWFISH study. In general, the most frequently observed adverse effects include fever, diarrhea, and rash. Especially in SMA infants, respiratory tract infections, pneumonia, bronchiolitis, hypotonia, constipation and vomiting have been observed (listed in https://www. drugs.com/sfx/risdiplam-side-effects.html).

Another small molecule termed Branaplam is still under investigation. Branaplam (previously known as LMI070) is a pyridazine derivative that interacts with SMN2 pre-mRNA and enhances exon 7 inclusion to increase the level of functional SMN protein [227, 279]. Like Risdiplam, Branaplam can be orally administrated. Branaplam was originally expected to be tested in SMA type 1 infants in an open-label, two-part phase 1/2 study (NCT02268552). However, this study has not been initiated yet.

\section{SMN1 gene-therapy: Onasemnogene abeparvovec/ Zolgensma $^{\mathrm{TM}}$}

An alternative way to increase SMN protein levels in motoneurons and other cell types is the SMN1 gene therapy. Since SMA is a monogenetic autosomal recessive disorder that is caused by loss of function of the SMN protein, it appears as an excellent target for gene therapies. The small SMN1 cDNA can be easily packed into a non-replicating self-complementary (sc)AAV9 vector and delivered systemically. scAAV9 cannot only deliver the SMN1 cDNA to muscle and other peripheral tissue, but also cross the $\mathrm{BBB}$ to reach the CNS and spinal motoneurons [92, 93, 195, 299]. Preclinical studies confirmed elevated SMN expression from AAVmediated gene transfer in motoneurons and peripheral tissues in a mouse model of SMA [17, 93]. SMA mice that were treated with scAAV9-mediated SMN1 gene therapy exhibited a significant extension of life span to over 250 days [93]. This successful viral gene delivery system for SMN1 was termed as Onasemnogene abeparvovec. Onasemnogene abeparvovec commonly known as AVXS-101 is commercialized under the name Zolgensma $^{\mathrm{TM}}$. Onasemnogene abeparvovec became the first gene therapy to be approved in the U.S. for the treatment of pediatric SMA patients (up to two years of age), and by the EMA. The recommended dose of $1.1 \times 10^{14}$ vector genomes (vg) per kilogram ( $\mathrm{kg}$ ) body weight is delivered via a single intravenous injection. It appeared to be well tolerated in patients with SMA type 1 or 2 and pre-symptomatic SMA infants [125].

Two clinical trials AVXS-101-CL-101 (START, NCT02122952) and CL-303 (STR1VE-US, NCT03306277; STR1VE-EU, NCT03461289; STR1VE AP, NCT03837184) were performed with symptomatic SMA type 1 patients carrying a two-allelic SMN1 mutation and two SMN2 copies [57, 58, 195, 198]. START was an open-label study with 15 SMA type 1 infants enrolled in two cohorts. Three infants were given a low dose of Onasemnogene abeparvovec $\left(6.7 \times 10^{13} \mathrm{vg} / \mathrm{kg}\right)$. All patients in the cohort $(n=15)$ were still alive without permanent ventilation at 20 months of age. In the highdose cohort (12 patients, $1.1 \times 10^{14} \mathrm{vg} / \mathrm{kg}$ ), an increase from baseline of 9.8 points at 1 month and 15.4 points at 3 months in the CHOP INTEND score became detectable. In addition, 11 of the high-dose patients sat unassisted, 9 rolled over, 11 fed orally and could speak, and 2 walked independently. Elevated serum aminotransferase levels occurred in 4 patients and were treated by prednisolone [195]. The STR1VE-US study was an openlabel, single-dose phase 3 trial. SMA patients with biallelic SMN1 mutations (deletion or point mutations) and one to two SMN2 copies were younger than 6 months and symptomatic. They received a single intravenous Onasemnogene abeparvovec dose of $1.1 \times 10^{14} \mathrm{vg} / \mathrm{kg}$ body weight for $30-60 \mathrm{~min}$. The monitoring of the 22 SMA patients was initially scheduled once per week and after 4 weeks once per month. All patients were able to sit independently for $30 \mathrm{~s}$. 20 patients were free from permanent ventilation. All but one of the 12 patients in the high-dose cohort had gained significant motor milestones such as unassisted sitting, and serial incremental increases on the CHOP INTEND score of 50-60 points $[57,58]$. Based on the data that had been collected in these trials, a long-lasting beneficial effect of Onasemnogene abeparvovec on motor function is expected. Adverse effects were bronchiolitis, pneumonia and respiratory distress. Only two patients showed elevated aminotransferases. The mechanisms of the immune and especially the hepatic response observed in these clinical studies are still not fully understood. One patient developed signs of hydrocephalus for which the mechanism is unclear. The CHOP INTEND results depicted early and fast benefits. The patients were able to thrive and swallow effectively without any cardiac pathology at the end of the study $[57,58]$. Another clinical trial with Onasemnogene abeparvovec is ongoing as an open-label phase 1-2 trial 
with intrathecal administration in SMA type 2 patients (6 months to 60 months) with three SMN2 copies (STRONG, NCT03381729). The STRONG study showed a sustained gain of motor milestones and treatment safety [90]. The intrathecal administration could circumvent potential immunological reactions in patients that had been pre-exposed to the virus before therapy. When an individual is exposed to endogenous AAV infections, an immune response can be initiated. [27, 312]. Thus a significant number of individuals produce neutralizing antibodies and block the gene transfer to cellular targets $[3,312]$. The two studies by Day et al. $[57,58]$ revealed that $7.7 \%$ of the SMA patients and $14.8 \%$ of their biological mothers were positive for AAV9 reactive antibodies with exclusionary antibody titers $>1: 50$ on their initial screening tests. $5.6 \%$ showed elevated titers on their final screening and were excluded from receiving Onasemnogene abeparvovec in clinical trials. Therefore, the majority of SMA infants should benefit from Onasemnogene abeparvovec administration when given intrathecally [57, 58]. Another phase 3 study with intravenous administration in pre-symptomatic SMA type 1 or 2 patients with two or three copies of SMN2 (SPR1NT, NCT03505099) has been initiated. Preliminary data suggest that Onasemnogene abeparvovec is well tolerated when applied at high concentrations $\left(6.0 \times 10^{13} \mathrm{vg} / \mathrm{kg}\right)$. Two long-term follow up studies (LTFU) are currently monitored until December 2033 and 2035. LT-001/NCT03421977 is the follow up safety study of 13 SMA patients type 1 in the AVXS-101-CL-101 trial (2017-2033), whereas LT-002/
NCT04042025 (2020-2035) still enrolls patients from STRONG, STR1VE and SPR1NT. All clinical trials of Onasemnogene abeparvovec/Zolgensma ${ }^{\mathrm{TM}}$ along their timelines are summarized in Fig. 3.

\section{Temporal considerations for SMA therapies}

Increasing the amount of SMN protein in neurons and other cell types does not only have advantages but also bears risks. The expression levels of SMN are highly controlled during normal development and cannot be fine-tuned by the gene therapy approach. Observations in mouse models argue that the viral overexpression could have long-term adverse side effects by interference with complex RNA processing mechanisms. In a recent study, it has been reported that long-term overexpression of AAV9-SMN1 induces dose-dependent loss of proprioceptive synapses and neurodegeneration in SMA mouse models associated with loss of already achieved motor mile stones [301]. AAV9-SMN1 leads to cytoplasmic SMN aggregation in neurons that corresponds to impaired snRNP biogenesis and widespread transcription abnormalities in DRG neurons [301]. These observations indicate that additional therapeutic targets other than SMN1 and SMN2 genes should be evaluated and considered (see below non-SMN treatments). For successful long-term treatment of SMA, it appears important to understand the time frames in which the SMN protein is needed to prevent disease development, and which cell types and organs need SMN at which time periods for proper homeostasis. SMN deficiency is embryonic

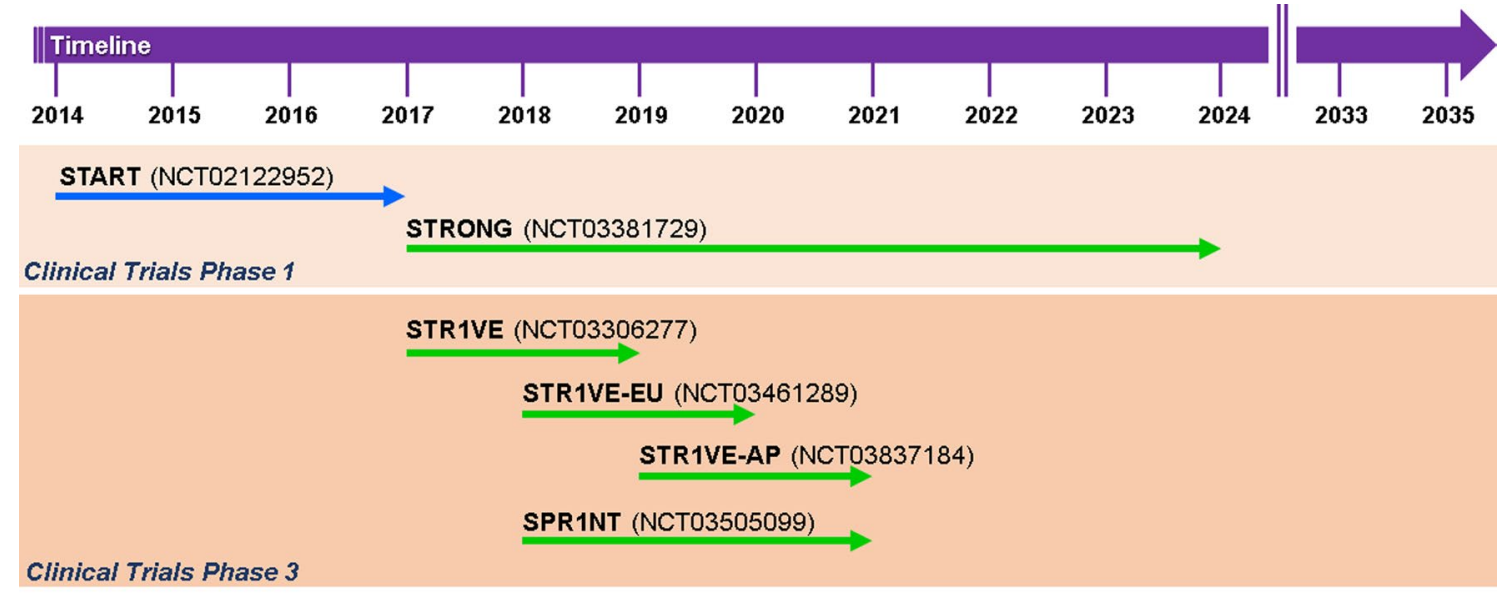

LTFU-001 (NCT03421977)

LTFU-002 (NCT04042025)

Long-term Follow-up Studies (LTFU)

Fig. 3 Timeline of the current Onasemnogene abeparvovec/Zolgensma ${ }^{\mathrm{TM}}$ trials. Illustration of the different clinical trials (clinical trials 1 and 3, LFTU) with Onasemnogene abeparvovec/Zolgensma ${ }^{\mathrm{TM}}$ according to their scheduled duration 
lethal and SMA develops in early childhood or even prenatally within the critical time window when neuromuscular synapses are strengthened and become mature. The reconstitution of the SMN2 protein via an ASO approach during the early postnatal period in a severe SMA mouse model (P 1-4) was effective at preventing the onset of the disease. The survival rate of the treated SMA mice was prolonged up to 250 days of age [127] that corresponds to a 16-fold increase. Starting SMN elevation at 10 days after birth failed to deliver any benefit. Strikingly, the disease phenotype is reversible in milder SMA forms. In an intermediate SMA mouse model, post-symptomatic non-SMN treatment had beneficial effects [86]. However, delaying treatment for only one or a few days in severe SMA type 1 mice after symptom onset markedly lowered the benefit $[93,249]$ on motoneuron loss, and morphological alterations of neuromuscular endplates remained [183]. SMN protein deficits first impact the distal end of the motor unit $[156,208,255]$. Therefore, the optimal time window for reinstatement of SMN protein in severe cases depends on the maturation level of the neuromuscular endplates [147]. Studies with mouse models of SMA indicate that the optimal clinical effect in severe cases depends on early postnatal applications. This was also shown for SMN-independent therapeutic approaches in mouse models [291]. In two clinical trials with patients, similar observations were made. Starting the treatment pre-symptomatically in babies with two or three SMN2 copies had significantly stronger effects than starting the therapy when first symptoms already occurred. When treatment with Nusinersen/Spinraza ${ }^{\mathrm{TM}}$ is initiated at less than 2 months of life, and after a median of 2.9 years of treatment, $100 \%$ of children could reach the milestone of sitting independently. Moreover, $88 \%$ patients could also walk independently [59]. In contrast, effects of therapy appeared markedly reduced in the phase 3 trial with Nusinersen/Spinraza ${ }^{\mathrm{TM}}$ where therapy was initiated after symptom onset in children with 2 copies of SMN2. Postsymptomatic treatment resulted in reduced mortality, but only $51 \%$ patients showed improved motor function and only $8 \%$ were able to sit independently at 13 months after therapy onset [89]. In conclusion, a delay of SMN elevation by several weeks up to 5 months can substantially reduce achievement of motor milestones. Therefore, it appears important that therapy in children with SMA starts immediately after diagnosis. These observations also provide a strong argument for systematic newborn screening, in order to detect pre-symptomatic and early symptomatic cases. Before symptoms appear and irreversible motoneuron degeneration starts, babies identified via newborn screening should be referred immediately to therapy. When SMN levels are very low, motoneurons lose their function within a short time frame and progress towards a stage when restoration might be limited, and the time window for successful restoration of motoneuron function and/or cellular regeneration could be missed.

The expenses for a Spinraza ${ }^{\mathrm{TM}}$ application in the first year amount to approximately $\$ 400,000-500,000$ (or $€ 400,000-500,000$ ). In total $\$ 250,000-300,000$ (or $€ 250,000-300,000)$ per year are calculated for a patient's lifetime. One single application of Zolgensma ${ }^{\mathrm{TM}}$ costs $\$ 2$ million. In the near future an increasing number of gene-targeted therapeutic strategies are expected to be approved by the FDA and EMA. The costs for such therapies could then become problematic for health care providers.

\section{Non-SMN approaches}

Enhanced synthesis of functional SMN protein via ASOs, small molecules or AAV9 vectors are current treatment options for SMA patients. However, with respect to the temporal requirements for SMN-based therapies, many SMA patients who cannot receive these therapies within an ideal time window will not fully recover and symptoms will remain or progress despite therapy, especially when the treatment starts at a later symptomatic stage. However, even when therapy starts at pre-symptomatic stages, not all SMA patients respond equally well and symptoms progress. In such cases, non-SMN approaches might support the SMN-based treatment strategies. Many of these non-SMN approaches target muscles, axons and presynaptic terminals at neuromuscular endplates.

\section{Neuromuscular endplate}

Neuromuscular endplates are severely affected in SMA. Not only reduced acetylcholine release [157, 260, 292], but also altered signaling mechanisms between motoneuron and muscle contribute to a degenerative process that ultimately results in muscle atrophy. Counteracting such signaling defects depends on (1) proper initial development of the neuromuscular endplates, including the presynaptic structures for controlled vesicle release, and (2) homeostatic mechanisms that maintain axons and presynaptic terminals in motoneurons. Primary cultured motoneurons from Smn-deficient mouse models have been used for characterization of the defective presynaptic compartment. Besides axon elongation alterations, defective F-actin assembly and reduced cluster formations of $\mathrm{Ca}_{\mathrm{v}} 2.2$, a voltage-gated calcium channel predominantly expressed in embryonic motoneurons, became apparent, leading to decreased spontaneous calcium transients $[139,211]$. Dysregulated calcium influx due to disturbed cluster formations of $\mathrm{Ca}_{\mathrm{v}} 2.1$ which predominates in the neuromuscular endplate, have also been observed in vivo in mouse models of SMA [291, 292]. 
To sustain the required levels of presynaptic calcium for cellular differentiation and/or neurotransmission in Smn-deficient motoneurons, molecules that prolong the closing kinetics of $\mathrm{Ca}_{\mathrm{v}} 2.2$ and $\mathrm{Ca}_{\mathrm{v}} 2.1$ could be used as candidates. R-Roscovitine, a Cdk5 inhibitor with calcium channel modulating properties appears as a good candidate for this purpose [193, 324]. Acute R-Roscovitine application induces spontaneous $\mathrm{Ca}^{2+}$-transients in vitro and increases quantal content ex vivo. It improves motoneuron survival and expands life span of a severely affected mouse model after systemic treatment [291]. Histopathological analysis of R-Roscovitine-treated SMA mice revealed that application with this substance supports synapses in the spinal cord and counteracts degeneration of neuromuscular endplates [291]. In cultured Smn-deficient motoneurons, application of R-Roscovitine also rescued altered axon elongation. This effect was also observed by application of GV-58, another calcium channel opener [291]. GV-58 is more potent on $\mathrm{Ca}_{\mathrm{v}} 2 \cdot 1 / 2$ and has less inhibitory activity for Cdk5 at physiological ATP levels [289]. It has already been tested in SMA mouse models where it showed significant benefits in terms of neuromuscular transmission and muscle strength [222]. However, both drugs also need to be administered during a critical period of NMJ development [308]. Thus, restoring intracellular $\mathrm{Ca}^{2+}$-homeostasis by external stimuli might be a therapeutic option for SMA, together with current ASO therapies, small molecules or adenoviral SMN1-gene transfer. Such kind of therapy needs also to be applied during a critical and early time window. Major recovery effects will not be obtained when treatment starts with delay and after symptom onset.

Substances with blocking properties of voltage-gated potassium channels such as 3,4-diaminopyridine (3,4DAP) and 4-aminopyridine (4-AP) have also been discussed as candidates for increasing presynaptic calcium influx. On anatomical level, they increase the number of proprioceptive synapses projecting to motoneuron cell bodies in the spinal cord, as well as the number of NMJs in Smn-deficient mouse models. However, 4-AP treatment has no effect on motoneuron survival [273]. Clinical trials for both substances are ongoing (3,4-DAP, NCT03781479, NCT03819660 and 4-AP, NCT01645787).

In addition to these two molecules that modulate the kinetics of presynaptic voltage-gated $\mathrm{Ca}^{2+}$-channels, the effects of Pyridostigmine, an acetylcholinesterase inhibitor have been tested in SMA. This drug has been reported to increase fitness/perseverance in 2 of 4 SMA type 2 and 3 patients [310] (Clinicaltrials.gov: NCT02941328). Results from the last three clinical trials are still pending.

The genetic modifiers Plastin 3 and NCALD also act in a $\mathrm{Ca}^{2+}$-dependent manner in motoneurons. NCALD is a neuronal calcium sensor and functions as a negative regulator of endocytosis. NCALD knockdown improves endocytosis in SMA patients ' fibroblasts as well as axon elongation and neuromuscular morphology and function in SMA mice [246, 293]. However, the therapeutic potential of a NCALD knowdown needs to be further investigated, in particular with respect to toxicity and side effects. This appears important since MAP3K10 interacts with NCALD as an activator of c-Jun N-terminal kinases (JNKs). The activity of JNK is markedly upregulated in $N C A L D^{-/-}$mice, probably affecting cellular differentiation, since morphology of NCALD-deficient hippocampal neurons is significantly altered [298]. Plastin 3 (PLS3), $[224,282]$ and other members of the Plastin family are evolutionarily conserved and act as modulators of the actin cytoskeleton. They play an important role in cell migration, adhesion and exo- and endocytosis [321]. In an Smn-deficient zebrafish model $P l s 3$ protein levels are reduced. However, Pls3 mRNA-splicing is unaffected. A partial restoration of $P l s 3$ in these animals compensates presynaptic defects, independent of SMN expression [113]. Pls3 orthologs are thus also considered as Smn modifier genes in Caenorhabditis elegans, Drosophila and mouse models [5, 65]. PLS3 appears as an interesting candidate for further therapeutic development, because of its regulation by $\mathrm{Ca}^{2+}$-ions in the presynaptic terminals of motoneurons, and its effect on actin bundling. These data and the observation of $\mathrm{Ca}^{2+}$-dysregulations in growth cones of Smn-deficient motoneurons in cell culture [139] and in vivo in neuromuscular endplates [260, 291, 292] support the hypothesis that $\mathrm{Ca}^{2+}$-dependent F-actin bundling could be a specific target for therapy development in SMA, in particular during early/prenatal development stages of the neuromuscular endplate.

\section{Neuroprotection}

Cellular differentiation of motoneurons depends on the presence and proper responsiveness to neurotrophic factors. It has been widely recognized that neurotrophic factor signalling contributes to motoneuron survival [11, $116,129,234,235,265,268]$. The application of brainderived neurotrophic factor (BDNF), ciliary neurotrophic factor (CNTF) and/or glial derived neurotrophic factor (GDNF) to isolated primary motoneurons from chick, human, rat and Xenopus promotes their survival [116, 172, 266, 267], upregulates cholinergic differentiation and transmitter production $[148,322]$, and leads to increased acetylcholine release in quantal packets [175]. BDNF, as a member of the neurotrophin family, acts through the tropomyosin-related kinase (TrkB) family of receptor tyrosine kinases [152-154, 200, 281]. BDNF/TrkB signaling drives local calcium transients in mouse motoneurons cultured on synapse-specific laminin-221 [67]. The 
activation of TrkB downstream signaling cascades in turn promotes the stabilization of $\beta$-actin via the LIM kinase pathway and phosphorylation of Profilin at Tyr129 [67]. The specific effect of BDNF/TrkB signaling on on the cluster formation of presynaptic $\mathrm{Ca}^{2+}$-channels indicates that molecules which positively modify this signaling could beneficially act on this pathological aspect and improve neurotransmission in SMA. Neurotrophic factors and small molecules that activate specific pathways could also perform on other aspects of motoneuron pathology in SMA. Smn-deficiency leads to a downregulation of the Akt signaling pathway [295]. Loganin, a neuroprotective iridoid glycoside, has been described to upregulate BDNF and Akt signaling, resulting in improved motor function and mildly improved lifespan in SMN $\Delta 7$ mice [295]. IGF-1, a trophic factor that acts both on muscle, motoneuron development and survival, is reduced in severe SMA mouse models [215]. Systemic administration of IPLEX, a recombinant hIGF-1 complex with rhIGFBP-3, counteracts motoneuron degeneration and loss of motor function in SMN $\Delta 7$ mice, with minor effects on survival [215]. The overexpression of IGF-1 via systemic AAV1-mediated overexpression causes a slight upregulation of lifespan and improved motor coordination of SMN $\Delta 7$ mice [294]. Muscle-specific overexpression of IGF-1 through the myosin light chain promoter in $S M N \Delta 7$ mice had a positive effect on myofiber size. It also increases animal survival, but revealed no significant beneficial effect on motor function [26]. Nevertheless IGF-1 is still considered as an SMN-independent supplementary therapeutic approach. Likewise, Olesoxime (OLEOS, NCT02628743), a small orally active cholesterol-like molecule that targets components of the mitochondrial permeability complex, thereby preventing the apoptotic death pathways, has been tested. However, this drug candidate did not show convincing effects in clinical trials. At the preclinical level, Olesoxime preserves mitochondrial homeostasis and thus motoneuron integrity and reduces muscle denervation, astrogliosis, and microglial activation [25, 285]. However, the OLEOS clinical trials with type 2-3 SMA patients did not demonstrate any significant beneficial outcome.

\section{Muscle-directed strategies}

Muscle-autonomous disease mechanisms in SMA could contribute to the course of disease, in particular at later stages in SMA type 2 and 3 patients [50]. SMN levels in muscle and other tissues are very low in adult SMA mice and patients [50,138]. In order to prevent loss of muscle mass, myostatin inhibition has been proposed as an option since this secreted growth/differentiation factor acts as a negative regulator of skeletal muscle fiber growth and size [169, 191, 332]. Myostatin activity is normally inhibited by follistatin and myostatin propeptide [118]. First studies with myostatin inhibition in models of severe SMA did not show significant effects [248, 284]. Interestingly, the effects of myostatin inhibition were stronger in mouse models of milder forms of SMA. In particular at later stages of disease, myostatin inhibition seems to have a positive effect on motor function and survival as well as muscle and bone atrophy [86, 179, 331]. SRK-015/Apitegromap is a selective monoclonal antibody that blocks myostatin $[86,236]$. It is currently under investigation in the phase 2 TOPAZ study for 57 type 2 and type 3 SMA patients which already received Nusinersen (ambulatory cohort; 2-20 mg/ $\mathrm{kg})$. In the non-ambulatory cohort $(20 \mathrm{mg} / \mathrm{kg})$, it is tested both as a monotherapy and in combination with Nusinersen.

Along the same line, the troponin activator Reldesemtiv (CK-2127107) is considered as another modulator of muscle atrophy and loss of muscle strength. This molecule acts by slowing down calcium release from the troponin complex and thus sensitizes the sarcomere response to calcium [130], resulting in enhanced contractility. Most importantly, it amplifies the skeletal muscle force-frequency response upon nerve stimulation [9]. Reldesemtiv has been studied in a double blind, randomized, placebo-controlled, phase 2 study (NCT02644668) in two cohorts. Oral application of a single dose of Reldesemtiv has been well tolerated. Whether this treatment also improves motor function is currently investigated with larger cohorts of SMA patients [258].

Human Insulin-like growth factor 1 (IGF1), which has already shown neuroprotective potential in mouse models for SMA, was also tested in SMARD1/DSMA1 mouse models $\left(N m d^{2 J}\right.$ mouse). Nmd ${ }^{2 J}$ mice are IGF-1-deficient and show an upregulation of IGF-1 receptor in gastrocnemius muscle and diaphragm, that is not observed in spinal cord [159]. The IGF-1 deficiency can be compensated by pharmacological application of human pegylatedIGF-1. This external application normalizes muscle fiber differentiation in the diaphragm and leads to a partial rescue in the gastrocnemius muscle [159]. Unfortunately, the compensatory effect of PEG-IGF-1 could not counteract atrophy. Cell body and axon loss of motoneurons is not diminished by IGF-1 treatment in $N m d^{2 I}$ mice [159].

\section{Oligonucleotide and gene therapies beyond SMA for other neurodegenerative and muscular disorders}

Most oligonucleotide therapies focus on gene silencing, transcriptional and splice modulation. Since oligonucleotides usually interact with their target molecules via complementary base pairing, gene-specific lead compounds can be derived from the primary sequence of the target 
gene. Also modifications for increasing bioavailability, such as for properly passing the plasma membrane and increased resistance to nucleases are feasible and have been successfully introduced [182]. In addition, bioinformatics tools allow avoiding predictable off-target effects. In terms of the ASO applications for individualized therapies, it is also possible to target patient-specific sequences in specific alleles such as single nucleotide polymorphisms (SNPs) or expanded repeat-containing mutant transcripts that are causative for rare diseases. This appears as an advantage over conventional screening for small molecules on the basis of effects on defined cellular target mechanisms. Although small molecules also bear the advantage of systemic application, they usually need extensive toxicological analyses and chemical optimization in order to lower off-target effects.

ASOs are classified into RNase $\mathrm{H}$-competent ASOs and steric block ASOs without RNase $\mathrm{H}$ activity. Steric block oligonucleotides can interfere with transcript RNA-RNA and/or RNA-protein interactions and mask specific sequences within a target transcript [250]. They are mostly used for modulation of alternative splicing to exclude (exon skipping) or retain specific exon(s) (exon inclusion). In these cases, the oligonucleotide 'masks' a splicing signal converting it invisible to the spliceosome. This ultimately leads to alterations in splicing events e.g. for SMN2 exon 7 retention [277]. In the following, we will give an overview of current ASO applications in neurodegenerative and muscular disorders beyond SMA.

\section{ASO therapies in amyotrophic lateral sclerosis (ALS)}

Amyotrophic lateral sclerosis is a fatal motoneuron disorder, predominantly with adult onset. $10 \%$ of ALS cases are familial (fALS), whereas the remaining cases are considered "sporadic" (sALS) without a clear familial history [150]. Extended genetic analyses discovered all major genes for monogenetic forms of ALS [42]. However, the question concerning of how the relevant mutations affect the function of the corresponding gene products is in almost all cases not appropriately answered. This has consequences on the development of genetically based therapeutic strategies. In case such mutations cause loss of function (LOF), relevant approaches need to be designed for re-establishing this function. Gain of function (GOF) mutations would require the blockade/inhibition of the mutated gene and its product. However, downregulation of the expression of the mutated gene usually also affects expression of the unaffected allele. Most of the mutations described for the familial forms of ALS show dominant inheritance pattern and imply GOF mechanisms such as protein aggregates or altered protein properties affecting essential cellular processes [290]. However, there is evidence that GOF and LOF come together in some ALS-causing gene mutations such as the intronic expansion of C9ORF72 [278, 290]. This situation then requires strategies that only affect the mutant gene and transcript. Herein we will exemplify ASO application in cases of SOD1, C9ORF72, and FUS and genetic ALS modifiers.

\section{SOD1}

The gene encoding $\mathrm{Cu} / \mathrm{Zn}$ superoxide dismutase (SOD1) was the first identified mutation that causes fALS [62, 254]. The majority of the SOD1 mutations (18.9\%) correspond to fALS, while $1.2 \%$ coincide with sALS cases [334], both exhibiting a dominant inheritance pattern [6-8]. Most of the ALS-causing SOD1 mutations do not reveal any correlation between SOD1 enzymatic activity and ALS disease severity [48, 221, 269]. Loss of function for Sod1 in Sod1 gene knockout mice does not cause per se defects in motor axon elongation [142] or motoneuron degeneration [244]. In addition, the presence or absence of endogenous mouse Sod1 does not affect survival of mice expressing the human SOD1G85R transgene [36]. This argues for a toxic GOF although SOD1-LOF might not be completely excluded. In a recently completed placebo-controlled phase $1 / 2 / 3$ clinical study, SOD1 was targeted by the ASO Tofersen/BIIB067 (NCT02623699 December 8th 2015 until March 24th 2021) for silencing the mutant as well as the wild type allele [201,202]. This was a 3-part (A, B, C) study to examine efficacy, safety and tolerability of BIIB067. BIIB067 administration resulted in an approximately $36 \%$ suppression of SOD1 in the CSF which appeared safe for SOD1-ALS patients [201]. It remained open, whether this is sufficient for long-term suppression of toxic effects of mutant SOD1, although administration appeared safe. Only some lumbar puncture-related side effects have been reported [201]. The first two parts (phase 1/2) were primarily not designed for assessment of motor function. However, they revealed that this treatment possibly slows disease progression and leads to better performances in vital capacity and hand-held dynamometry tests [201]. These effects have been pursued in phase 3 started in May 2019 to evaluate clinical efficacy. All types of SOD1 mutations and severity levels of symptomatic ALS patients were included. In order to explore therapeutic effects of BIIB067 in pre-symptomatic ALS patients, again a placebo-controlled phase 3 study (which is currently in the recruitment status) has been started on May 17th 2021 (NCT04856982). The primary objective is to evaluate efficacy of BII067 in pre-symptomatic ALS-SOD1 patients with elevated neurofilament levels. The secondary objectives include evaluation of safety, pharmacodynamics, and treatment-response biomarkers. The estimated study completion date is the second half of 2027. 


\section{C9ORF72}

At least in Europe and the US, the most common genetic cause of both ALS and Frontotemporal Dementia (FTD) is a GGGGCC (G4C2) hexanucleotide repeat expansion in the open reading frame 72 (C9ORF72) gene localized on chromosome 9. The mutation constitutes approximately $34 \%$ of fALS and nearly $25 \%$ of familial FTD cases (C9ALS/FTD) in European populations [302, 334]. Up to 25 G4C2 repeats are found in healthy individuals, while C9ALS/FTD patients harbor hundreds to thousands of repeats $[60,245,253]$. The expansion is located in intron 1 which also contains the promoter region of the second transcript for C9ORF72 [161, 204, 205]. Thus, reduced expression levels of the corresponding second transcript led to decreased C9ORF72 protein levels in such patients. However, this intronic expansion region is also translated via a non-canonical form of protein biosynthesis (repeatassociated non-AUG [RAN] translation) [15, 212, 335]. Based on the observations of RNA-foci or aberrant RNAs as well as the production of toxic homopolymeric dipeptide repeat proteins (DPRs) through RAN translation [94, 163, 205, 212, 286, 290, 315], a GOF mechanism appears to take place. Antisense RNA-foci are known to sequester RNA-binding proteins (RBPs), leading to LOF of RBPs in corresponding neurons [163, 168, 189]. Depletion of C9orf72 in isolated mouse motoneurons leads to alterations in axon growth and presynaptic differentiation [278]. This phenotype is also observed in C9ORF72 ALS patients' inducible pluripotent stem cell (iPSC)-derived motoneurons and resembles some of the alterations that are observed in cell culture models of SMA. Based on these findings, a combined therapeutic approach with silencing the G4C2-repeat-containing RNAs and simultaneous increase of C9ORF72 expression by gene therapy has been proposed for C9ORF72 patients [101]. The ASO BIIB078 that targets the sense-strand of C9ORF72 transcripts containing the hexanucleotide G4C2 repeat has been tested for safety and tolerability in a phase 1 clinical trial with adult C9ORF72 ALS patients (NCT03626012). The study is still active with an estimated completion date end of 2021. The trial already starts to be followed by a phase 1 extension study (NCT04288856) to assess longterm safety, tolerability, pharmacokinetics and effects on disease progression of BIIB078 application to previously treated C9ORF72 patients. The study is still enrolling with an estimated completion in the middle of 2023.

\section{FUS}

Mutations in FUS/TLS (Fused in Sarcoma/Translocated in Liposarcoma) are a genetic cause for rare forms of fALS and FTD [35, 162, 303, 304]. FUS mutations are present in $4 \%$ of fALS patients and in less than $1 \%$ of sALS patients [61, 334] with an autosomal dominant inheritance pattern. The ubiquitously expressed DNA-/ RNA-binding protein FUS localizes predominantly to the nucleus under physiological conditions [333]. FUS is involved in DNA repair [313] but also acts as an RNAbinding protein in several aspects of RNA metabolism including transcriptional regulation [188, 288], alternative splicing [121, 135, 164, 252], mRNA transport [96], mRNA stability [145, 297, 327], and microRNA biogenesis [105, 213]. Toxic GOF and LOF due to FUS aggregation and cytoplasmic mislocalization play a role in FUS-ALS/FTD pathogenesis [150]. An ASO-based therapeutic approach has been initiated for ALS caused by a specific FUS mutation (P525L) that is associated with an aggressive form of ALS with juvenile onset. Three of such FUS-ALS patients have received Jacifusen, a personalized ASO [13]. A FUS-ALS patient who already had developed respiratory problems received this personalized ASO treatment and died one year later [14]. The preliminary results from this case implicate, that adverse effects might also emerge by knocking down the wild type FUS transcript. FUS interacts as an RNA-binding protein with transcripts from about 5500 genes [164]. Thus, knocking down FUS via an ASO approach could interfere with the turnover of RNAs with long introns, many of which especially encode for synaptic proteins [164]. Downregulation of such transcripts and corresponding proteins in rodent primary neurons causes morphological alterations such as enlarged growth cones [225], shorter neurites [134, 225], abnormal dendritic spines [95, 327] and altered neurotransmission [297]. In vivo knockdown of FUS in murine hippocampal neurons causes increased phospho-tau accumulations as well as decreased neurogenesis, and thus a FTD-like phenotype [134, 297]. These data ultimately require enhanced efforts in the exploration of therapeutics which specifically target FUS expression. Jacifusen is scheduled to be given to eight additional patients with FUS mutations (Figueiredo, M. (2020)Collaboration Funds Experimental Therapy for Rare FUS-ALS, accessed 3.28.20. https://alsnewstoday.com/ 2020/03/16/jacifusen-collaboration-funds-experimentaltherapy-for-patients-with-rarefus-als/). Additional trials are planned with ION3763-CS1 which also targets this FUS mutation. Recruitment for this trial will start in June 2021, and there are so far no clinical data available. The relevant gene therapies for SOD1-, C9ORF72-, and FUSALS are depicted in Fig. 4.

\section{Genetic modifiers in ALS}

Ataxin-2 is a protein encoded by the ATXN2 gene. Expansion of the polyglutamine tract in the human ATXN2 gene leads to spinocerebellar ataxia type 2 (SCA2) [131, $238,262]$. SCA2 is characterized by neuronal degeneration in the cerebellum and inferior olive that causes 


\section{Amyotrophic lateral sclerosis}

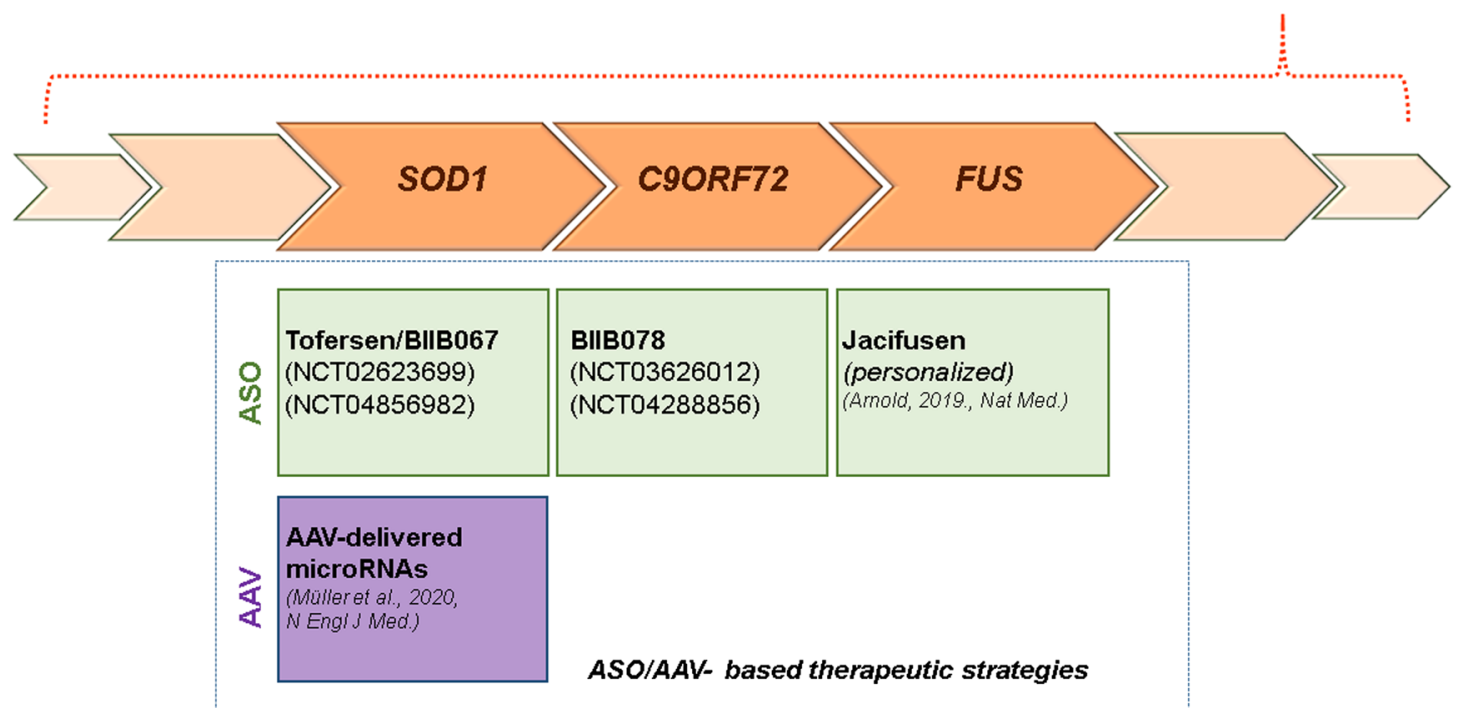

Fig. 4 Different therapeutic strategies in familial forms of amyotrophic lateral sclerosis. Illustration of the different ASO and AAV approaches for the SOD1-, C9ORF72-, and FUS-ALS forms

ataxia, parkinsonism, and dementia. More than ten years ago, it has been discovered that this CAG repeat expansion is associated with a higher risk for ALS [76]. Since 2017, it is known that reduced levels of Ataxin-2 via ASO approaches extend life span and diminish functional and behavioral deficits in a TDP-43-ALS mouse model [21]. In September 2020, recruitment for a study of ALS patients with or without CAG expansion in the ATXN2 gene has been started to assess safety, tolerability, and pharmacokinetics of the Ataxin-2 ASO termed BIIB105. The estimated study completion date is February 2023. The study is listed in https://clinicaltrials.gov.

\section{ASO treatments for muscular dystrophies}

Duchenne's muscular dystrophy (DMD) and Becker's muscular dystrophy (BMD), the two forms of X-linked muscular dystrophy are caused by mutations in the Dystrophin gene. DMD occurs with an incidence of about 1:5000, whereas BMD affects children with an incidence of 1:30,000 [155]. The severe form, DMD, usually starts before 4 years. Affected boys lose ambulation around 12 years of age and get ventilation by the age of 18 [119]. The average life span today is $20-30$ years due to advances in cardiac and respiratory care. In contrast to SMA, the spectrum of mutations in DMD is broad and ranges from point mutations to deletions as well as small insertions to large duplications [24].The dystrophin gene is one of the largest human genes containing 79 exons and approximately 2.4 million base pairs [2, 24, 41]. The primary role of the dystrophin protein is to link the actin-cytoskeleton with the extracellular matrix in cardiac and skeletal muscles by forming interactions with the subsarcolemmal actin and the large oligomeric dystrophin-glycoprotein complex (DPG). This regulates the proper functioning of muscle fibers. Defects of the DPG result in muscle weakness due to contraction-induced damage, necrosis, and inflammation, and a replacement of functional myofibers by fibrous and fatty connective tissue [29]. Disease severity depends very much on residual functions of the truncated dystrophin protein, which is derived from the mutant gene. Interestingly, mild forms of the disease have not only been detected in patients with point mutations which have only minor consequences for protein structure and function, but also in BMD patients in which multiple exon-encoded domains are not transcribed, resulting in a highly truncated dystrophin mRNA of only $8.8 \mathrm{~kb}$ [79]. This observation has paved the way to define essential subdomains within the dystrophin protein and exons within transcripts which are functionally important and needed to be present for mitigating disease severity. Similarly, these findings are the basis for the design of artificial mini-dystrophin genes which could be used for gene therapy through viral vectors which can only carry cDNAs of limited length [52]. 


\section{Exon skipping}

Retention or preservation of the open-reading frame (ORF) is an option to restrict the physiological consequences of dystrophin loss in DMD patients with nonsense mutations. Retention of the ORF can be mediated via ASO delivery. Binding of the ASOs to the dystrophin pre-mRNA transcript induces deletion/skipping of certain exon(s) and can thus restore the ORF [72]. The resulting shorter ORF produces a phenotype similar to that described for the milder form of DMD-the BMD. Three ASOs with phosphorodiamidate morpholino oligomer (PMO) backbone which are used for exonskipping-eleplisen (exon 51), golodirsen (exon 53) and viltolarsen (exon 53) - have been approved by the FDA. However, the ASOs also show some limitations [75, 306] [1]. Since DMD patients have variants in many different exons that cause multiple reading frame disruptions, such single exon treatments are only applicable to a subset of DMD patients. Multi-exon skipping has been proposed to overcome the limited scope of single exon skipping by targeting DMD patients with variant exons [16]. A cocktail of ASOs targeting the variant hotspots of exons $45-55$ can efficiently skip these exons in both immortalized DMD patient muscle cells and mouse models $[73,167]$. However, a mixture of several ASOs also has a higher risk for off-target effects. This needs to be tested in clinical trials. If this finding is successfully translated to the clinic, it could potentially be useful for more than $65 \%$ of the DMD patients [74].

\section{Genome editing}

Genome editing with CRISPR-Cas9 appears as an attractive option for ORF restoration of the dystrophin gene. Application of CRISPR-Cas9 does not require re-injections because DNA instead of pre-mRNA is targeted. This approach could also be useful for treating patients with duplications in certain exons of the DMD gene, since it allows removal of extra exons and other gene insertions. The use of a multiplexed guide-RNA (gRNA) targeting the variant-prone exons $45-55$ or $47-58$, has been shown to restore dystrophin expression [306] in cultured patientderived myoblasts. When these myoblasts were implanted into mice, expression was maintained [226]. However, because Cas9 induces double strand breaks (DSBs) by the gRNA in a targeted manner, off-target DNA-cutting remains an issue. Currently there are no clinical trials using genome editing approaches for DMD [75].

\section{Perspectives of AAV-based gene therapies beyond SMA}

In the case of mutation-based LOF, relevant therapeutic approaches need to re-establish gene function. In the case of SMA, the scAAV9-SMN1 gene therapy provided proof that this approach is feasible for treatment of a neurodegenerative disease. The dose of $1.1 \times 10^{14} \mathrm{vg} / \mathrm{kg}$ body weight appeared sufficient to transduce the gene into a clinically relevant number of motoneurons, and to keep adverse effects such as severe acute liver injury at a low level. An increase of liver transaminase levels has been discussed as a consequence of a massive immune response against viral particles [195]. Unfortunately, in the case of another neuromuscular disorder-X-linked myotubular myopathy-the systemic delivery of a high dose of AAV8 particles containing the cDNA for myotubularin-1 was fatal. Two of six patients who received a dose of $2 \times 10^{14} \mathrm{vg} / \mathrm{kg}$ or more died by progressive liver dysfunction followed by sepsis; it is presumed that AAVs directly damage liver cells [117]. Thus, AAVs are on one side effective gene-transfer-vehicles but on the other side bear the disadvantage of severe inflammatory reactions, particularly in systemic treatments with high doses. Strategies have been proposed to identify patients at risk for severe side effects $[57,58]$, and to overcome this problem by modulating the immune reaction towards a dampened response. This could be achieved either by depleting immunoglobulins via plasmapheresis; or even more specifically, by use of the IgG cleaving metalloproteases IdeS or IdeZ [63]. Such approaches to reduce AAV-autoantibodies could help to reduce side effects of AAV-based gene therapies for disorders such as DMD where systemic treatment with high numbers of virus particles is necessary. Furthermore, it can be beneficial for therapies of adult-onset disorders when patients are expected to have developed high AAV-antibody titers due to multiple previous exposures to such viruses.

Another strategy could be local injection, either by intrathecal application of the recombinant viruses or injection into the cisterna magna. This approach is currently followed with an AAV1-based gene therapy trial to increase expression of Progranulin in patients with frontotemporal dementia with granulin mutations [120] (Press release January 28th 2021: Passage Bio-Passage Bio Receives FDA Clearance of IND Application for PBFT02 Gene Therapy Candidate for Treatment of Patients with Frontotemporal Dementia with Granulin Mutations). It will show how the immune system reacts when AAV particles are injected into the CSF, how many brain cells can take up the viral particles to produce the transgene, and which levels of transgene expression are necessary for a clinically relevant effect.

In a study reported by Mueller et al., two ALS patients were treated with a single intrathecal infusion of AAVrh10 containing microRNAs to target SOD1. Downregulation of SOD1 transcripts and protein was identified in spinal cord autopsy samples via Western blot in one of these patients. The same patient showed transient improvements in the strength of his right leg but 
no change in vital capacity, whereas the second patient maintained a stable vital capacity over the 12-month observation period [214]. The authors proposed that intrathecal infusion of AAV-delivered microRNAs for SOD1 might have the potential for sustained beneficial effects, but possibly requiring immunsuppression.

\section{AAV-based micro-dystrophin ( $\mu$ Dys) gene transfer}

Causal therapies for DMD ideally should restore dystrophin expression in skeletal muscle. Unfortunately, the full-length dystrophin gene is too large for being packed into a functional AAV particle. Current strategies try to bypass this bottle neck by using truncated forms of dystrophin with residual function that is sufficient for attenuation of the disease [56]. Three independent clinical trials, using gene therapy with such micro-dystrophin constructs are currently ongoing (summarized in [52]. Initial results from one of these ongoing clinical trials with $\mu$ Dys showed that more than $80 \%$ of the muscle fibers were micro-dystrophin positive with significant expression of $\mu$ Dys in post-treatment biopsies (95.8\% compared to normal) (Sarepta Therapeutics Announces Positive Updated Results from Micro-Dystrophin Trial to Treat Patients with DMD. https://investorrelations.sarep ta.com/news-releases/news-release-details/sarepta-thera peutics-announces-23rd-internationalcongress-world), and summarized by $[75,306]$. In addition, long-term therapy with $\mu$ Dys has beneficial effects in a canine model [165]. MicroDys does not contain all of the functional elements of the full-length dystrophin that are important for interactions with other proteins to convey forces on contractile actin. For this purpose novel variants of $\mu \mathrm{Dys}$ with modified central rod domains, which are expected to exhibit higher cellular rescue activity, have been developed $[240,241]$ and are currently tested in clinical trials [178]. Another option which is currently followed is the use of miniaturised utrophin ( $\mu$ Utro), a shortened codonoptimized version of utrophin that differs in some protein-protein interactions from dystrophin. It prevents muscle pathology and appears in a non-immunogenic manner in large dog models. However, a positive effect on the disease phenotype has not been confirmed [280]. The overexpression of b1,4-N-acetylgalactosaminyltransferase (GALGT2) is a third possibility. GALGT2 stimulates the upregulation of key cytoskeletal binding proteins that can act as surrogates of dystrophin [43, 328]. After demonstrating safety in pre-clinical models, this therapy is now being tested in a phase I/IIa trial to evaluate its safety in humans. (Gene Transfer Clinical Trial to deliver rAAVrh74.MCK. GALGT2 for Duchenne Muscular Dystrophy-NCT03333590. https://clinicaltrials.gov/ct2/ show/NCT03333590 48).

\section{AAV gene transfer in Parkinson disease (PD)}

Parkinson's disease is a long-term degenerative disorder that affects multiple neuronal systems, in particular the motor system. The most common symptoms include tremor, rigidity, slowness of movement combined with walking difficulties. As the disease progresses, nonmotor symptoms such as cognitive and behavioral alterations also become apparent. Motor symptoms are caused by degeneration of dopaminergic neurons in the substantia nigra. Loss of these dopaminergic neurons results in over-excitation of the subthalamic nucleus (STN) leading to increased inhibition of the thalamus [203]. Thus, Parkinson patients suffer from defects in movement initiation. Deep brain stimulation of the subthalamic nucleus appears as an attractive therapeutic option, because Levodopa [80] and other pharmacological treatments cannot halt the degenerative process in this disease. Hence, gene strategies using AAV vectors appear as an option for treatment of PD, also in combination with deep brain stimulation. Currently, there are several trials involving PD and gene therapy listed on clinicaltrials.gov. The allencompassing approach of gene therapy for PD is to preserve the dopamine production in neuronal cells which are not affected, in order to functionally maintain the circuitry of the basal ganglia. For this purpose, direct intraparenchymal delivery via MRI-guided administration of AAV2 encoding the cDNA for aromatic $\mathrm{L}$-amino acid decarboxylase (VY-AADC01) has been established [46]. Fifteen subjects with moderately advanced PD and drug refractory motor fluctuations received VY-AADC01. MRI-guided administration achieved putaminal coverage of $20-40 \%$ in accordance to increased enzyme activity assessed by PET and dose-related clinical improvements. Simultaneous reduction of antiparkinsonian medication led to reduced symptoms of dyskinesia [46]. A similar strategy is the MRI-guided AAV2-GAD (Glutamatdecarboxylase) delivery into the STN in an effort to increase local GABA inhibition and to correct pathological hyperactivity in this brain structure. Phase 1 and 2 trials have been performed with AAV2-GAD delivery via Convection-enhanced delivery (CED) to the STN of PD patients [146, 171]. These patients displayed improvements in their motor symptoms, but not to such an extent as could be achieved by deep brain stimulation of the STN [171].

\section{Gene therapy approaches in Alzheimer's disease (AD)}

Generation of the pathological amyloid- $\beta$ (A $\beta)$ peptide is believed to be the initial event in the AD process. Since several previous clinical trials including immune therapies to reduce the load with amyloid plaques failed or showed only minor effects [228], the FDA has now approved Aducanumab marketed under the name 
Aduhelm $^{\mathrm{TM}}$ as an $\mathrm{A} \beta$-directed antibody. The effects of this therapy appear to be less than expected, and this draws attention back to potential gene therapies which interfere with synaptic dysfunction and degeneration. Technical challenges for this approach are similar as in PD. Interventional MRI-guided convection-enhanced delivery is not exclusively relevant for treatment of PD patients. Likewise, AD patients could benefit from viral gene transfer and this technical approach. Some therapeutic developments focus on the tau protein [49, 329]. Pathological tau in AD brain is prevalent in a hyperphosphorylated state (i.e. phosphorylated at multiple sites within the tau protein). This posttranslational modification corresponds to tau aggregation and neurofibrillary tangle formation [133].

AAV-mediated gene transfer of the constitutively active tau kinase-p38y has been shown to reduce tau-related dementia in pre-clinical dementia mouse models even when advanced cognitive deficits are present [136]. This strategy has not yet entered the stage of clinical trials for $\mathrm{AD}$ patients. However, it might become feasible since viral gene transfer of $B D N F$ has entered the clinic. This trial is based on preclinical studies showing that BDNF delivery (via transgenic expression or infusions) in rodent models reverses synaptic loss after disease onset corresponding to improved learning and cognitive performance. BDNF also prevented lesion-induced entorhinal neuronal death in the primate model. In aged monkeys, BDNF improved performances in visuospatial discrimination tasks that correspond to increased mean entorhinal neuronal sizes [216]. Based on this data, a phase 1 clinical trial has started in February 2021. This trial assesses the effects of direct injection of AAV2-BDNF into the brain of $\mathrm{AD}$ patients or patients with Mild Cognitive Impairment (MCI) (Scott LaFee, First-in-Human clinical trial to assess gene therapy for Alzheimer's Disease, UC San Diego News Center February 18th, 2021).

\section{Conclusions}

Childhood proximal SMA is a genetically homogenous disease caused by lost or mutated SMN1 and modulated by variable $S M N 2$ copies. This is an ideal condition to identify the underlying cellular defects and to develop therapeutic strategies compensating the lack of SMN protein, which is the key of SMA pathophysiology. Extensive research on this condition allowed the introduction of therapies with oligonucleotides and molecules that modulate pre-mRNA splicing. Additionally, AAV-based gene therapy entered the clinical stage for treatment of a neurodegenerative disease. Since most cases of SMA are diagnosed early in life and therapy usually starts immediately after diagnosis, immunological reactions against AAVs are less problematic compared to patients of advanced age being exposed to such viruses during their life. The clinical experience with these applications could help to develop and optimize analogous approaches beyond SMA. Currently, the development of therapeutic strategies is ongoing and hopefully will make a difference to the treatment of other neurodegenerative disorders such as amyotrophic lateral sclerosis, Parkinson's and Alzheimer's disease as well as muscular dystrophies.

\begin{abstract}
Abbreviations
3,4-DAP: 3,4-Diaminopyridine; 4-AP: 4-Aminopyridine; AAV: Adeno associated virus; AD: Alzheimer's disease; ALS: Amyotrophic lateral sclerosis; ASO: Antisense oligonucleotide; ATXN2: Ataxin 2; ATP: Adenosine triphosphate; BBB: Blood-brain barrier; BDNF: Brain-derived neurotrophic factor; BMD: Becker muscular dystrophy; bp: Base pairs; CED: Convection-enhanced delivery; CHIP1: Calcineurin-like EF-hand Protein 1; CHOP INTEND: Children's hospital of Philadelphia infant test of neuromuscular disorders; CMAP: Compound muscle action potential; CNTF: Ciliary neurotrophic factor; CSF: Cerebrospinal fluid; DMD: Duchenne muscular dystrophy; DPRs: Homopolymeric dipeptide repeat proteins; DSB: Double strand break; DSMA: Distal spinal muscular atrophy; E: Embryonic day; EAP: Expanded access program; EMA: European Medicines Agency; fALS: Familial amyotrophic lateral sclerosis; FDA: Food and drug administration; GABA: Gamma aminobutyric acid; GAD: Glutamate decarboxylase; GDNF: Glial cell-derived neurotrophic factor; GOF: Gain of function; gRNA: guide-RNA; HFMSE: Hammersmith functional motor scale expanded; hIGF-1: Complexed with rhIGFBP-3; HINE-2: Hammersmith infant neurological examination-2; IGF1: Insulin-like growth factor 1; iPSC: Induced pluripotent stem cell; ISS: Intronic splice silencer; JNKs: C-Jun N-terminal kinases; kb: Kilo base; LOF: Loss of function; LTFU: Long term follow up; MCl: Mild cognitive impairment; MMD: Microcystoid macular degeneration; MRI: Magnetic Resonance Imaging; NCALD: Neurocalcin delta; NMJ: Neuromuscular junction; OLE: Open-label extension; ORF: Open-reading frame; P: Postnatal day; PD: Parkinson's disease; PLS3: Plastin 3; PMO: Phosphorodiamidate morpholino oligomer; Ran: Repeatassociated non-AUG translation; RBP: RNA binding protein; RULM: Revised Upper Limb Module; sALS: Sporadic amyotrophic lateral sclerosis; sCAAV: Selfcomplementary AAV; SMA: Spinal muscular atrophy; SMARD1: Spinal muscular atrophy with respiratory distress type 1; SMN: Survival Motor Neuron; SNP: Single nucleotide polymorphism; snRNP: Small nuclear ribonuclear particle; SOD1: Superoxid dismutase 1; STN: Subthalamic nucleus; TrkB: Tropomyosinrelated kinase.
\end{abstract}

\section{Acknowledgements}

We thank Dr. Michael Briese for critical reflection on the manuscript.

\section{Authors' contributions \\ SJ and MS conceived and wrote the review. LH contributed to conceiving the review and created the figures. LH used Servier medical art for the illustra- tions (https://smart.servier.com). All authors read and approved the final manuscript.}

\section{Funding}

Work in the authors' lab is supported by the Deutsche Forschungsgemeinschaft (DFG), Grants JA 1823/3-1, 2-1 to SJ and SE 697/6-1, 4-2, 5-2, and 7-1 to MS, by a grant from Picoquant, the BMBF through the CalsER Network, and support from the Hermann and Lilly Schilling Stiftung im Stifterverband der Deutschen Wissenschaft and by Cure SMA (JAB1920) to SJ.

Availability of data and materials

Not applicable.

\section{Declarations}

Ethics approval and consent to participate Not applicable. 


\section{Consent for publication}

Not applicable.

\section{Competing interests}

The authors declare no competing interests.

Received: 20 July 2021 Accepted: 21 October 2021 Published online: 04 January 2022

\section{References}

1. Aartsma-Rus, A., Straub, V., Hemmings, R., Haas, M., Schlosser-Weber, G., Stoyanova-Beninska, V., Mercuri, E., Muntoni, F., Sepodes, B., Vroom, E., \& Balabanov, P. (2017). Development of exon skipping therapies for duchenne muscular dystrophy: A critical review and a perspective on the outstanding issues [Review]. Nucleic Acid Therapeutics, 27(5), 251-259. https://doi.org/10.1089/nat.2017.0682

2. Ahn, A. H., \& Kunkel, L. M. (1993). The structural and functional diversity of dystrophin. Nature Genetics, 3(4), 283-291. https://doi.org/10.1038/ ng0493-283

3. Al-Zaidy, S. A., \& Mendell, J. R. (2019). From clinical trials to clinical practice: Practical considerations for gene replacement therapy in SMA Type 1. Pediatric Neurology, 100,3-11. https://doi.org/10.1016/j.pediatrneurol. 2019.06.007

4. Alami, N. H., Smith, R. B., Carrasco, M. A., Williams, L. A., Winborn, C. S Han, S. S. W., Kiskinis, E., Winborn, B., Freibaum, B. D., Kanagaraj, A., Clare, A. J., Badders, N. M., Bilican, B., Chaum, E., Chandran, S., Shaw, C. E., Eggan, K. C., Maniatis, T., \& Taylor, J. P. (2014). Axonal transport of TDP-43 mRNA granules is impaired by ALS-causing mutations [Research Support, N.I.H., Extramural Research Support, Non-U.S. Gov't]. Neuron, 81(3), 536-543. https://doi.org/10.1016/j.neuron.2013.12.018

5. Alrafiah, A., Karyka, E., Coldicott, I., Iremonger, K., Lewis, K. E., Ning, K. \& Azzouz, M. (2018). Plastin 3 promotes motor neuron axonal growth and extends survival in a mouse model of spinal muscular atrophy. Molecular Therapy-Methods \& Clinical Development, 9, 81-89. https://doi. org/10.1016/j.omtm.2018.01.007

6. Andersen, P. M., Forsgren, L., Binzer, M., Nilsson, P., Ala-Hurula, V., Keranen, M. L., Bergmark, L., Saarinen, A., Haltia, T., Tarvainen, I., Kinnunen, E., Udd, B., \& Marklund, S. L. (1996). Autosomal recessive adult-onset amyotrophic lateral sclerosis associated with homozygosity for Asp90Ala CuZn-superoxide dismutase mutation. A clinical and genealogical study of 36 patients [Research Support, Non-U.S. Gov't]. Brain, 119(Pt 4), 1153-1172. https://doi.org/10.1093/brain/119.4.1153

7. Andersen, P. M., Nilsson, P., Ala Hurula, V., Keranen, M. L., Tarvainen, I., Haltia, T., Nilsson, L., Binzer, M., Forsgren, L., \& Marklund, S. L. (1995). Amyotrophic lateral sclerosis associated with homozygosity for an Asp90Ala mutation in CuZn-superoxide dismutase. Nature Genetics, 10, 61-66.

8. Andersen, P. M., Nilsson, P., Forsgren, L., \& Marklund, S. L. (1998). CuZn-superoxide dismutase, extracellular superoxide dismutase, and glutathione peroxidase in blood from individuals homozygous for Asp90Ala CuZu-superoxide dismutase mutation [Research Support, Non-U.S. Gov't]. Journal of Neurochemistry, 70(2), 715-720. https://doi. org/10.1046/j.1471-4159.1998.70020715.x

9. Andrews, J. A., Miller, T. M., Vijayakumar, V., Stoltz, R., James, J. K., Meng, L., Wolff, A. A., \& Malik, F. I. (2018). CK-2127107 amplifies skeletal muscle response to nerve activation in humans [Clinical Trial, Phase I Randomized Controlled Trial Research Support, Non-U.S. Gov't]. Muscle and Nerve, 57(5), 729-734. https://doi.org/10.1002/mus.26017

10. Aragon-Gawinska, K., Seferian, A. M., Daron, A., Gargaun, E., Vuillerot, C., Cances, C., Ropars, J., Chouchane, M., Cuppen, I., Hughes, I., Illingworth, M., Marini-Bettolo, C., Rambaud, J., Taytard, J., Annoussamy, M., Scoto, M., Gidaro, T., \& Servais, L. (2018). Nusinersen in patients older than 7 months with spinal muscular atrophy type 1: A cohort study [Clinical Trial Research Support, Non-U.S. Gov't]. Neurology, 91(14), e1312-e1318. https://doi.org/10.1212/WNL.0000000000006281

11. Arakawa, Y., Sendtner, M., \& Thoenen, H. (1990). Survival effect of ciliary neurotrophic factor (CNTF) on chick embryonic motoneurons in culture: Comparison with other neurotrophic factors and cytokines. Journal of Neuroscience, 10, 3507-3515.
12. Arnold, A. S., Gueye, M., Guettier-Sigrist, S., Courdier-Fruh, I., Coupin, G., Poindron, P., \& Gies, J. P. (2004). Reduced expression of nicotinic AChRs in myotubes from spinal muscular atrophy I patients [Research Support, Non-U.S. Gov't]. Laboratory Investigation, 84(10), 1271-1278. https://doi. org/10.1038/labinvest.3700163

13. Arnold, C. (2019). Custom therapies pose huge financial burdens. Nature Medicine. https://doi.org/10.1038/d41591-019-00021-w

14. Arnold, C. (2019). Tailored treatment for ALS poised to move ahead. Nature Medicine. https://doi.org/10.1038/d41591-019-00013-w

15. Ash, P. E., Bieniek, K. F., Gendron, T. F., Caulfield, T., Lin, W. L., DejesusHernandez, M., van Blitterswijk, M. M., Jansen-West, K., Paul, J. W., 3rd., Rademakers, R., Boylan, K. B., Dickson, D. W., \& Petrucelli, L. (2013), Unconventional translation of C9ORF72 GGGGCC expansion generates insoluble polypeptides specific to c9FTD/ALS [Research Support, N.I.H., Extramural Research Support, Non-U.S. Gov't]. Neuron, 77(4), 639-646. https://doi.org/10.1016/j.neuron.2013.02.004

16. Aslesh, T., Maruyama, R., \& Yokota, T. (2018). Skipping multiple exons to treat DMD-promises and challenges [review]. Biomedicines, 6(1), 1. https://doi.org/10.3390/biomedicines6010001

17. Azzouz, M., Le, T., Ralph, G. S., Walmsley, L., Monani, U. R., Lee, D. C., Wilkes, F., Mitrophanous, K. A., Kingsman, S. M., Burghes, A. H., \& Mazarakis, N. D. (2004). Lentivector-mediated SMN replacement in a mouse model of spinal muscular atrophy. The Journal of Clinical Investigation, 114(12), 1726-1731. https://doi.org/10.1172/JCI22922

18. Baldwin, K. R., Godena, V. K., Hewitt, V. L., \&Whitworth, A. J. (2016). Axonal transport defects are a common phenotype in Drosophila models of ALS. Human Molecular Genetics, 25(12), 2378-2392. https:// doi.org/10.1093/hmg/ddw105

19. Baranello, G., Darras, B. T., Day, J. W., Deconinck, N., Klein, A., Masson, R., Mercuri, E., Rose, K., El-Khairi, M., Gerber, M., Gorni, K., Khwaja, O., Kletzl, H., Scalco, R. S., Seabrook, T., Fontoura, P., Servais, L., \& Group, F. W. (2021). Risdiplam in Type 1 Spinal Muscular Atrophy. New England Journal of Medicine, 384(10), 915-923. https://doi.org/10.1056/NEJMoa2009965

20. Battaglia, G., Princivalle, A., Forti, F., Lizier, C., \& Zeviani, M. (1997). Expression of the SMN gene, the spinal muscular atrophy determining gene, in the mammalian central nervous system. Human Molecular Genetics, 6(11), 1961-1971.

21. Becker, L. A., Huang, B., Bieri, G., Ma, R., Knowles, D. A., Jafar-Nejad, P., Messing, J., Kim, H. J., Soriano, A., Auburger, G., Pulst, S. M., Taylor, J. P., Rigo, F., \& Gitler, A. D. (2017). Therapeutic reduction of ataxin-2 extends lifespan and reduces pathology in TDP-43 mice. Nature, 544(7650), 367-371. https://doi.org/10.1038/nature22038

22. Berciano, M. T., Castillo-Iglesias, M. S., Val-Bernal, J. F., Lafarga, V., Rodriguez-Rey, J. C., Lafarga, M., \& Tapia, O. (2020). Mislocalization of SMN from the I-band and M-band in human skeletal myofibers in spinal muscular atrophy associates with primary structural alterations of the sarcomere. Cell and Tissue Research, 381(3), 461-478. https://doi.org/10. 1007/s00441-020-03236-3

23. Bertini, E., Gadisseux, J. L., Palmieri, G., Ricci, E., Di, C. M., Ferriere, G., \& Lyon, G. (1989). Distal infantile spinal muscular atrophy associated with paralysis of the diaphragm: a variant of infantile spinal muscular atrophy. American Journal of Medical Genetics, 33(3), 328-335.

24. Bladen, C. L., Salgado, D., Monges, S., Foncuberta, M. E., Kekou, K., Kosma, K., Dawkins, H., Lamont, L., Roy, A. J., Chamova, T., Guergueltcheva, V., Chan, S., Korngut, L., Campbell, C., Dai, Y., Wang, J., Barisic, N., Brabec, P., Lahdetie, J., ... Lochmuller, H. (2015). The TREAT-NMD DMD Global Database: analysis of more than 7,000 Duchenne muscular dystrophy mutations [Research Support, Non-U.S. Gov't]. Human Mutatation, 36(4), 395-402. https://doi.org/10.1002/humu.22758

25. Bordet, T., Berna, P., Abitbol, J. L., \& Pruss, R. M. (2010). Olesoxime (TRO19622): A novel mitochondrial-targeted neuroprotective compound. Pharmaceuticals (Basel), 3(2), 345-368. https://doi.org/10.3390/ ph3020345

26. Bosch-Marce, M., Wee, C. D., Martinez, T. L., Lipkes, C. E., Choe, D. W., Kong, L., Van Meerbeke, J. P., Musaro, A., \& Sumner, C. J. (2011). Increased IGF-1 in muscle modulates the phenotype of severe SMA mice. Human Molecular Genetics, 20(9), 1844-1853.

27. Boutin, S., Monteilhet, V., Veron, P., Leborgne, C., Benveniste, O., Montus, M. F., \& Masurier, C. (2010). Prevalence of serum IgG and neutralizing factors against adeno-associated virus (AAV) types 1, 2, 5, 6, 8, and 9 in the healthy population: Implications for gene therapy using AAV 
vectors. Human Gene Therapy, 21(6), 704-712. https://doi.org/10.1089/ hum.2009.182

28. Bowerman, M., Becker, C. G., Yanez-Munoz, R. J., Ning, K., Wood, M. J. A., Gillingwater, T. H., Talbot, K., \& Consortium, U. S. R. (2017). Therapeutic strategies for spinal muscular atrophy: SMN and beyond [Review Research Support, Non-U.S. Gov't]. Disease Models \& Mechanisms, 10(8), 943-954. https://doi.org/10.1242/dmm.030148

29. Braun, R., Wang, Z., Mack, D. L., \& Childers, M. K. (2014). Gene therapy for inherited muscle diseases: Where genetics meets rehabilitation medicine [Review]. American Journal of Physical Medicine and Rehabilitation, 93(11 Suppl 3), S97-107. https://doi.org/10.1097/PHM.0000000000 000138

30. Braun, S., Croizat, B., Lagrange, M. C., Warter, J. M., \& Poindron, P. (1995). Constitutive muscular abnormalities in culture in spinal muscular atrophy. Lancet, 345(8951), 694-695. https://doi.org/10.1016/s01406736(95) $90869-2$

31. Bricceno, K. V., Martinez, T., Leikina, E., Duguez, S., Partridge, T. A., Chernomordik, L. V., Fischbeck, K. H., Sumner, C. J., \& Burnett, B. G. (2014). Survival motor neuron protein deficiency impairs myotube formation by altering myogenic gene expression and focal adhesion dynamics. Human Molecular Genetics, 23(18), 4745-4757. https://doi.org/10.1093/ $\mathrm{hmg} / \mathrm{ddu} 189$

32. Briese, M., Saal-Bauernschubert, L., Ji, C., Moradi, M., Ghanawi, H., Uhl, M., Appenzeller, S., Backofen, R., \& Sendtner, M. (2018). hnRNP R and its main interactor, the noncoding RNA 7SK, coregulate the axonal transcriptome of motoneurons [Research Support, Non-U.S. Gov't]. Proceedings of the National Academy of Sciences USA, 115(12), E2859-E2868. https://doi.org/10.1073/pnas.1721670115

33. Briese, M., Saal-Bauernschubert, L., Luningschror, P., Moradi, M., Dombert, B., Surrey, V., Appenzeller, S., Deng, C., Jablonka, S., \& Sendtner, M. (2020). Loss of Tdp-43 disrupts the axonal transcriptome of motoneurons accompanied by impaired axonal translation and mitochondria function. Acta Neuropathologica Communications, 8(1), 116. https://doi. org/10.1186/s40478-020-00987-6

34. Briese, M., Saal, L., Appenzeller, S., Moradi, M., Baluapuri, A., \& Sendtner, M. (2016). Whole transcriptome profiling reveals the RNA content of motor axons. Nucleic Acids Research., 44(4), e33.

35. Broustal, O., Camuzat, A., Guillot-Noel, L., Guy, N., Millecamps, S., Deffond, D., Lacomblez, L., Golfier, V., Hannequin, D., Salachas, F., Camu, W., Didic, M., Dubois, B., Meininger, V., Le Ber, I., Brice, A., French, C., \& genetic research network on, F. F.-M. (2010). FUS mutations in frontotemporal lobar degeneration with amyotrophic lateral sclerosis. Journal of Alzheimer's Disease, 22(3), 765-769.

36. Bruijn, L. I., Houseweart, M. K., Kato, S., Anderson, K. L., Anderson, S. D., Ohama, E., Reaume, A. G., Scott, R. W., \& Cleveland, D. W. (1998). Aggregation and motor neuron toxicity of an ALS-linked SOD1 mutant independent from wild-type SOD1 [Research Support, Non-U.S. Gov't Research Support, U.S. Gov't, P.H.S.]. Science, 281(5384), 1851-1854. https://doi.org/10.1126/science.281.5384.1851

37. Burghes, A. H. (1997). When is a deletion not a deletion? When it is converted. American Journal of Human Genetics, 61 (1), 9-15.

38. Burlet, P., Huber, C., Bertrandy, S., Ludosky, M. A., Zwaenepoel, I., Clermont, O., Roume, J., Delezoide, A. L., Cartaud, J., Munnich, A., \& Lefebvre, S. (1998). The distribution of SMN protein complex in human fetal tissues and its alteration in spinal muscular atrophy. Human Molecular Genetics, 7(12), 1927-1933.

39. Campagne, S., Boigner, S., Rudisser, S., Moursy, A., Gillioz, L., Knorlein, A., Hall, J., Ratni, H., Clery, A., \& Allain, F. H. (2019). Structural basis of a small molecule targeting RNA for a specific splicing correction [Research Support, Non-U.S. Gov't]. Nature Chemical Biology, 15(12), 1191-1198. https://doi.org/10.1038/s41589-019-0384-5

40. Campbell, L., Potter, A., Ignatius, J., Dubowitz, V., \& Davies, K. (1997) Genomic variation and gene conversion in spinal muscular atrophy: Implications for disease process and clinical phenotype. American Journal of Human Genetics, 61 (1), 40-50.

41. Carter, J. C., Sheehan, D. W., Prochoroff, A., \& Birnkrant, D. J. (2018). Muscular dystrophies [review]. Clinics in Chest Medicine, 39(2), 377-389. https://doi.org/10.1016/j.ccm.2018.01.004

42. Chia, R., Chio, A., \& Traynor, B. J. (2018). Novel genes associated with amyotrophic lateral sclerosis: Diagnostic and clinical implications
[Review]. Lancet Neurology, 17(1), 94-102. https://doi.org/10.1016/ S1474-4422(17)30401-5

43. Chicoine, L. G., Rodino-Klapac, L. R., Shao, G., Xu, R., Bremer, W. G., Camboni, M., Golden, B., Montgomery, C. L., Shontz, K., Heller, K. N., Griffin, D. A., Lewis, S., Coley, B. D., Walker, C. M., Clark, K. R., Sahenk, Z., Mendell, J. R., \& Martin, P.T. (2014). Vascular delivery of rAAVrh74.MCK.GALGT2 to the gastrocnemius muscle of the rhesus macaque stimulates the expression of dystrophin and laminin alpha2 surrogates [Research Support, N.I.H., Extramural Research Support, Non-U.S. Gov't]. Molecular Therapy, 22(4), 713-724. https://doi.org/10.1038/mt.2013.246

44. Chiriboga, C. A., Swoboda, K. J., Darras, B. T., lannaccone, S. T., Montes, J., De Vivo, D. C., Norris, D. A., Bennett, C. F., \& Bishop, K. M. (2016). Results from a phase 1 study of nusinersen (ISIS-SMN(Rx)) in children with spinal muscular atrophy [Clinical Trial, Phase I Multicenter Study Research Support, Non-U.S. Gov't]. Neurology, 86(10), 890-897. https://doi.org/10. 1212/WNL.0000000000002445

45. Cho, S., \& Dreyfuss, G. (2010). A degron created by SMN2 exon 7 skipping is a principal contributor to spinal muscular atrophy severity [Research Support, Non-U.S. Gov't]. Genes \& Development, 24(5), 438-442. https://doi.org/10.1101/gad.1884910

46. Christine, C. W., Starr, P. A., Larson, P. S., Eberling, J. L., Jagust, W. J., Hawkins, R. A., VanBrocklin, H. F., Wright, J. F., Bankiewicz, K. S., \& Aminoff, M. J. (2009). Safety and tolerability of putaminal AADC gene therapy for Parkinson disease. Neurology, 73(20), 1662-1669. https://doi.org/10. 1212/WNL.0b013e3181c29356

47. Cifuentes-Diaz, C., Frugier, T., Tiziano, F. D., Lacene, E., Roblot, N., Joshi, V., Moreau, M. H., \& Melki, J. (2001). Deletion of murine SMN exon 7 directed to skeletal muscle leads to severe muscular dystrophy. Journal of Cell Biology, 152(5), 1107-1114. https://doi.org/10.1083/jcb.152.5.1107

48. Cleveland, D. W., Laing, N., Hurse, P. V., \& Brown, R. H., Jr. (1995). Toxic mutants in Charcot's sclerosis [Comment Letter]. Nature, 378(6555), 342-343. https://doi.org/10.1038/378342a0

49. Congdon, E. E., \& Sigurdsson, E. M. (2018). Tau-targeting therapies for Alzheimer disease [Research Support, N.I.H., Extramural Research Support, Non-U.S. Gov't Review]. Nature Reviews Neurology, 14(7), 399-415. https://doi.org/10.1038/s41582-018-0013-z

50. Coovert, D. D., Le, T. T., McAndrew, P. E., Strasswimmer, J., Crawford, T. O., Mendell, J. R., Coulson, S. E., Androphy, E. J., Prior, T. W., \& Burghes, A. H. (1997). The survival motor neuron protein in spinal muscular atrophy. Human Molecular Genetics, 6(8), 1205-1214.

51. Cox, G. A., Mahaffey, C. L., \& Frankel, W. N. (1998). Identification of the mouse neuromuscular degeneration gene and mapping of a second site suppressor allele. Neuron, 21(6), 1327-1337.

52. Crudele, J. M., \& Chamberlain, J. S. (2019). AAV-based gene therapies for the muscular dystrophies. Human Molecular Genetics, 28(R1), R102R107. https://doi.org/10.1093/hmg/ddz128

53. d'Ydewalle, C., Ramos, D. M., Pyles, N. J., Ng, S. Y., Gorz, M., Pilato, C. M., Ling, K., Kong, L., Ward, A. J., Rubin, L. L., Rigo, F., Bennett, C. F., \& Sumner, C. J. (2017). The antisense transcript SMN-AS1 regulates SMN expression and is a novel therapeutic target for spinal muscular atrophy. Neuron, 93(1), 66-79.

54. Darras, B. T., Chiriboga, C. A., lannaccone, S. T., Swoboda, K. J., Montes, J., Mignon, L., Xia, S., Bennett, C. F., Bishop, K. M., Shefner, J. M., Green, A. M., Sun, P., Bhan, I., Gheuens, S., Schneider, E., Farwell, W., De Vivo, D. C., \& Groups, I.-C. I.-C. S. (2019). Nusinersen in later-onset spinal muscular atrophy: Long-term results from the phase 1/2 studies [Clinical Trial, Phase I Clinical Trial, Phase II Multicenter Study Research Support, NonU.S. Gov't]. Neurology, 92(21), e2492-e2506. https://doi.org/10.1212/ WNL.00000000000007527

55. Darras, B. T., Masson, R., Mazurkiewicz-Beldzinska, M., Rose, K., Xiong, H., Zanoteli, E., Baranello, G., Bruno, C., Vlodavets, D., Wang, Y., El-Khairi, M., Gerber, M., Gorni, K., Khwaja, O., Kletzl, H., Scalco, R. S., Fontoura, P., Servais, L., \& Group, F. W. (2021). Risdiplam-treated infants with Type 1 spinal muscular atrophy versus historical controls. New England Journal of Medicine, 385(5), 427-435. https://doi.org/10.1056/NEJMoa2102047

56. Davies, K. E., \& Chamberlain, J. S. (2019). Surrogate gene therapy for muscular dystrophy. Nature Medicine, 25(10), 1473-1474. https://doi. org/10.1038/s41591-019-0604-2

57. Day, J. W., Finkel, R. S., Chiriboga, C. A., Connolly, A. M., Crawford, T. O., Darras, B. T., lannaccone, S. T., Kuntz, N. L., Pena, L. D. M., Shieh, P. B., Smith, E. C., Kwon, J. M., Zaidman, C. M., Schultz, M., Feltner, D. E., 
Tauscher-Wisniewski, S., Ouyang, H., Chand, D. H., Sproule, D. M., ... Mendell, J. R. (2021). Onasemnogene abeparvovec gene therapy for symptomatic infantile-onset spinal muscular atrophy in patients with two copies of SMN2 (STR1VE): An open-label, single-arm, multicentre, phase 3 trial. Lancet Neurology, 20(4), 284-293. https://doi.org/10. 1016/S1474-4422(21)00001-6

58. Day, J. W., Finkel, R. S., Mercuri, E., Swoboda, K. J., Menier, M., van Olden, R., Tauscher-Wisniewski, S., \& Mendell, J. R. (2021). Adeno-associated virus serotype 9 antibodies in patients screened for treatment with onasemnogene abeparvovec. Molecular Therapy - Methods \& Clinical Development, 21, 76-82. https://doi.org/10.1016/j.omtm.2021. 02.014

59. De Vivo, D. C., Bertini, E., Swoboda, K. J., Hwu, W. L., Crawford, T. O., Finkel, R. S., Kirschner, J., Kuntz, N. L., Parsons, J. A., Ryan, M. M., Butterfield, R. J., Topaloglu, H., Ben-Omran, T., Sansone, V. A., Jong, Y. J., Shu, F., Staropoli, J. F., Kerr, D., Sandrock, A. W., ... Group, N. S. (2019), Nusinersen initiated in infants during the presymptomatic stage of spinal muscular atrophy: Interim efficacy and safety results from the Phase 2 NURTURE study. Neuromuscular Disorders, 29(11), 842-856. https://doi.org/10.1016/j.nmd.2019.09.007

60. DeJesus-Hernandez, M., Mackenzie, I. R., Boeve, B. F., Boxer, A. L., Baker, M., Rutherford, N. J., Nicholson, A. M., Finch, N. A., Flynn, H., Adamson, J., Kouri, N., Wojtas, A., Sengdy, P., Hsiung, G. Y., Karydas, A., Seeley, W. W., Josephs, K. A., Coppola, G., Geschwind, D. H., .. Rademakers, R. (2011). Expanded GGGGCC hexanucleotide repeat in noncoding region of C9ORF72 causes chromosome 9p-linked FTD and ALS [Research Support, N.I.H., Extramural Research Support, NonU.S. Gov't]. Neuron, 72(2), 245-256. https://doi.org/10.1016/j.neuron. 2011.09.011

61. Deng, H., Gao, K., \& Jankovic, J. (2014). The role of FUS gene variants in neurodegenerative diseases [Research Support, Non-U.S. Gov't Review]. Nature Reviews Neurology, 10(6), 337-348. https://doi.org/10.1038/nrneu rol.2014.78

62. Deng, H. X., Hentati, A., Tainer, J. A., Iqbal, Z., Cayabyab, A., Hung, W. Y., Getzoff, E. D., Hu, P., Herzfeldt, B., \& Roos, R. P. (1993). Amyotrophic lateral sclerosis and structural defects in $\mathrm{Cu}, \mathrm{Zn}$ superoxide dismutase. Science, 261(5124), 1047-1051.

63. Deveuve, Q., Lajoie, L., Barrault, B., \& Thibault, G. (2020). The proteolytic cleavage of therapeutic monoclonal antibody hinge region: More than a matter of subclass. Frontiers in Immunology, 11, 168. https://doi.org/10. 3389/fimmu.2020.00168

64. Dimitriadi, M., Derdowski, A., Kalloo, G., Maginnis, M. S., O'Hern, P., Bliska, B., Sorkac, A., Nguyen, K. C., Cook, S. J., Poulogiannis, G., Atwood, W. J., Hall, D. H., \& Hart, A. C. (2016). Decreased function of survival motor neuron protein impairs endocytic pathways [Research Support, N.I.H., Extramural]. Proceedings of the National Academy of Sciences USA, 113(30), E4377-4386. https://doi.org/10.1073/pnas.1600015113

65. Dimitriadi, M., Sleigh, J. N., Walker, A., Chang, H. C., Sen, A., Kalloo, G., Harris, J., Barsby, T., Walsh, M. B., Satterlee, J. S., Li, C., Van Vactor, D., Artavanis-Tsakonas, S., \& Hart, A. C. (2010). Conserved genes act as modifiers of invertebrate SMN loss of function defects [Research Support, N.I.H., Extramural Research Support, Non-U.S. Gov't]. PLoS Genetics, 6(10), e1001172. https://doi.org/10.1371/journal.pgen.1001172

66. Doktor, T. K., Hua, Y., Andersen, H. S., Broner, S., Liu, Y. H., Wieckowska, A., Dembic, M., Bruun, G. H., Krainer, A. R., \& Andresen, B. S. (2017). RNA-sequencing of a mouse-model of spinal muscular atrophy reveals tissue-wide changes in splicing of U12-dependent introns. Nucleic Acids Research, 45(1), 395-416. https://doi.org/10.1093/nar/gkw731

67. Dombert, B., Balk, S., Luningschror, P., Moradi, M., Sivadasan, R., SaalBauernschubert, L., \& Jablonka, S. (2017). BDNF/trkB induction of calcium transients through Cav2.2 calcium channels in motoneurons corresponds to F-actin assembly and growth cone formation on beta2Chain Laminin (221). Frontiers in Molecular Neuroscience, 10, 346. https:// doi.org/10.3389/fnmol.2017.00346

68. Dombert, B., Sivadasan, R., Simon, C. M., Jablonka, S., \& Sendtner, M. (2014). Presynaptic localization of $S m n$ and hnRNP R in axon terminals of embryonic and postnatal mouse motoneurons. PLOS ONE, 9(10), e11046.

69. Dubowitz, V. (1964). Infantile muscular atrophy. A prospective study with particular reference to a slowly progressive variety. Brain, 87 , 707-718. https://doi.org/10.1093/brain/87.4.707
70. Dubowitz, V. (1995). Chaos in the classification of SMA: A possible resolution. Neuromuscular Disorders, 5(1), 3-5.

71. Echaniz-Laguna, A., Miniou, P., Bartholdi, D., \& Melki, J. (1999). The promoters of the survival motor neuron gene (SMN) and its copy (SMNC) share common regulatory elements. American Journal of Human Genetics, 64(5), 1365-1370.

72. Echevarria, L., Aupy, P., \& Goyenvalle, A. (2018). Exon-skipping advances for Duchenne muscular dystrophy [Research Support, Non-U.S. Gov't Review]. Human Molecular Genetics, 27(R2), R163-R172. https://doi.org/ 10.1093/hmg/ddy171

73. Echigoya, Y., Lim, K. R. Q., Melo, D., Bao, B., Trieu, N., Mizobe, Y., Maruyama, R., Mamchaoui, K., Tanihata, J., Aoki, Y., Takeda, S., Mouly, V., Duddy, W., \& Yokota, T. (2019). Exons 45-55 Skipping Using Mutation-Tailored Cocktails of Antisense Morpholinos in the DMD Gene [Research Support, Non-U.S. Gov't]. Molecular Therapy, 27(11), 2005-2017. https://doi. org/10.1016/j.ymthe.2019.07.012

74. Echigoya, Y., Lim, K. R. Q., Nakamura, A., \& Yokota, T. (2018). Multiple exon skipping in the Duchenne muscular dystrophy hot spots: Prospects and challenges [review]. Journal of Personalized Medicine, 8(4), 41. https:// doi.org/10.3390/jpm8040041

75. Elangkovan, N., \& Dickson, G. (2021). Gene therapy for Duchenne muscular dystrophy. Journal of Neuromuscular Diseases. https://doi.org/ 10.3233/JND-210678

76. Elden, A. C., Kim, H. J., Hart, M. P., Chen-Plotkin, A. S., Johnson, B. S., Fang, X., Armakola, M., Geser, F., Greene, R., Lu, M. M., Padmanabhan, A., Clay-Falcone, D., McCluskey, L., Elman, L., Juhr, D., Gruber, P. J., Rub, U., Auburger, G., Trojanowski, J. Q., ... Gitler, A. D. (2010). Ataxin-2 intermediate-length polyglutamine expansions are associated with increased risk for ALS. Nature, 466(7310), 1069-1075. https://doi.org/10. 1038/nature09320

77. Emery, A. E. (1991). Population frequencies of inherited neuromuscular diseases-a world survey. Neuromuscular Disorders, 1(1), 19-29.

78. Emery, A. E., Hausmanowa-Petrusewicz, I., Davie, A. M., Holloway, S., Skinner, R., \& Borkowska, J. (1976). International collaborative study of the spinal muscular atrophies. Part 1. Analysis of clinical and laboratory data. Journal of the Neurological Sciences, 29(1), 83-94. https://doi.org/ 10.1016/0022-510x(76)90082-4

79. England, S. B., Nicholson, L. V., Johnson, M. A., Forrest, S. M., Love, D. R., Zubrzycka-Gaarn, E. E., Bulman, D. E., Harris, J. B., \& Davies, K. E. (1990). Very mild muscular dystrophy associated with the deletion of $46 \%$ of dystrophin. Nature, 343(6254), 180-182. https://doi.org/10.1038/34318 OaO

80. Fahn, S., Oakes, D., Shoulson, I., Kieburtz, K., Rudolph, A., Lang, A., Olanow, C. W., Tanner, C., \& Marek, K. (2004). Levodopa and the progression of Parkinson's disease [Clinical Trial Multicenter Study Randomized Controlled Trial Research Support, U.S. Gov't, Non-P.H.S. Research Support, U.S. Gov't, P.H.S.]. New England Journal of Medicine, 351(24), 2498-2508. https://doi.org/10.1056/NEJMoa033447

81. Fallini, C., Bassell, G. J., \& Rossoll, W. (2012). Spinal muscular atrophy: The role of SMN in axonal mRNA regulation. Brain Research, 1462, 81-92.

82. Fallini, C., Zhang, H., Su, Y., Silani, V., Singer, R. H., Rossoll, W., \& Bassell, G. J. (2011). The survival of motor neuron (SMN) protein interacts with the mRNA-binding protein $\mathrm{HuD}$ and regulates localization of poly(A) mRNA in primary motor neuron axons. Journal of Neuroscience, 37(10), 3914-3925

83. Farrar, M. A., Teoh, H. L., Carey, K. A., Cairns, A., Forbes, R., Herbert, K., Holland, S., Jones, K. J., Menezes, M. P., Morrison, M., Munro, K., Villano, D. Webster, R., Woodcock, I. R., Yiu, E. M., Sampaio, H., \& Ryan, M. M. (2018). Nusinersen for SMA: expanded access programme [Multicenter Study Research Support, Non-U.S. Gov't]. Journal of Neurology, Neurosurgery \& Psychiatry, 89(9), 937-942. https://doi.org/10.1136/jnnp-2017-317412

84. Feinstein, B., Lindegard, B., Nyman, E., \& Wohlfart, G. (1955). Morphologic studies of motor units in normal human muscles. Acta Anatomica (Basel), 23(2), 127-142. https://doi.org/10.1159/000140989

85. Feldkotter, M., Schwarzer, V., Wirth, R., Wienker, T. F., \& Wirth, B. (2002) Quantitative analyses of SMN1 and SMN2 based on real-time lightCycler PCR: fast and highly reliable carrier testing and prediction of severity of spinal muscular atrophy [Research Support, Non-U.S. Gov't]. The American Journal of Human Genetics, 70(2), 358-368. https://doi.org/ $10.1086 / 338627$ 
86. Feng, Z., Ling, K. K., Zhao, X., Zhou, C., Karp, G., Welch, E. M., Naryshkin, N., Ratni, H., Chen, K. S., Metzger, F., Paushkin, S., Weetall, M., \& Ko, C. P. (2016). Pharmacologically induced mouse model of adult spinal muscular atrophy to evaluate effectiveness of therapeutics after disease onset. Human Molecular Genetics, 25(5), 964-975. https://doi.org/10. 1093/hmg/ddv629

87. Fidzianska, A., Goebel, H. H., \&Warlo, I. (1990). Acute infantile spinal muscular atrophy. Muscle apoptosis as a proposed pathogenetic mechanism. Brain, 113(Pt 2), 433-445. https://doi.org/10.1093/brain/ 113.2.433

88. Finkel, R. S., Chiriboga, C. A., Vajsar, J., Day, J. W., Montes, J., De Vivo, D. C., Yamashita, M., Rigo, F., Hung, G., Schneider, E., Norris, D. A., Xia, S., Bennett, C. F., \& Bishop, K. M. (2016). Treatment of infantile-onset spinal muscular atrophy with nusinersen: a phase 2, open-label, dose-escalation study [Clinical Trial, Phase II Research Support, Non-U.S. Gov't]. Lancet, 388(10063), 3017-3026. https://doi.org/10.1016/S0140-6736(16) 31408-8

89. Finkel, R. S., Mercuri, E., Darras, B. T., Connolly, A. M., Kuntz, N. L., Kirschner, J., Chiriboga, C. A., Saito, K., Servais, L., Tizzano, E., Topaloglu, H., Tulinius, M., Montes, J., Glanzman, A. M., Bishop, K., Zhong, Z. J., Gheuens, S., Bennett, C. F., Schneider, E., ... Group, E. S. (2017). Nusinersen versus Sham control in infantile-onset spinal muscular atrophy [Clinical Trial, Phase III Multicenter Study Randomized Controlled Trial]. New England Journal of Medicine, 377(18), 1723-1732. https://doi.org/10. 1056/NEJMoa1702752

90. Finkel, R. S., Day, J. W., Darras, B. T., Kuntz, N. L., Connolly, A. M., et al. (2019). Phase 1 study of intrathecal administration of AVXS-101 genereplacement therapy (GRT) for spinal muscular atrophy type 2 (SMA2) (STRONG) (P1.6-059). Neurology, 92, P1.6-059.

91. Fischer, U., Liu, Q., \& Dreyfuss, G. (1997). The SMN-SIP1 complex has an essential role in spliceosomal snRNP biogenesis. Cell 77(5), 727-736, 90(6), 1023-1029.

92. Foust, K. D., Nurre, E., Montgomery, C. L., Hernandez, A., Chan, C. M., \& Kaspar, B. K. (2009). Intravascular AAV9 preferentially targets neonatal neurons and adult astrocytes [Research Support, N.I.H., Extramural Research Support, Non-U.S. Gov't]. Nature Biotechnology, 27(1), 59-65. https://doi.org/10.1038/nbt.1515

93. Foust, K. D., Wang, X., McGovern, V. L., Braun, L., Bevan, A. K., Haidet, A. M., Le, T. T., Morales, P. R., Rich, M. M., Burghes, A. H., \& Kaspar, B. K. (2010), Rescue of the spinal muscular atrophy phenotype in a mouse model by early postnatal delivery of SMN. Nature Biotechnology, 28(3), 271-274.

94. Freibaum, B. D., \& Taylor, J. P. (2017). The role of dipeptide repeats in C9ORF72-related ALS-FTD [review]. Frontiers in Molecular Neuroscience, 10, 35. https://doi.org/10.3389/fnmol.2017.00035

95. Fujii, R., Okabe, S., Urushido, T., Inoue, K., Yoshimura, A., Tachibana, T., Nishikawa, T., Hicks, G. G., \& Takumi, T. (2005). The RNA binding protein TLS is translocated to dendritic spines by mGluR5 activation and regulates spine morphology. Current Biology, 15(6), 587-593. https://doi.org/ 10.1016/j.cub.2005.01.058

96. Fujii, R., \& Takumi, T. (2005). TLS facilitates transport of mRNA encoding an actin-stabilizing protein to dendritic spines [Research Support, NonU.S. Gov't]. Journal of Cell Science, 118(Pt 24), 5755-5765. https://doi.org/ $10.1242 /$ jcs.02692

97. Gabanella, F., Carissimi, C., Usiello, A., \& Pellizzoni, L. (2005). The activity of the spinal muscular atrophy protein is regulated during development and cellular differentiation [Research Support, Non-U.S. Gov't] Human Molecular Genetics, 14(23), 3629-3642. https://doi.org/10.1093/ $\mathrm{hmg} / \mathrm{ddi} 390$

98. Garcia, E. L., Lu, Z., Meers, M. P., Praveen, K., \& Matera, A. G. (2013). Developmental arrest of Drosophila survival motor neuron (Smn) mutants accounts for differences in expression of minor intron-containing genes. RNA, 19(11), 1510-1516

99. Gavrilina, T. O., McGovern, V. L., Workman, E., Crawford, T. O., Gogliotti, R. G., DiDonato, C. J., Monani, U. R., Morris, G. E., \& Burghes, A. H. (2008), Neuronal SMN expression corrects spinal muscular atrophy in severe SMA mice while muscle-specific SMN expression has no phenotypic effect [Research Support, N.I.H., Extramural Research Support, Non-U.S. Gov't]. Human Molecular Genetics, 17(8), 1063-1075. https://doi.org/10. 1093/hmg/ddm379

100. Gidaro, T., \& Servais, L. (2019). Nusinersen treatment of spinal muscular atrophy: Current knowledge and existing gaps [Review]. Developmental
Medicine and Child Neurology, 61(1), 19-24. https://doi.org/10.1111/ dmcn. 14027

101. Gilbert, L. A., Horlbeck, M. A., Adamson, B., Villalta, J. E., Chen, Y., Whitehead, E. H., Guimaraes, C., Panning, B., Ploegh, H. L., Bassik, M. C., Qi, L. S. Kampmann, M., \&Weissman, J. S. (2014). Genome-scale CRISPR-mediated control of gene repression and activation [Research Support, N.I.H., Extramural Research Support, Non-U.S. Gov't]. Cell, 159(3), 647-661. https://doi.org/10.1016/j.cell.2014.09.029

102. Glinka, M., Herrmann, T., Funk, N., Havlicek, S., Rossoll, W., Winkler, C., \& Sendtner, M. (2010). The heterogeneous nuclear ribonucleoprotein- $R$ is necessary for axonal beta-actin mRNA translocation in spinal motor neurons. Human Molecular Genetics, 19(10), 1951-1966.

103. Gogliotti, R. G., Quinlan, K. A., Barlow, C. B., Heier, C. R., Heckman, C. J., \& Didonato, C. J. (2012). Motor neuron rescue in spinal muscular atrophy mice demonstrates that sensory-motor defects are a consequence, not a cause, of motor neuron dysfunction. Journal of Neuroscience, 32(11), 3818-3829. https://doi.org/10.1523/JNEUROSCI.5775-11.2012

104. Gopal, P. P., Nirschl, J. J., Klinman, E., \& Holzbaur, E. L. (2017). Amyotrophic lateral sclerosis-linked mutations increase the viscosity of liquid-like TDP-43 RNP granules in neurons. Proceedings of the National Academy of Sciences USA, 114(12), E2466-E2475. https://doi.org/10.1073/pnas.16144 62114

105. Gregory, R. I., Yan, K. P., Amuthan, G., Chendrimada, T., Doratotaj, B., Cooch, N., \& Shiekhattar, R. (2004). The Microprocessor complex mediates the genesis of microRNAs [Research Support, Non-U.S. Gov't Research Support, U.S. Gov't, Non-P.H.S. Research Support, U.S. Gov't, P.H.S.]. Nature, 432(7014), 235-240. https://doi.org/10.1038/nature03120

106. Grohmann, K., Rossoll, W., Kobsar, I., Holtmann, B., Jablonka, S., Wessig, C., Stoltenburg-Didinger, G., Fischer, U., Hubner, C., Martini, R., \& Sendtner, M. (2004). Characterization of Ighmbp2 in motor neurons and implications for the pathomechanism in a mouse model of human spinal muscular atrophy with respiratory distress type 1 (SMARD1). Human Molecular Genetics, 13(18), 2031-2042.

107. Grohmann, K., Schuelke, M., Diers, A., Hoffmann, K., Lucke, B., Adams, C., Bertini, E., Leonhardt-Horti, H., Muntoni, F., Ouvrier, R., Pfeufer, A., Rossi, R., Van Maldergem, L., Wilmshurst, J. M., Wienker, T. F., Sendtner, M., Rudnik-Schoneborn, S., Zerres, K., \& Hubner, C. (2001). Mutations in the gene encoding immunoglobulin mu-binding protein 2 cause spinal muscular atrophy with respiratory distress type 1. Nature Genetics, 29(1), 75-77.

108. Grohmann, K., Varon, R., Stolz, P., Schuelke, M., Janetzki, C., Bertini, E., Bushby, K., Muntoni, F., Ouvrier, R., Van Maldergem, L., Goemans, N. M., Lochmuller, H., Eichholz, S., Adams, C., Bosch, F., Grattan-Smith, P., Navarro, C., Neitzel, H., Polster, T., ... Hubner, C. (2003). Infantile spinal muscular atrophy with respiratory distress type 1 (SMARD1). Annals of Neurology, 54(6), 719-724. (IN FILE).

109. Grohmann, K., Wienker, T. F., Saar, K., Rudnik-Schoneborn, S., Stoltenburg-Didinger, G., Rossi, R., Novelli, G., Nurnberg, G., Pfeufer, A., Wirth, B., Reis, A., Zerres, K., \& Hubner, C. (1999). Diaphragmatic spinal muscular atrophy with respiratory distress is heterogeneous, and one form is linked to chromosome 11q13-q21. American Journal of Human Genetics, 65(5), 1459-1462.

110. Guo, W., Naujock, M., Fumagalli, L., Vandoorne, T., Baatsen, P., Boon, R., Ordovas, L., Patel, A., Welters, M., Vanwelden, T., Geens, N., Tricot, T., Benoy, V., Steyaert, J., Lefebvre-Omar, C., Boesmans, W., Jarpe, M., Sterneckert, J., Wegner, F., ... Van Den Bosch, L. (2017). HDAC6 inhibition reverses axonal transport defects in motor neurons derived from FUSALS patients. Nature Communications, 8(1), 861. https://doi.org/10.1038/ s41467-017-00911-y

111. Hagenacker, T., Wurster, C. D., Gunther, R., Schreiber-Katz, O., Osmanovic, A., Petri, S., Weiler, M., Ziegler, A., Kuttler, J., Koch, J. C., Schneider, I., Wunderlich, G., Schloss, N., Lehmann, H. C., Cordts, I., Deschauer, M., Lingor, P., Kamm, C., Stolte, B., ... Kleinschnitz, C. (2020). Nusinersen in adults with $5 q$ spinal muscular atrophy: A non-interventional, multicentre, observational cohort study. Lancet Neurology, 19(4), 317-325. https:// doi.org/10.1016/S1474-4422(20)30037-5

112. Hamilton, G., \& Gillingwater, T. H. (2013). Spinal muscular atrophy: Going beyond the motor neuron [Review]. Trends in Molecular Medicine, 19(1), 40-50. https://doi.org/10.1016/j.molmed.2012.11.002

113. le Hao, T., Wolman, M., Granato, M., \& Beattie, C. E. (2012). Survival motor neuron affects plastin 3 protein levels leading to motor defects. Journal 
of Neuroscience, 32(15), 5074-5084. https://doi.org/10.1523/JNEUROSCl. 5808-11.2012

114. Hayhurst, M., Wagner, A. K., Cerletti, M., Wagers, A. J., \& Rubin, L. L. (2012). A cell-autonomous defect in skeletal muscle satellite cells expressing low levels of survival of motor neuron protein. Developmental Biology, 368(2), 323-334. https://doi.org/10.1016/j.ydbio.2012.05.037

115. Heckman, C. J. \& Enoka, R. M. (2004). Physiology of the motor neuron and the motor unit, clinical neurophysiology of motor neuron diseases. In Handbook of clinical neurophysiology, Vol. 4, Chapter 6.

116. Henderson, C. E., Phillips, H. S., Pollock, R. A., Davies, A. M., Lemeulle, C., Armanini, M., Simpson, L. C., Moffet, B., Vandlen, R. A., Koliatsos, V. E., \& Rosenthal, A. (1994). GDNF: A potent survival factor for motoneurons present in peripheral nerve and muscle. Science, 266, 1062-1064.

117. High-dose AAV gene therapy deaths. (2020, 2020/08/01). Nature Biotechnology, 38(8), 910. https://doi.org/10.1038/s41587-020-0642-9

118. Hill, J. J., Davies, M. V., Pearson, A. A., Wang, J. H., Hewick, R. M., Wolfman, N. M., \& Qiu, Y. (2002). The myostatin propeptide and the follistatinrelated gene are inhibitory binding proteins of myostatin in normal serum. Journal of Biological Chemistry, 277(43), 40735-40741. https://doi. org/10.1074/jbc.M206379200

119. Himic, V., \& Davies, K. E. (2021). Evaluating the potential of novel genetic approaches for the treatment of Duchenne muscular dystrophy. European Journal of Human Genetics. https://doi.org/10.1038/ s41431-021-00811-2

120. Hinderer, C., Miller, R., Dyer, C., Johansson, J., Bell, P., Buza, E., \& Wilson, J. M. (2020). Adeno-associated virus serotype 1-based gene therapy for FTD caused by GRN mutations. Annals of Clinical Translational Neurology, 7(10), 1843-1853. https://doi.org/10.1002/acn3.51165

121. Hoell, J. I., Larsson, E., Runge, S., Nusbaum, J. D., Duggimpudi, S., Farazi, T. A., Hafner, M., Borkhardt, A., Sander, C., \& Tuschl, T. (2011). RNA targets of wild-type and mutant FET family proteins [Research Support, N.I.H., Extramural Research Support, Non-U.S. Gov't]. Nature Structural \& Molecular Biology, 18(12), 1428-1431. https://doi.org/10.1038/nsmb. 2163

122. Hoffmann, J. (1893). Ueber chronische spinal Muskelatrophie im Kindesalter, auf familiärer Basis. Deutsche Zeitschrift für Nervenheilkunde, 3, 427.

123. Hoffmann, J. (1897). Weiterer Beitrag zur Lehre von der hereditären progressiven spinalen Muskelatrophie im Kindesalter. Deutsche Zeitschrift für Nervenheilkunde, 10, 13.

124. Hosseinibarkooie, S., Peters, M., Torres-Benito, L., Rastetter, R. H., Hupperich, K., Hoffmann, A., Mendoza-Ferreira, N., Kaczmarek, A., Janzen, E., Milbradt, J., Lamkemeyer, T., Rigo, F., Bennett, C. F., Guschlbauer, C., Buschges, A., Hammerschmidt, M., Riessland, M., Kye, M. J., Clemen, C. S., \&Wirth, B. (2016). The power of human protective modifiers: PLS3 and CORO1C unravel impaired endocytosis in spinal muscular atrophy and rescue SMA phenotype. The American Journal of Human Genetics, 99(3), 647-665.

125. Hoy, S. M. (2019). Onasemnogene Abeparvovec: First global approval [review]. Drugs, 79(11), 1255-1262. https://doi.org/10.1007/ s40265-019-01162-5

126. Hsieh-Li, H. M., Chang, J. G., Jong, Y. J., Wu, M. H., Wang, N. M. Tsai, C. H., \& Li, H. (2000). A mouse model for spinal muscular atrophy. Nature Genetics, 24(1), 66-70

127. Hua, Y., Sahashi, K., Rigo, F., Hung, G., Horev, G., Bennett, C. F., \& Krainer, A. R. (2011). Peripheral SMN restoration is essential for long-term rescue of a severe spinal muscular atrophy mouse model. Nature 377(6547), 340-344, 478(7367), 123-126.

128. Hua, Y., Vickers, T. A., Okunola, H. L., Bennett, C. F., \& Krainer, A. R. (2008), Antisense masking of an hnRNP A1/A2 intronic splicing silencer corrects SMN2 splicing in transgenic mice [Research Support, N.I.H., Extramural Research Support, Non-U.S. Gov't]. The American Journal of Human Genetics, 82(4), 834-848. https://doi.org/10.1016/j.ajhg.2008.01. 014

129. Hughes, R. A., Sendtner, M., Goldfarb, M., Lindholm, D., \& Thoenen, H. (1993). Evidence that fibroblast growth factor 5 is a major muscle derived survival factor for cultured spinal motoneurons. Neuron, 10, 369-377. (IN FILE).

130. Hwee, D. T., Kennedy, A. R., Hartman, J. J., Ryans, J., Durham, N., Malik, F. I., \& Jasper, J. R. (2015). The small-molecule fast skeletal troponin activator, CK-2127107, improves exercise tolerance in a rat model of heart failure [Research Support, Non-U.S. Gov't]. Journal of Pharmacology and
Experimental Therapeutics, 353(1), 159-168. https://doi.org/10.1124/jpet. 114.222224

131. Imbert, G., Saudou, F., Yvert, G., Devys, D., Trottier, Y., Garnier, J. M., Weber, C., Mandel, J. L., Cancel, G., Abbas, N., Durr, A., Didierjean, O., Stevanin, G., Agid, Y., \& Brice, A. (1996). Cloning of the gene for spinocerebellar ataxia 2 reveals a locus with high sensitivity to expanded CAG/glutamine repeats. Nature Genetics, 14(3), 285-291. https://doi.org/10.1038/ ng1196-285

132. Imlach, W. L., Beck, E. S., Choi, B. J., Lotti, F., Pellizzoni, L., \& McCabe, B. D. (2012). SMN is required for sensory-motor circuit function in Drosophila. Cell 77(5), 727-736, 151(2), 427-439.

133. Iqbal, K., Liu, F., \& Gong, C. X. (2016). Tau and neurodegenerative disease: The story so far [Review]. Nature Reviews. Neurology, 12(1), 15-27. https://doi.org/10.1038/nrneurol.2015.225

134. Ishigaki, S., Fujioka, Y., Okada, Y., Riku, Y., Udagawa, T., Honda, D., Yokoi, S., Endo, K., Ikenaka, K., Takagi, S., Iguchi, Y., Sahara, N., Takashima, A., Okano, H., Yoshida, M., Warita, H., Aoki, M., Watanabe, H., Okado, H., ... Sobue, G. (2017). Altered Tau isoform ratio caused by loss of FUS and SFPQ function leads to FTLD-like phenotypes. Cell Reports, 18(5), 1118-1131. https://doi.org/10.1016/j.celrep.2017.01.013

135. Ishigaki, S., Masuda, A., Fujioka, Y., Iguchi, Y., Katsuno, M., Shibata, A., Urano, F., Sobue, G., \& Ohno, K. (2012). Position-dependent FUS-RNA interactions regulate alternative splicing events and transcriptions [Research Support, Non-U.S. Gov't]. Scientific Reports, 2, 529. https://doi. org/10.1038/srep00529

136. Ittner, A., Asih, P. R., Tan, A. R. P., Prikas, E., Bertz, J., Stefanoska, K., Lin, Y., Volkerling, A. M., Ke, Y. D., Delerue, F., \& Ittner, L. M. (2020). Reduction of advanced tau-mediated memory deficits by the MAP kinase p38gamma [Research Support, Non-US Gov't]. Acta Neuropathologica, 140(3), 279-294. https://doi.org/10.1007/s00401-020-02191-1

137. Iyer, C. C., McGovern, V. L., Murray, J. D., Gombash, S. E., Zaworski, P. G. Foust, K. D., Janssen, P. M., \& Burghes, A. H. (2015). Low levels of Survival Motor Neuron protein are sufficient for normal muscle function in the SMNDelta7 mouse model of SMA. Human Molecular Genetics, 24(21), 6160-6173. https://doi.org/10.1093/hmg/ddv332

138. Jablonka, S., Bandilla, M., Wiese, S., Buhler, D., Wirth, B., Sendtner, M., \& Fischer, U. (2001). Co-regulation of survival of motor neuron (SMN) protein and its interactor SIP1 during development and in spinal muscular atrophy. Human Molecular Genetics, 10(5), 497-505. https://doi.org/10. 1093/hmg/10.5.497

139. Jablonka, S., Beck, M., Lechner, B. D., Mayer, C., \& Sendtner, M. (2007). Defective $\mathrm{Ca} 2+$ channel clustering in axon terminals disturbs excitability in motoneurons in spinal muscular atrophy. Journal of Cell Biology, 179(1), 139-149. (IN FILE).

140. Jablonka, S., Schrank, B., Kralewski, M., Rossoll, W., \& Sendtner, M. (2000). Reduced survival motor neuron ( $\mathrm{mmn}$ ) gene dose in mice leads to motor neuron degeneration: an animal model for spinal muscular atrophy type III [Research Support, Non-U.S. Gov't]. Human Molecular Genetics, 9(3), 341-346. https://doi.org/10.1093/hmg/9.3.341

141. Jablonka, S., \& Sendtner, M. (2017). Developmental regulation of SMN expression: Pathophysiological implications and perspectives for therapy development in spinal muscular atrophy [Review]. Gene Therapy. https://doi.org/10.1038/gt.2017.46

142. Jablonka, S., Wiese, S., \& Sendtner, M. (2004). Axonal defects in mouse models of motoneuron disease. Journal of Neurobiology, 58(2), 272-286.

143. Janzen, E., Mendoza-Ferreira, N., Hosseinibarkooie, S., Schneider, S., Hupperich, K., Tschanz, T., Grysko, V., Riessland, M., Hammerschmidt, M., Rigo, F., Bennett, C. F., Kye, M. J., Torres-Benito, L., \& Wirth, B. (2018). CHP1 reduction ameliorates spinal muscular atrophy pathology by restoring calcineurin activity and endocytosis [Research Support, Non-U.S. Gov't]. Brain, 141(8), 2343-2361. https://doi.org/10.1093/brain/awy167

144. Ji, C., Bader, J., Ramanathan, P., Hennlein, L., Meissner, F., Jablonka, S., Mann, M., Fischer, U., Sendtner, M., \& Briese, M. (2021). Interaction of 7SK with the Smn complex modulates snRNP production [Research Support, Non-U.S. Gov't]. Nature Communications, 12(1), 1278. https://doi. org/10.1038/s41467-021-21529-1

145. Kapeli, K., Pratt, G. A., Vu, A. Q., Hutt, K. R., Martinez, F. J., Sundararaman, B., Batra, R., Freese, P., Lambert, N. J., Huelga, S. C., Chun, S. J., Liang, T.Y., Chang, J., Donohue, J. P., Shiue, L., Zhang, J., Zhu, H., Cambi, F., Kasarskis, E., ... Yeo, G. W. (2016). Distinct and shared functions of ALS-associated proteins TDP-43, FUS and TAF15 revealed by multisystem analyses 
[Research Support, N.I.H., Extramural Research Support, Non-U.S. Gov't]. Nature Communications, 7, 12143. https://doi.org/10.1038/ncomm s12143

146. Kaplitt, M. G., Feigin, A., Tang, C., Fitzsimons, H. L., Mattis, P., Lawlor, P. A. Bland, R. J., Young, D., Strybing, K., Eidelberg, D., \& During, M. J. (2007). Safety and tolerability of gene therapy with an adeno-associated virus (AAV) borne GAD gene for Parkinson's disease: an open label, phase I trial [Clinical Trial, Phase I Research Support, Non-U.S. Gov't]. Lancet, 369(9579), 2097-2105. https://doi.org/10.1016/S0140-6736(07)60982-9

147. Kariya, S., Obis, T., Garone, C., Akay, T., Sera, F., Iwata, S., Homma, S., \& Monani, U. R. (2014). Requirement of enhanced Survival Motoneuron protein imposed during neuromuscular junction maturation [Research Support, N.I.H., Extramural Research Support, Non-U.S. Gov't Research Support, U.S. Gov't, Non-P.H.S.]. Journal of Clinical Investigation, 124(2), 785-800. https://doi.org/10.1172/JCl72017

148. Kato, A. C., \& Lindsay, R. M. (1994). Overlapping and additive effects of neurotrophins and CNTF on cultured human spinal cord neurons. Experimental Neurology, 130, 196-201.

149. Kernochan, L. E., Russo, M. L., Woodling, N. S., Huynh, T. N., Avila, A. M., Fischbeck, K. H., \& Sumner, C. J. (2005). The role of histone acetylation in SMN gene expression. Human Molecular Genetics, 14(9), 1171-1182.

150. Kim, G., Gautier, O., Tassoni-Tsuchida, E., Ma, X. R., \& Gitler, A. D. (2020). ALS genetics: Gains, losses, and implications for future therapies [Research Support, N.I.H., Extramural Research Support, Non-U.S. Gov't Research Support, U.S. Gov't, Non-P.H.S. Review]. Neuron, 108(5), 822-842. https://doi.org/10.1016/j.neuron.2020.08.022

151. Kim, J. K., Jha, N. N., Feng, Z., Faleiro, M. R., Chiriboga, C. A., Wei-Lapierre, L., Dirksen, R. T., Ko, C. P., \& Monani, U. R. (2020). Muscle-specific SMN reduction reveals motor neuron-independent disease in spinal muscular atrophy models. The Journal of Clinical Investigation, 130(3), 1271-1287. https://doi.org/10.1172/JCl131989

152. Klein, R., Jing, S., Nanduri, V., O'Rourke, E., \& Barbacid, M. (1991). The trk proto-oncogene encodes a receptor for nerve growth factor. Cell 77(5), 727-736, 65, 189-197.

153. Klein, R., Nanduri, V., Jing, S., Lamballe, F., Tapley, P., Bryant, S., CordonCardo, C., Jones, K. R., Reichardt, L. F., \& Barbacid, M. (1991). The trk B tyrosine protein kinase is a receptor for brain-derived neurotrophic factor and neurotrophin-3. Cell 77(5), 727-736, 66, 395-403.

154. Klein, R., Parada, L. F., Coulier, F., \& Barbacid, M. (1989). trk B, a novel tyrosine protein kinase receptor expressed during mouse neural development. EMBO Journal, 8, 3701-3709. (IN FILE).

155. Koenig, M., Beggs, A. H., Moyer, M., Scherpf, S., Heindrich, K., Bettecken T., Meng, G., Muller, C. R., Lindlof, M., Kaariainen, H., de la Chapellet, A., Kiuru, A., Savontaus, M. L., Gilgenkrantz, H., Recan, D., Chelly, J., Kaplan, J. C., Covone, A. E., Archidiacono, N., ... Kunkel, L. M. (1989). The molecular basis for Duchenne versus Becker muscular dystrophy: Correlation of severity with type of deletion. American Journal of Human Genetics, 45(4), 498-506.

156. Kong, L., Valdivia, D. O., Simon, C. M., Hassinan, C. W., Delestree, N., Ramos, D. M., Park, J. H., Pilato, C. M., Xu, X., Crowder, M., Grzyb, C. C., King, Z. A., Petrillo, M., Swoboda, K. J., Davis, C., Lutz, C. M., Stephan, A. H., Zhao, X., Weetall, M., ... Sumner, C. J. (2021). Impaired prenatal motor axon development necessitates early therapeutic intervention in severe SMA. Science Translational Medicine. https://doi.org/10.1126/scitranslm ed.abb6871

157. Kong, L., Wang, X., Choe, D. W., Polley, M., Burnett, B. G., Bosch-Marce, M., Griffin, J. W., Rich, M. M., \& Sumner, C. J. (2009). Impaired synaptic vesicle release and immaturity of neuromuscular junctions in spinal muscular atrophy mice. Journal of Neuroscience, 29(3), 842-851.

158. Krieger, F., Elflein, N., Ruiz, R., Guerra, J., Serrano, A. L., Asan, E., Tabares, L., \& Jablonka, S. (2013). Fast motor axon loss in SMARD1 does not correspond to morphological and functional alterations of the NMJ. Neurobiology of Disease, 54, 169-182.

159. Krieger, F., Elflein, N., Saenger, S., Wirthgen, E., Rak, K., Frantz, S., Hoeflich, A., Toyka, K. V., Metzger, F., \& Jablonka, S. (2014). Polyethylene glycolcoupled IGF1 delays motor function defects in a mouse model of spinal muscular atrophy with respiratory distress type 1. Brain, 137(Pt 5), 1374-1393.

160. Kugelberg, E., \& Welander, L. (1956). Heredofamilial juvenile muscular atrophy simulating muscular dystrophy. Archives of Neurology, 75, 500
161. Kumar, V., Hasan, G. M., \& Hassan, M. I. (2017). Unraveling the role of RNA mediated toxicity of C9orf72 repeats in C9-FTD/ALS [Review]. Frontiers in Neuroscience, 11, 711. https://doi.org/10.3389/fnins.2017.00711

162. Kwiatkowski, T. J., Jr., Bosco, D. A., Leclerc, A. L., Tamrazian, E., Vanderburg, C. R., Russ, C., Davis, A., Gilchrist, J., Kasarskis, E. J., Munsat, T., Valdmanis, P., Rouleau, G. A., Hosler, B. A., Cortelli, P., de Jong, P. J., Yoshinaga, Y., Haines, J. L., Pericak-Vance, M. A., Yan, J., ... Brown, R. H., Jr. (2009). Mutations in the FUS/TLS gene on chromosome 16 cause familial amyotrophic lateral sclerosis. Science, 323(5918), 1205-1208. https://doi. org/10.1126/science.1166066

163. Kwon, I., Xiang, S., Kato, M., Wu, L., Theodoropoulos, P., Wang, T., Kim, J., Yun, J., Xie, Y., \& McKnight, S. L. (2014). Poly-dipeptides encoded by the C9orf72 repeats bind nucleoli, impede RNA biogenesis, and kill cells [Research Support, Non-U.S. Gov't]. Science, 345(6201), 1139-1145. https://doi.org/10.1126/science.1254917

164. Lagier-Tourenne, C., Polymenidou, M., Hutt, K. R., Vu, A. Q., Baughn, M., Huelga, S. C., Clutario, K. M., Ling, S. C., Liang, T. Y., Mazur, C., Wancewicz, E., Kim, A. S., Watt, A., Freier, S., Hicks, G. G., Donohue, J. P., Shiue, L., Bennett, C. F., Ravits, J., ... Yeo, G. W. (2012). Divergent roles of ALS-linked proteins FUS/TLS and TDP-43 intersect in processing long pre-mRNAs [Research Support, N.I.H., Extramural Research Support, Non-U.S. Gov't Research Support, U.S. Gov't, Non-P.H.S.]. Nature Neurosciences, 15(11), 1488-1497. https://doi.org/10.1038/nn.3230

165. Le Guiner, C., Servais, L., Montus, M., Larcher, T., Fraysse, B., Moullec, S., Allais, M., Francois, V., Dutilleul, M., Malerba, A., Koo, T., Thibaut, J. L., Matot, B., Devaux, M., Le Duff, J., Deschamps, J. Y., Barthelemy, I., Blot, S., Testault, I., ... Dickson, G. (2017). Long-term microdystrophin gene therapy is effective in a canine model of Duchenne muscular dystrophy [Research Support, Non-U.S. Gov't]. Nature Communications, 8, 16105. https://doi.org/10.1038/ncomms16105

166. Le, T. T., Pham, L. T., Butchbach, M. E., Zhang, H. L., Monani, U. R., Coovert D. D., Gavrilina, T. O., Xing, L., Bassell, G. J., \& Burghes, A. H. (2005). SMNDelta7, the major product of the centromeric survival motor neuron (SMN2) gene, extends survival in mice with spinal muscular atrophy and associates with full-length SMN. Human Molecular Genetics, 14(6), 845-857.

167. Lee, J., Echigoya, Y., Duddy, W., Saito, T., Aoki, Y., Takeda, S., \& Yokota, T. (2018). Antisense PMO cocktails effectively skip dystrophin exons 45-55 in myotubes transdifferentiated from DMD patient fibroblasts [Research Support, Non-U.S. Gov't]. PLoS ONE, 13(5), e0197084. https://doi.org/10. 1371/journal.pone.0197084

168. Lee, K. H., Zhang, P., Kim, H. J., Mitrea, D. M., Sarkar, M., Freibaum, B. D., Cika, J., Coughlin, M., Messing, J., Molliex, A., Maxwell, B. A., Kim, N. C., Temirov, J., Moore, J., Kolaitis, R. M., Shaw, T. I., Bai, B., Peng, J., Kriwacki, R. W., \& Taylor, J. P. (2016). C9orf72 dipeptide repeats impair the assembly, dynamics, and function of membrane-less organelles [Research Support, N.I.H., Extramural Research Support, Non-U.S. Gov't]. Cell, 167(3), 774-788717. https://doi.org/10.1016/j.cell.2016.10.002

169. Lee, S. J., \& McPherron, A. C. (2001). Regulation of myostatin activity and muscle growth. Proceedings of the National Academy of Sciences USA, 98(16), 9306-9311. https://doi.org/10.1073/pnas.151270098

170. Lefebvre, S., Burglen, L., Reboullet, S., Clermont, O., Burlet, P., Viollet, L., Benichou, B., Cruaud, C., Millasseau, P., Zeviani, M., \& et al. (1995). Identification and characterization of a spinal muscular atrophy- determining gene [see comments]. Cell 77(5), 727-36, 80(1), 155-165.

171. LeWitt, P. A., Rezai, A. R., Leehey, M. A., Ojemann, S. G., Flaherty, A. W., Eskandar, E. N., Kostyk, S. K., Thomas, K., Sarkar, A., Siddiqui, M. S., Tatter, S. B., Schwalb, J. M., Poston, K. L., Henderson, J. M., Kurlan, R. M., Richard, I. H., Van Meter, L., Sapan, C. V., During, M. J., ... Feigin, A. (2011). AAV2GAD gene therapy for advanced Parkinson's disease: A double-blind, sham-surgery controlled, randomised trial [Randomized Controlled Trial Research Support, Non-U.S. Gov't]. The Lancet Neurology, 10(4), 309-319. https://doi.org/10.1016/S1474-4422(11)70039-4

172. Li, L., Oppenheim, R. W., Lei, M.\& \& Houenou, L. J. (1994). Neurotrophic agents prevent motoneuron death following sciatic nerve section in the neonatal mouse. Journal of Neurobiology, 25, 759-766. (IN FILE).

173. Lichtman, J. W., \& Colman, H. (2000). Synapse elimination and indelible memory. Neuron, 25(2), 269-278. https://doi.org/10.1016/s08966273(00)80893-4 
174. Ling, K. K., Gibbs, R. M., Feng, Z., \& Ko, C. P. (2012). Severe neuromuscular denervation of clinically relevant muscles in a mouse model of spinal muscular atrophy. Human Molecular Genetics, 21(1), 185-195.

175. Liou, J. C., Yang, R. S., \& Fu, W. M. (1997). Regulation of quantal secretion by neurotrophic factors at developing motoneurons in xenopus cell cultures. Journal of Physiology (London), 503, 129-139.

176. Liu, Q., \& Dreyfuss, G. (1996). A novel nuclear structure containing the survival of motor neurons protein. EMBO Journal, 15, 3555-3565.

177. Liu, Q., Fischer, U., Wang, F., \& Dreyfuss, G. (1997). The spinal muscular atrophy disease gene product, SMN, and its associated protein SIP1 are in a complex with spliceosomal snRNP proteins. Cell 77(5), 727-736, 90(6), 1013-1021.

178. Loboda, A., \& Dulak, J. (2020). Muscle and cardiac therapeutic strategies for Duchenne muscular dystrophy: Past, present, and future. Pharmacological Reports, 72(5), 1227-1263. https://doi.org/10.1007/ s43440-020-00134-x

179. Long, K. K., O'Shea, K. M., Khairallah, R. J., Howell, K., Paushkin, S., Chen, K. S., Cote, S. M., Webster, M. T., Stains, J. P., Treece, E., Buckler, A., \& Donovan, A. (2019). Specific inhibition of myostatin activation is beneficial in mouse models of SMA therapy. Human Molecular Genetics, 28(7), 1076-1089. https://doi.org/10.1093/hmg/ddy382

180. Lorson, C. L., Hahnen, E., Androphy, E. J., \&Wirth, B. (1999). A single nucleotide in the SMN gene regulates splicing and is responsible for spinal muscular atrophy. Proceedings of the National academy of Sciences of the United States of America, 96(11), 6307-6311.

181. Lotti, F., Imlach, W. L., Saieva, L., Beck, E. S., le Hao, T., Li, D. K., Jiao, W., Mentis, G. Z., Beattie, C. E., McCabe, B. D., \& Pellizzoni, L. (2012). An SMN-dependent U12 splicing event essential for motor circuit function [Research Support, N.I.H., Extramural Research Support, Non-U.S. Gov't Research Support, U.S. Gov't, Non-P.H.S.]. Cell, 151(2), 440-454. https:// doi.org/10.1016/j.cell.2012.09.012

182. Lundin, K. E., Gissberg, O., \& Smith, C. I. (2015). Oligonucleotide therapies: The past and the present. Human Gene Therapy, 26(8), 475-485. https://doi.org/10.1089/hum.2015.070

183. Lutz, C. M., Kariya, S., Patruni, S., Osborne, M. A., Liu, D., Henderson, C. E., Li, D. K., Pellizzoni, L., Rojas, J., Valenzuela, D. M., Murphy, A. J., Winberg, M. L., \& Monani, U. R. (2011). Postsymptomatic restoration of SMN rescues the disease phenotype in a mouse model of severe spinal muscular atrophy [Research Support, N.I.H., Extramural Research Support, Non-U.S. Gov't]. Journal of Clinical Investigation, 121(8), 3029-3041. https://doi.org/10.1172/JCl57291

184. Maggi, L., Bello, L., Bonanno, S., Govoni, A., Caponnetto, C., Passamano, L., Grandis, M., Trojsi, F., Cerri, F., Ferraro, M., Bozzoni, V., Caumo, L., Piras, R., Tanel, R., Saccani, E., Meneri, M., Vacchiano, V., Ricci, G., Soraru, G., ... Pegoraro, E. (2020). Nusinersen safety and effects on motor function in adult spinal muscular atrophy type 2 and 3. Journal of Neurology, Neurosurgery and Psychiatry, 91(11), 1166-1174. https://doi.org/10.1136/ jnnp-2020-323822

185. Mailman, M. D., Heinz, J. W., Papp, A. C., Snyder, P. J., Sedra, M. S., Wirth, B., Burghes, A. H., \& Prior, T. W. (2002). Molecular analysis of spinal muscular atrophy and modification of the phenotype by SMN2. Genetics in Medicine, 4(1), 20-26.

186. Martinez-Hernandez, R., Bernal, S., Alias, L., \&Tizzano, E. F. (2014). Abnormalities in early markers of muscle involvement support a delay in myogenesis in spinal muscular atrophy. Journal of Neuropathology and Experimental Neurology, 73(6), 559-567. https://doi.org/10.1097/NEN. 0000000000000078

187. Martinez-Hernandez, R., Soler-Botija, C., Also, E., Alias, L., Caselles, L., Gich, I., Bernal, S., \& Tizzano, E. F. (2009). The developmental pattern of myotubes in spinal muscular atrophy indicates prenatal delay of muscle maturation. Journal of Neuropathology and Experimental Neurology, 68(5), 474-481. https://doi.org/10.1097/NEN.0b013e3181a10ea1

188. Masuda, A., Takeda, J., Okuno, T., Okamoto, T., Ohkawara, B., Ito, M., Ishigaki, S., Sobue, G., \& Ohno, K. (2015). Position-specific binding of FUS to nascent RNA regulates mRNA length [Research Support, Non-U.S Gov't]. Genes \& Development, 29(10), 1045-1057. https://doi.org/10. 1101/gad.255737.114

189. May, S., Hornburg, D., Schludi, M. H., Arzberger, T., Rentzsch, K., Schwenk, B. M., Grasser, F. A., Mori, K., Kremmer, E., Banzhaf-Strathmann, J., Mann, M., Meissner, F., \& Edbauer, D. (2014). C9orf72 FTLD/ALS-associated Gly-Ala dipeptide repeat proteins cause neuronal toxicity and Unc119 sequestration [Research Support, Non-U.S. Gov't]. Acta Neuropathologica, 128(4), 485-503. https://doi.org/10.1007/s00401-014-1329-4

190. McCormack, N. M., Villalon, E., Viollet, C., Soltis, A. R., Dalgard, C. L., Lorson, C. L., \& Burnett, B. G. (2021). Survival motor neuron deficiency slows myoblast fusion through reduced myomaker and myomixer expression. Journal of Cachexia, Sarcopenia and Muscle. https://doi.org/ 10.1002/jcsm. 12740

191. McPherron, A. C., Lawler, A. M., \& Lee, S. J. (1997). Regulation of skeletal muscle mass in mice by a new TGF-beta superfamily member. Nature, 387(6628), 83-90. https://doi.org/10.1038/387083a0

192. McWhorter, M. L., Monani, U. R., Burghes, A. H., \& Beattie, C. E. (2003). Knockdown of the survival motor neuron ( $\mathrm{Smn}$ ) protein in zebrafish causes defects in motor axon outgrowth and pathfinding. Journal of Cell Biology, 162(5), 919-932.

193. Meijer, L., Borgne, A., Mulner, O., Chong, J. P., Blow, J. J., Inagaki, N., Inagaki, M., Delcros, J. G., \& Moulinoux, J. P. (1997). Biochemical and cellular effects of roscovitine, a potent and selective inhibitor of the cyclin-dependent kinases cdc2, cdk2 and cdk5. European Journal of Biochemistry, 243(1-2), 527-536.

194. Meister, G., Eggert, C., \& Fischer, U. (2002). SMN-mediated assembly of RNPs: A complex story. Trends in Cell Biology, 12(10), 472-478.

195. Mendell, J. R., Al-Zaidy, S., Shell, R., Arnold, W. D., Rodino-Klapac, L. R., Prior, T. W., Lowes, L., Alfano, L., Berry, K., Church, K., Kissel, J. T., Nagendran, S., L'Italien, J., Sproule, D. M., Wells, C., Cardenas, J. A., Heitzer, M. D., Kaspar, A., Corcoran, S., ... Kaspar, B. K. (2017). Single-dose genereplacement therapy for spinal muscular atrophy [Clinical Trial, Phase | Clinical Trial, Phase II Controlled Clinical Trial]. New England Journal of Medicine, 377(18), 1713-1722. https://doi.org/10.1056/NEJMoa1706198

196. Mercuri, E., Darras, B. T., Chiriboga, C. A., Day, J. W., Campbell, C., Connolly, A. M., lannaccone, S. T., Kirschner, J., Kuntz, N. L., Saito, K., Shieh, P. B., Tulinius, M., Mazzone, E. S., Montes, J., Bishop, K. M., Yang, Q., Foster, R., Gheuens, S., Bennett, C. F., ... Group, C. S. (2018). Nusinersen versus Sham control in later-onset spinal muscular atrophy [Clinical Trial, Phase III Comparative Study Multicenter Study Randomized Controlled Trial Research Support, Non-U.S. Gov't]. New England Journal of Medicine, 378(7), 625-635. https://doi.org/10.1056/NEJMoa1710504

197. Mercuri, E., Finkel, R. S., Muntoni, F., Wirth, B., Montes, J., Main, M., Mazzone, E. S., Vitale, M., Snyder, B., Quijano-Roy, S., Bertini, E., Davis, R. H., Meyer, O. H., Simonds, A. K., Schroth, M. K., Graham, R. J., Kirschner, J., lannaccone, S. T., Crawford, T. O., ... Group, S. M. A. C. (2018). Diagnosis and management of spinal muscular atrophy: Part 1: Recommendations for diagnosis, rehabilitation, orthopedic and nutritional care [Practice Guideline Research Support, Non-U.S. Gov't Review]. Neuromuscular Disorders, 28(2), 103-115. https://doi.org/10.1016/j.nmd.2017.11.005

198. Mercuri, E., Muntoni, F., Baranello, G., Masson, R., Boespflug-Tanguy, O., Bruno, C., Corti, S., Daron, A., Deconinck, N., Servais, L., Straub, V., Ouyang, H., Chand, D., Tauscher-Wisniewski, S., Mendonca, N., Lavrov, A., \& group, S. V.-E. s. (2021). Onasemnogene abeparvovec gene therapy for symptomatic infantile-onset spinal muscular atrophy type 1 (STR1VEEU): An open-label, single-arm, multicentre, phase 3 trial. Lancet Neuro/ogy, 20(10), 832-841. https://doi.org/10.1016/S1474-4422(21)00251-9

199. Messina, S., Pane, M., Sansone, V., Bruno, C., Catteruccia, M., Vita, G., Palermo, C., Albamonte, E., Pedemonte, M., Bertini, E., Binetti, L., Mercuri, E., \& Italian, E. A. P. W. G. (2017). Expanded access program with Nusinersen in SMA type I in Italy: Strengths and pitfalls of a successful experience [Editorial]. Neuromuscular Disorders, 27(12), 1084-1086. https://doi. org/10.1016/j.nmd.2017.09.006

200. Middlemas, D. S., Lindberg, R. A., \& Hunter, T. (1991). trk B, A neural receptor protein-tyrosine kinase: Evidence for a full-length and two truncated receptors. Molecular and Cellular Biology, 11, 143-153.

201. Miller, T., Cudkowicz, M., Shaw, P. J., Andersen, P. M., Atassi, N., Bucelli, R. C., Genge, A., Glass, J., Ladha, S., Ludolph, A. L., Maragakis, N. J., McDermott, C. J., Pestronk, A., Ravits, J., Salachas, F., Trudell, R., Van Damme, P., Zinman, L., Bennett, C. F., ... Ferguson, T. A. (2020). Phase 1-2 trial of antisense oligonucleotide Tofersen for SOD1 ALS [Clinical Trial, Phase | Clinical Trial, Phase I| Multicenter Study Randomized Controlled Trial Research Support, Non-U.S. Gov't]. New England Journal of Medicine, 383(2), 109-119. https://doi.org/10.1056/NEJMoa2003715

202. Miller, T. M., Pestronk, A., David, W., Rothstein, J., Simpson, E., Appel, S. H., Andres, P. L., Mahoney, K., Allred, P., Alexander, K., Ostrow, L. W., Schoenfeld, D., Macklin, E. A., Norris, D. A., Manousakis, G., Crisp, M., Smith, 
R., Bennett, C. F., Bishop, K. M., \& Cudkowicz, M. E. (2013). An antisense oligonucleotide against SOD1 delivered intrathecally for patients with SOD1 familial amyotrophic lateral sclerosis: a phase 1, randomised, first-in-man study [Clinical Trial, Phase I Randomized Controlled Trial Research Support, N.I.H., Extramural Research Support, Non-U.S. Gov't. The Lancet Neurology, 12(5), 435-442. https://doi.org/10.1016/S14744422(13)70061-9

203. Miller, W. C., \& DeLong, M. R. (1987). The Basal Ganglia II: Structure and Function. In M. B. Carpenter \& A. Jayaraman (Eds.), Altered tonic activity of neurons in the globus pallidus and subthalamic nucleus in the primate model of parkjinsonism (pp. 415-427). Plenum.

204. Mizielinska, S., \& Isaacs, A. M. (2016). Neurodegeneration. One target for amyotrophic lateral sclerosis therapy? [Comment]. Science, 353(6300), 647-648. https://doi.org/10.1126/science.aah5408

205. Mizielinska, S., Lashley, T., Norona, F. E., Clayton, E. L., Ridler, C. E., Fratta, P., \& Isaacs, A. M. (2013). C9orf72 frontotemporal lobar degeneration is characterised by frequent neuronal sense and antisense RNA foci [Research Support, Non-U.S. Gov't]. Acta Neuropathologica, 126(6), 845-857. https://doi.org/10.1007/s00401-013-1200-z

206. Monani, U. R., Lorson, C. L., Parsons, D. W., Prior, T.W., Androphy, E. J., Burghes, A. H., \& McPherson, J. D. (1999). A single nucleotide difference that alters splicing patterns distinguishes the SMA gene SMN1 from the copy gene SMN2. Human Molecular Genetics, 8(7), 1177-1183.

207. Monani, U. R., McPherson, J. D., \& Burghes, A. H. (1999). Promoter analysis of the human centromeric and telomeric survival motor neuron genes (SMNC and SMNT) [In Process Citation]. Biochimica et Biophysica Acta, 1445(3), 330-336.

208. Monani, U. R., Sendtner, M., Coovert, D. D., Parsons, D. W., Andreassi, C., Le, T.T., Jablonka, S., Schrank, B., Rossoll, W., Prior, T. W., Morris, G. E., \& Burghes, A. H. (2000). The human centromeric survival motor neuron gene (SMN2) rescues embryonic lethality in Smn(-/-) mice and results in a mouse with spinal muscular atrophy [Research Support, Non-U.S. Gov't Research Support, U.S. Gov't, P.H.S.]. Human Molecular Genetics, 9(3), 333-339. https://doi.org/10.1093/hmg/9.3.333

209. Montes, J., Dunaway Young, S., Mazzone, E. S., Pasternak, A., Glanzman, A. M., Finkel, R. S., Darras, B. T., Muntoni, F., Mercuri, E., De Vivo, D. C., Bishop, K. M., Schneider, E., Bennett, C. F., Foster, R., Farwell, W., \& Groups, C. S. S. (2019). Nusinersen improves walking distance and reduces fatigue in later-onset spinal muscular atrophy. Muscle and Nerve, 60(4), 409-414. https://doi.org/10.1002/mus.26633

210. Montes, J., McDermott, M. P., Mirek, E., Mazzone, E. S., Main, M., Glanzman, A. M., Duong, T., Young, S. D., Salazar, R., Pasternak, A., Gee, R., De Sanctis, R., Coratti, G., Forcina, N., Fanelli, L., Ramsey, D., Milev, E., Civitello, M., Pane, M., ... Mercuri, E. (2018). Ambulatory function in spinal muscular atrophy: Age-related patterns of progression. PLOS ONE, 13(6), e0199657. https://doi.org/10.1371/journal.pone.0199657

211. Moradi, M., Sivadasan, R., Saal, L., Luningschror, P., Dombert, B., Rathod, R. J., Dieterich, D. C., Blum, R., \& Sendtner, M. (2017). Differential roles of alpha-, beta-, and gamma-actin in axon growth and collateral branch formation in motoneurons. Journal of Cell Biology, 216(3), 793-814. https://doi.org/10.1083/jcb.201604117

212. Mori, K., Weng, S. M., Arzberger, T., May, S., Rentzsch, K., Kremmer, E., Schmid, B., Kretzschmar, H. A., Cruts, M., Van Broeckhoven, C., Haass, C., \& Edbauer, D. (2013). The C9orf72 GGGGCC repeat is translated into aggregating dipeptide-repeat proteins in FTLD/ALS [Research Support, Non-U.S. Gov't]. Science, 339(6125), 1335-1338. https://doi.org/10.1126/ science.1232927

213. Morlando, M., Dini Modigliani, S., Torrelli, G., Rosa, A., Di Carlo, V., Caffarelli, E., \& Bozzoni, I. (2012). FUS stimulates microRNA biogenesis by facilitating co-transcriptional Drosha recruitment [Research Support, Non-U.S. Gov't]. The EMBO Journal, 31(24), 4502-4510. https://doi.org/ 10.1038/emboj.2012.319

214. Mueller, C., Berry, J. D., McKenna-Yasek, D. M., Gernoux, G., Owegi, M. A., Pothier, L. M., Douthwright, C. L., Gelevski, D., Luppino, S. D., Blackwood, M., Wightman, N. S., Oakley, D. H., Frosch, M. P., Flotte, T. R., Cudkowicz, M. E., \& Brown, R. H., Jr. (2020). SOD1 suppression with adeno-associated virus and MicroRNA in familial ALS. New England Journal of Medicine, 383(2), 151-158. https://doi.org/10.1056/NEJMoa2005056

215. Murdocca, M., Malgieri, A., Luchetti, A., Saieva, L., Dobrowolny, G., de Leonibus, E., Filareto, A., Quitadamo, M. C., Novelli, G., Musaro, A., \& Sangiuolo, F. (2012). IPLEX administration improves motor neuron survival and ameliorates motor functions in a severe mouse model of spinal muscular atrophy. Molecular Medicine, 18, 1076-1085.

216. Nagahara, A. H., Merrill, D. A., Coppola, G., Tsukada, S., Schroeder, B. E., Shaked, G. M., Wang, L., Blesch, A., Kim, A., Conner, J. M., Rockenstein, E., Chao, M. V., Koo, E. H., Geschwind, D., Masliah, E., Chiba, A. A., \& Tuszynski, M. H. (2009). Neuroprotective effects of brain-derived neurotrophic factor in rodent and primate models of Alzheimer's disease. Nature Medicine, 15(3), 331-337. https://doi.org/10.1038/nm.1912

217. Naryshkin, N. A., Weetall, M., Dakka, A., Narasimhan, J., Zhao, X., Feng, Z., Ling, K. K., Karp, G. M., Qi, H., Woll, M. G., Chen, G., Zhang, N., Gabbeta, V., Vazirani, P., Bhattacharyya, A., Furia, B., Risher, N., Sheedy, J., Kong, R., ... Metzger, F. (2014). Motor neuron disease. SMN2 splicing modifiers improve motor function and longevity in mice with spinal muscular atrophy. Science, 345(6197), 688-693.

218. Naumann, M., Pal, A., Goswami, A., Lojewski, X., Japtok, J., Vehlow, A., Naujock, M., Gunther, R., Jin, M., Stanslowsky, N., Reinhardt, P., Sterneckert, J., Frickenhaus, M., Pan-Montojo, F., Storkebaum, E., Poser, I., Freischmidt, A., Weishaupt, J. H., Holzmann, K., ... Hermann, A. (2018). Impaired DNA damage response signaling by FUS-NLS mutations leads to neurodegeneration and FUS aggregate formation. Nature Communications, 9(1), 335. https://doi.org/10.1038/s41467-017-02299-1

219. Nicole, S., Desforges, B., Millet, G., Lesbordes, J., Cifuentes-Diaz, C., Vertes, D., Cao, M. L., De Backer, F., Languille, L., Roblot, N., Joshi, V., Gillis, J. M., \& Melki, J. (2003). Intact satellite cells lead to remarkable protection against Smn gene defect in differentiated skeletal muscle. Journal of Cell Biology, 161(3), 571-582.

220. Nijssen, J., Aguila, J., \& Hedlund, E. (2019). Axon-seq for in Depth Analysis of the RNA Content of Neuronal Processes. Bio Protocol, 9(14), 3312. https://doi.org/10.21769/BioProtoc.3312

221. Nishida, C. R., Gralla, E. B., \& Valentine, J. S. (1994). Characterization of three yeast copper-zinc superoxide dismutase mutants analogous to those coded for in familial amyotrophic lateral sclerosis. Proceedings of the National Academy of Sciences USA, 91(21), 9906-9910. https://doi. org/10.1073/pnas.91.21.9906

222. Ojala, K. S., Reedich, E. J., DiDonato, C. J., \& Meriney, S. D. (2021). In search of a cure: The development of therapeutics to alter the progression of spinal muscular atrophy. Brain Sciences, 11(2), 194. https://doi. org/10.3390/brainsci11020194

223. O'Keefe L. FDA approves oral treatment for spinal muscular atrophy. FDA News Release, August 7, 2020. https://www.fda.gov/news-events/ pressannouncements/fda-approves-oral-treatment-spinal-muscularatrophy

224. Oprea, G. E., Krober, S., McWhorter, M. L., Rossoll, W., Muller, S., Krawczak, M., Bassell, G. J., Beattie, C. E., \& Wirth, B. (2008). Plastin 3 is a protective modifier of autosomal recessive spinal muscular atrophy. Science, 320(5875), 524-527.

225. Orozco, D., Tahirovic, S., Rentzsch, K., Schwenk, B. M., Haass, C., \& Edbauer, D. (2012). Loss of fused in sarcoma (FUS) promotes pathological Tau splicing. EMBO Reports, 13(8), 759-764. https://doi.org/10.1038/ embor.2012.90

226. Ousterout, D. G., Kabadi, A. M., Thakore, P. I., Majoros, W. H., Reddy, T. E., \& Gersbach, C. A. (2015). Multiplex CRISPR/Cas9-based genome editing for correction of dystrophin mutations that cause Duchenne muscular dystrophy [Research Support, N.I.H., Extramural Research Support, NonU.S. Gov't Research Support, U.S. Gov't, Non-P.H.S.]. Nature Communications, 6, 6244. https://doi.org/10.1038/ncomms7244

227. Palacino, J., Swalley, S. E., Song, C., Cheung, A. K., Shu, L., Zhang, X., Van, H. M., Shin, Y., Chin, D. N., Keller, C. G., Beibel, M., Renaud, N. A., Smith, T. M., Salcius, M., Shi, X., Hild, M., Servais, R., Jain, M., Deng, L., ... Sivasankaran, R. (2015). SMN2 splice modulators enhance U1-premRNA association and rescue SMA mice. Nature Chemical Biology, 11(7), 511-517.

228. Panza, F., Lozupone, M., Logroscino, G., \& Imbimbo, B. P. (2019). A critical appraisal of amyloid-beta-targeting therapies for Alzheimer disease [Review]. Nature Reviews. Neurology, 15(2), 73-88. https://doi.org/10. 1038/s41582-018-0116-6

229. Pearn, J. (1978). Incidence, prevalence, and gene frequency studies of chronic childhood spinal muscular atrophy. Journal of Medical Genetics, 15(6), 409-413.

230. Pearn, J. (1980). Classification of spinal muscular atrophies. Lancet, 1(8174), 919-922. 
231. Pearn, J. H. (1973). The gene frequency of acute Werdnig-Hoffmann disease (SMA type 1). A total population survey in North-East England. Journal of Medical Genetics, 10(3), 260-265.

232. Pechmann, A., Langer, T., Schorling, D., Stein, S., Vogt, S., Schara, U., Kolbel, H., Schwartz, O., Hahn, A., Giese, K., Johannsen, J., Denecke, J., Weiss, C., Theophil, M., \& Kirschner, J. (2018). Evaluation of children with SMA Type 1 under treatment with Nusinersen within the expanded access program in Germany. Journal of Neuromuscular Diseases, 5(2), 135-143. https://doi.org/10.3233/JND-180315

233. Pellizzoni, L., Kataoka, N., Charroux, B., \& Dreyfuss, G. (1998). A novel function for $\mathrm{SMN}$, the spinal muscular atrophy disease gene product, in pre-mRNA splicing. Cell 77(5), 727-736, 95(5), 615-624.

234. Pennica, D., Arce, V., Swanson, T. A., Vejsada, R., Pollock, R. A., Armanini, M., Dudley, K., Phillips, H. S., Rosenthal, A., Kato, A. C., \& Henderson, C. E. (1996). Cardiotrophin-1, a cytokine present in embryonic muscle, supports long-term survival of spinal motoneurons. Neuron, 17(1), 63-74.

235. Pennica, D., Shaw, K. J., Swanson, T. A., Moore, M. W., Shelton, D. L., Zioncheck, K. A., Rosenthal, A., Taga, T., Paoni, N. F., \& Wood, W. I. (1995). Cardiotrophin-1. Biological activities and binding to the leukemia inhibitory factor receptor/gp130 signaling complex. Journal of Biological Chemistry, 270, 10915-10922.

236. Pirruccello-Straub, M., Jackson, J., Wawersik, S., Webster, M. T., Salta, L., Long, K., McConaughy, W., Capili, A., Boston, C., Carven, G. J., Mahanthappa, N. K., Turner, K. J., \& Donovan, A. (2018). Blocking extracellular activation of myostatin as a strategy for treating muscle wasting. Science and Reports, 8(1), 2292. https://doi.org/10.1038/ s41598-018-20524-9

237. Poirier, A., Weetall, M., Heinig, K., Bucheli, F., Schoenlein, K., Alsenz, J., Bassett, S., Ullah, M., Senn, C., Ratni, H., Naryshkin, N., Paushkin, S., \& Mueller, L. (2018). Risdiplam distributes and increases SMN protein in both the central nervous system and peripheral organs [Research Support, NonU.S. Gov't]. Pharmacology Research \& Perspectives, 6(6), e00447. https:// doi.org/10.1002/prp2.447

238. Pulst, S. M., Nechiporuk, A., Nechiporuk, T., Gispert, S., Chen, X. N., Lopes-Cendes, I., Pearlman, S., Starkman, S., Orozco-Diaz, G., Lunkes, A. DeJong, P., Rouleau, G. A., Auburger, G., Korenberg, J. R., Figueroa, C., \& Sahba, S. (1996). Moderate expansion of a normally biallelic trinucleotide repeat in spinocerebellar ataxia type 2. Nature Genetics, 14(3), 269-276. https://doi.org/10.1038/ng1196-269

239. Ramdas, S., \& Servais, L. (2020). New treatments in spinal muscular atrophy: An overview of currently available data [Review]. Expert Opinion on Pharmacotherapy, 21(3), 307-315. https://doi.org/10.1080/14656566. 2019.1704732

240. Ramos, D. M., d'Ydewalle, C., Gabbeta, V., Dakka, A., Klein, S. K., Norris, D. A., Matson, J., Taylor, S. J., Zaworski, P. G., Prior, T. W., Snyder, P. J., Valdivia, D., Hatem, C. L., Waters, I., Gupte, N., Swoboda, K. J., Rigo, F., Bennett, C. F., Naryshkin, N., ... Sumner, C. J. (2019). Age-dependent SMN expression in disease-relevant tissue and implications for SMA treatment [Clinical Trial Research Support, N.I.H., xtramural Research Support, NonU.S. Gov't]. Journal of Clinical Investigation, 129(11), 4817-4831. https:// doi.org/10.1172/JCl124120

241. Ramos, J. N., Hollinger, K., Bengtsson, N. E., Allen, J. M., Hauschka, S. D., \& Chamberlain, J. S. (2019). Development of novel micro-dystrophins with enhanced functionality [Research Support, N.I.H., Extramural Research Support, Non-U.S. Gov't]. Molecular Therapy, 27(3), 623-635. https://doi. org/10.1016/j.ymthe.2019.01.002

242. Ratni, H., Ebeling, M., Baird, J., Bendels, S., Bylund, J., Chen, K. S., Denk, N., Feng, Z., Green, L., Guerard, M., Jablonski, P., Jacobsen, B., Khwaja, O., Kletzl, H., Ko, C. P., Kustermann, S., Marquet, A., Metzger, F., Mueller, B., ... Mueller, L. (2018). Discovery of Risdiplam, a selective Survival of Motor Neuron-2 (SMN2) gene splicing modifier for the treatment of spinal muscular atrophy (SMA). Journal of Medicinal Chemistry, 61(15), 6501-6517. https://doi.org/10.1021/acs.jmedchem.8b00741

243. Ratni, H., Karp, G. M., Weetall, M., Naryshkin, N. A., Paushkin, S. V., Chen, K. S., McCarthy, K. D., Qi, H., Turpoff, A., Woll, M. G., Zhang, X., Zhang, N., Yang, T., Dakka, A., Vazirani, P., Zhao, X., Pinard, E., Green, L., DavidPierson, P., ... Metzger, F. (2016). Specific correction of alternative survival motor Neuron 2 splicing by small molecules: Discovery of a potential novel medicine to treat spinal muscular atrophy [Research Support, Non-US Gov't]. Journal of Medicinal Chemistry, 59(13), 6086-6100. https://doi.org/10.1021/acs.jmedchem.6b00459
244. Reaume, A. G., Elliott, J. L., Hoffman, E. K., Kowall, N. W., Ferrante, R. J., Siwek, D. F., Wilcox, H. M., Flood, D. G., Beal, M. F., Brown, R. H., Jr., Scott, R. W., \& Snider, W. D. (1996). Motor neurons in Cu/Zn superoxide dismutase-deficient mice develop normally but exhibit enhanced cell death after axonal injury. Nature Genetics, 13(1), 43-47.

245. Renton, A. E., Majounie, E., Waite, A., Simon-Sanchez, J., Rollinson, S., Gibbs, J. R., Schymick, J. C., Laaksovirta, H., van Swieten, J. C., Myllykangas, L., Kalimo, H., Paetau, A., Abramzon, Y., Remes, A. M., Kaganovich, A., Scholz, S. W., Duckworth, J., Ding, J., Harmer, D. W., Hernandez, D. G., Johnson, J. O., Mok, K., Ryten, M., Trabzuni, D., Guerreiro, R. J., Orrell, R. W., Neal, J., Murray, A., Pearson, J., Jansen, I. E., Sondervan, D., Seelaar, H., Blake, D., Young, K., Halliwell, N., Callister, J. B., Toulson, G., Richardson, A., Gerhard, A., Snowden, J., Mann, D., Neary, D., Nalls, M. A., Peuralinna, T., Jansson, L., Isoviita, V. M., Kaivorinne, A. L., Holtta-Vuori, M., Ikonen, E., Sulkava, R., Benatar, M., Wuu, J., Chio, A., Restagno, G., Borghero, G., Sabatelli, M., Consortium, I., Heckerman, D., Rogaeva, E., Zinman, L., Rothstein, J. D., Sendtner, M., Drepper, C., Eichler, E. E., Alkan, C., Abdullaev, Z., Pack, S. D., Dutra, A., Pak, E., Hardy, J., Singleton, A., Williams, N. M., Heutink, P., Pickering-Brown, S., Morris, H. R., Tienari, P. J., \& Traynor, B. J. (2011). A hexanucleotide repeat expansion in C9ORF72 is the cause of chromosome 9p21-linked ALS-FTD [Research Support, N.I.H., Intramural Research Support, Non-U.S. Gov't Research Support, U.S. Gov't, P.H.S.]. Neuron, 72(2), 257-268. https://doi.org/10.1016/j.neuron.2011.09.010

246. Riessland, M., Kaczmarek, A., Schneider, S., Swoboda, K. J., Lohr, H., Bradler, C., Grysko, V., Dimitriadi, M., Hosseinibarkooie, S., Torres-Benito, L., Peters, M., Upadhyay, A., Biglari, N., Krober, S., Holker, I., Garbes, L., Gilissen, C., Hoischen, A., Nurnberg, G., ... Wirth, B. (2017). Neurocalcin delta suppression protects against spinal muscular atrophy in humans and across species by restoring impaired endocytosis. American Journal of Human Genetics, 100(2), 297-315. https://doi.org/10.1016/j.ajhg.2017. 01.005

247. Rigo, F., Hua, Y., Krainer, A. R., \& Bennett, C. F. (2012). Antisense-based therapy for the treatment of spinal muscular atrophy [Research Support, N.I.H., Extramural Research Support, Non-U.S. Gov't]. The Journal of Cell Biology, 199(1), 21-25. https://doi.org/10.1083/jcb.201207087

248. Rindt, H., Buckley, D. M., Vale, S. M., Krogman, M., Rose, F. F., Jr., Garcia, M. L., \& Lorson, C. L. (2012). Transgenic inactivation of murine myostatin does not decrease the severity of disease in a model of Spinal Muscular Atrophy. Neuromuscular Disorders, 22(3), 277-285. https://doi.org/10. 1016/.nmd.2011.10.012

249. Robbins, K. L., Glascock, J. J., Osman, E. Y., Miller, M. R., \& Lorson, C. L. (2014). Defining the therapeutic window in a severe animal model of spinal muscular atrophy [Research Support, N.I.H., Extramural Research Support, Non-U.S. Gov't]. Human Molecular Genetics, 23(17), 4559-4568. https://doi.org/10.1093/hmg/ddu169

250. Roberts, T. C., Langer, R., \&Wood, M. J. A. (2020). Advances in oligonucleotide drug delivery. Nature Reviews Drug Discovery, 19(10), 673-694. https://doi.org/10.1038/s41573-020-0075-7

251. Rochette, C. F., Gilbert, N., \& Simard, L. R. (2001). SMN gene duplication and the emergence of the SMN2 gene occurred in distinct hominids: SMN2 is unique to Homo sapiens [Comparative Study Research Support, Non-U.S. Gov't]. Human Genetics, 108(3), 255-266. https://doi.org/ $10.1007 / \mathrm{s} 004390100473$

252. Rogelj, B., Easton, L. E., Bogu, G. K., Stanton, L. W., Rot, G., Curk, T., Zupan, B., Sugimoto, Y., Modic, M., Haberman, N., Tollervey, J., Fujii, R., Takumi, T., Shaw, C. E., \& Ule, J. (2012). Widespread binding of FUS along nascent RNA regulates alternative splicing in the brain [Research Support, NonU.S. Gov't]. Scientific Reports, 2, 603. https://doi.org/10.1038/srep00603

253. Rohrer, J. D., Isaacs, A. M., Mizielinska, S., Mead, S., Lashley, T., Wray, S., Sidle, K., Fratta, P., Orrell, R. W., Hardy, J., Holton, J., Revesz, T., Rossor, M. N., \& Warren, J. D. (2015). C9orf72 expansions in frontotemporal dementia and amyotrophic lateral sclerosis [Case Reports Research Support, Non-U.S. Gov't Review]. The Lancet Neurology, 14(3), 291-301. https:// doi.org/10.1016/S1474-4422(14)70233-9

254. Rosen, D. R., Siddique, T., Patterson, D., Figlewicz, D. A., Sapp, P., Hentati, A., Donaldson, D., Goto, J., O'Regan, J. P., Deng, H. X., Rahmani, Z., Krizus, A., McKenna-Yasek, D., Cayabyab, A., Gaston, S. M., Berger, R., Tanzi, R. E., Halperin, J. J., Herzfeldt, B., Van den Berg, R., Hung, W. Y., Bird, T., Deng, G., Mulder, D. W., Smyth, C., Laing, N. G., Soriano, E., Pericak-Vance, M. A., Haines, J., Rouleau, G. A., Gusella, J. S., Horvitz, H. R., \& Brown Jr, R. H. (1993). Mutation in Cu/Zn superoxide dismutase gene are associated 
with familial amyotrophic lateral sclerosis. Nature 377(6547): 340-344, 362, 59-62.

255. Rossoll, W., Jablonka, S., Andreassi, C., Kroning, A. K., Karle, K., Monani, U. R., \& Sendtner, M. (2003). Smn, the spinal muscular atrophy-determining gene product, modulates axon growth and localization of beta-actin mRNA in growth cones of motoneurons. Journal of Cell Biology, 163(4), 801-812.

256. Rossoll, W., Kroning, A. K., Ohndorf, U. M., Steegborn, C., Jablonka, S., \& Sendtner, M. (2002). Specific interaction of Smn, the spinal muscular atrophy determining gene product, with hnRNP-R and gry-rbp/hnRNPQ: A role for $\mathrm{Smn}$ in RNA processing in motor axons? Human Molecular Genetics, 11(1), 93-105.

257. Rouget, R., Vigneault, F., Codio, C., Rochette, C., Paradis, I., Drouin, R., \& Simard, L. R. (2005). Characterization of the survival motor neuron (SMN) promoter provides evidence for complex combinatorial regulation in undifferentiated and differentiated P19 cells [Research Support, Non-U.S. Gov't]. Biochemical Journal, 385(Pt 2), 433-443. https://doi.org/ 10.1042/BJ20041024

258. Rudnicki, S. A., Andrews, J. A., Duong, T., Cockroft, B. M., Malik, F. I., Meng, L., Wei, J., Wolff, A. A., Genge, A., Johnson, N. E., Tesi-Rocha, C., Connolly, A. M., Darras, B. T., Felice, K., Shieh, P. B., Mah, J. K., Statland, J., Campbell, C., Habib, A. A., ... Day, J. W. (2021). Reldesemtiv in patients with spinal muscular atrophy: A phase 2 hypothesis-generating study. Neurotherapeutics. https://doi.org/10.1007/s13311-020-01004-3

259. Rudnik-Schoneborn, S., Stolz, P., Varon, R., Grohmann, K., Schachtele, M., Ketelsen, U. P., Stavrou, D., Kurz, H., Hubner, C., \& Zerres, K. (2004). Long-term observations of patients with infantile spinal muscular atrophy with respiratory distress type 1 (SMARD1). Neuropediatrics, 35(3), 174-182.

260. Ruiz, R., Casanas, J. J., Torres-Benito, L., Cano, R., \& Tabares, L. (2010). Altered intracellular $\mathrm{Ca} 2+$ homeostasis in nerve terminals of severe spinal muscular atrophy mice. Journal of Neuroscience, 30(3), 849-857.

261. Saal, L., Briese, M., Kneitz, S., Glinka, M., \& Sendtner, M. (2014). Subcellular transcriptome alterations in a cell culture model of spinal muscular atrophy point to widespread defects in axonal growth and presynaptic differentiation. RNA, 20(11), 1789-1802.

262. Sanpei, K., Takano, H., Igarashi, S., Sato, T., Oyake, M., Sasaki, H., Wakisaka, A., Tashiro, K., Ishida, Y., Ikeuchi, T., Koide, R., Saito, M., Sato, A., Tanaka, T., Hanyu, S., Takiyama, Y., Nishizawa, M., Shimizu, N., Nomura, Y., ... Tsuji, S. (1996). Identification of the spinocerebellar ataxia type 2 gene using a direct identification of repeat expansion and cloning technique, DIRECT. Nature Genetics, 14(3), 277-284. https://doi.org/10.1038/ ng1196-277

263. Scharf, J. M., Damron, D., Frisella, A., Bruno, S., Beggs, A. H., Kunkel, L. M., \& Dietrich, W. F. (1996). The mouse region syntenic for human spinal muscular atrophy lies within the Lgn1 critical interval and contains multiple copies of Naip exon 5. Genomics, 38(3), 405-417.

264. Schrank, B., Gotz, R., Gunnersen, J. M., Ure, J. M., Toyka, K. V., Smith, A. G., \& Sendtner, M. (1997). Inactivation of the survival motor neuron gene, a candidate gene for human spinal muscular atrophy, leads to massive cell death in early mouse embryos. Proceedings of the National academy of Sciences of the United States of America, 94(18), 9920-9925.

265. Sendtner, M., Arakawa, Y., St"ckli, K. A., Kreutzberg, G. W., \& Thoenen, H. (1991). Effect of ciliary neurotrophic factor (CNTF) on motoneuron survival. Journal of Cell Science Supplement, 15, 103-109.

266. Sendtner, M., Holtmann, B., Kolbeck, R., Thoenen, H., \& Barde, Y. A. (1992). Brain-derived neurotrophic factor prevents the death of motoneurons in newborn rats after nerve section. Nature 377(6547), 340-344,360, 757-758

267. Sendtner, M., Kreutzberg, G. W., \&Thoenen, H. (1990). Ciliary neurotrophic factor prevents the degeneration of motor neurons after axotomy. Nature 377(6547), 340-4, 345, 440-441.

268. Sendtner, M., Schmalbruch, H., Stockli, K. A., Carroll, P., Kreutzberg, G. W., \& Thoenen, H. (1992). Ciliary neurotrophic factor prevents degeneration of motor neurons in mouse mutant progressive motor neuronopathy. Nature 377(6547): 340-344, 358(6386), 502-504.

269. Sendtner, M., \& Thoenen, H. (1994). Neurodegenerative disease: Oxidative stress and motorneuron disease. Current Biology, 4, 1036-1039.

270. Sergott, R. C., Amorelli, G. M., Baranello, G., Barreau, E., Beres, S., Kane, S., Mercuri, E., Orazi, L., SantaMaria, M., Tremolada, G., Santarsiero, D., Waskowska, A., Yashiro, S., Denk, N., Furst-Recktenwald, S., Gerber, M.,
Gorni, K., Jaber, B., Jacobsen, B., .. Firefish, S. J. W. G. (2021). Risdiplam treatment has not led to retinal toxicity in patients with spinal muscular atrophy [Research Support, Non-U.S. Gov't]. Annals of Clinical and Translational Neurology, 8(1), 54-65. https://doi.org/10.1002/acn3.51239

271. Shafey, D., Cote, P. D., \& Kothary, R. (2005). Hypomorphic Smn knockdown C2C12 myoblasts reveal intrinsic defects in myoblast fusion and myotube morphology. Experimental Cell Research, 311(1), 49-61. https:// doi.org/10.1016/j.yexcr.2005.08.019

272. Simic, G., Seso-Simic, D., Lucassen, P. J., Islam, A., Krsnik, Z., Cviko, A., Jelasic, D., Barisic, N., Winblad, B., Kostovic, l., \& Kruslin, B. (2000). Ultrastructural analysis and TUNEL demonstrate motor neuron apoptosis in Werdnig-Hoffmann disease [Research Support, Non-U.S. Gov't]. Journal of Neuropathology and Experimental Neurology, 59(5), 398-407. https:// doi.org/10.1093/jnen/59.5.398

273. Simon, C. M., Blanco-Redondo, B., Buettner, J. M., Pagiazitis, J. G., Fletcher, E. V., Sime Longang, J. K., \& Mentis, G. Z. (2021). Chronic pharmacological increase of neuronal activity improves sensory-motor dysfunction in spinal muscular atrophy mice. Journal of Neuroscience, 41(2), 376-389. https://doi.org/10.1523/JNEUROSCI.2142-20.2020

274. Simon, C. M., Jablonka, S., Ruiz, R., Tabares, L., \& Sendtner, M. (2010). Ciliary neurotrophic factor-induced sprouting preserves motor function in a mouse model of mild spinal muscular atrophy [Research Support, Non-U.S. Gov't]. Human Molecular Genetics, 19(6), 973-986. https://doi. org/10.1093/hmg/ddp562

275. Simon, C. M., Van Alstyne, M., Lotti, F., Bianchetti, E., Tisdale, S., Watterson, D. M., Mentis, G. Z., \& Pellizzoni, L. (2019). Stasimon Contributes to the Loss of Sensory Synapses and Motor Neuron Death in a Mouse Model of Spinal Muscular Atrophy. Cell Report, 29(12), 3885-3901e3885. https:// doi.org/10.1016/j.celrep.2019.11.058

276. Singh, R. N., Ottesen, E. W., \& Singh, N. N. (2020). The first orally deliverable small molecule for the treatment of spinal muscular atrophy [review]. Neuroscience Insights, 15, 2633105520973985. https://doi.org/ $10.1177 / 2633105520973985$

277. Singh, R. N., \& Singh, N. N. (2018). Mechanism of splicing regulation of spinal muscular atrophy genes. Advances in Neurobiology, 20, 31-61. https://doi.org/10.1007/978-3-319-89689-2_2

278. Sivadasan, R., Hornburg, D., Drepper, C., Frank, N., Jablonka, S., Hansel, A., Lojewski, X., Sterneckert, J., Hermann, A., Shaw, P. J., Ince, P. G., Mann, M., Meissner, F., \& Sendtner, M. (2016). C9ORF72 interaction with cofilin modulates actin dynamics in motor neurons. Nature Neuroscience, 19(12), 1610-1618. https://doi.org/10.1038/nn.4407

279. Son, H. W., \& Yokota, T. (2018). Recent advances and clinical applications of exon inclusion for spinal muscular atrophy [Research Support, NonU.S. Gov't Review]. Methods in Molecular Biology, 1828, 57-68. https:// doi.org/10.1007/978-1-4939-8651-4_3

280. Song, Y., Morales, L., Malik, A. S., Mead, A. F., Greer, C. D., Mitchell, M. A., Petrov, M. T., Su, L. T., Choi, M. E., Rosenblum, S. T., Lu, X., VanBelzen, D. J., Krishnankutty, R. K., Balzer, F. J., Loro, E., French, R., Propert, K. J., Zhou, S., Kozyak, B. W., ... Stedman, H. H. (2019). Non-immunogenic utrophin gene therapy for the treatment of muscular dystrophy animal models [Research Support, NIH, Extramural Research Support, Non-U.S. Gov't]. Nature Medicine, 25(10), 1505-1511. https://doi.org/10.1038/ s41591-019-0594-0

281. Soppet, D., Escandon, E., Maragos, J., Middlemas, D. S., Reid, S. W., Blair, J., Burton, L. E., Stanton, B. R., Kaplan, D. R., Hunter, T., Nikolics, K., \& Parada, L. F. (1991). The neurotrophic factors brain-derived neurotrophic factor and neurotrophin-3 are ligands for the trk B tyrosine kinase receptor. Cell 77(5): 727-736, 65, 895-903.

282. Stratigopoulos, G., Lanzano, P., Deng, L., Guo, J., Kaufmann, P., Darras, B., Finkel, R., Tawil, R., McDermott, M. P., Martens, W., Devivo, D. C., \& Chung, W. K. (2010). Association of plastin 3 expression with disease severity in spinal muscular atrophy only in postpubertal females [Research Support, N.I.H., Extramural Research Support, Non-U.S. Gov't]. Archives of Neurology, 67(10), 1252-1256. https://doi.org/10.1001/archneurol.2010. 239

283. Strauss, K. A., Carson, V. J., Brigatti, K. W., Young, M., Robinson, D. L., Hendrickson, C., Fox, M. D., Reed, R. M., Puffenberger, E. G., Mackenzie, W., \& Miller, F. (2018). Preliminary Safety and Tolerability of a Novel Subcutaneous Intrathecal Catheter System for Repeated Outpatient Dosing of Nusinersen to Children and Adults With Spinal Muscular Atrophy. 
Journal of Pediatric Orthopedics, 38(10), e610-e617. https://doi.org/10. 1097/BPO.0000000000001247

284. Sumner, C. J., Wee, C. D., Warsing, L. C., Choe, D. W., Ng, A. S., Lutz, C., \& Wagner, K. R. (2009). Inhibition of myostatin does not ameliorate disease features of severe spinal muscular atrophy mice. Human Molecular Genetics, 18(17), 3145-3152. https://doi.org/10.1093/hmg/ddp253

285. Sunyach, C., Michaud, M., Arnoux, T., Bernard-Marissal, N., Aebischer, J., Latyszenok, V., Gouarne, C., Raoul, C., Pruss, R. M., Bordet, T., \& Pettmann, B. (2012). Olesoxime delays muscle denervation, astrogliosis, microglial activation and motoneuron death in an ALS mouse model [Comparative Study Research Support, Non-U.S. Gov't]. Neuropharmacology, 62(7), 2346-2352. https://doi.org/10.1016/j.neuropharm.2012.02.013

286. Swinnen, B., Bento-Abreu, A., Gendron, T. F., Boeynaems, S., Bogaert, E., Nuyts, R., Timmers, M., Scheveneels, W., Hersmus, N., Wang, J., Mizielinska, S., Isaacs, A. M., Petrucelli, L., Lemmens, R., Van Damme, P., Van Den Bosch, L., \& Robberecht, W. (2018). A zebrafish model for C9orf72 ALS reveals RNA toxicity as a pathogenic mechanism [Research Support, Non-U.S. Gov't]. Acta Neuropathologica, 135(3), 427-443. https://doi.org/ 10.1007/s00401-017-1796-5

287. Takanashi, J. I., \& Takase, N. (2019). Reader response: Evidence in focus: Nusinersen use in spinal muscular atrophy: Report of the Guideline Development, Dissemination, and Implementation Subcommittee of the American Academy of Neurology [Comment]. Neurology, 93(10), 464. https://doi.org/10.1212/WNL.0000000000008074

288. Tan, A. Y., \& Manley, J. L. (2010). TLS inhibits RNA polymerase III transcription [Research Support, N.I.H., Extramural Research Support, Non-U.S. Gov't]. Molecular and Cellular Biology, 30(1), 186-196. https://doi.org/10. 1128/MCB.00884-09

289. Tarr, T. B., Malick, W., Liang, M., Valdomir, G., Frasso, M., Lacomis, D., Reddel, S. W., Garcia-Ocano, A., Wipf, P., \& Meriney, S. D. (2013). Evaluation of a novel calcium channel agonist for therapeutic potential in Lambert-Eaton myasthenic syndrome. Journal of Neuroscience, 33(25), 10559-10567.

290. Taylor, J. P., Brown, R. H., Jr., \& Cleveland, D. W. (2016). Decoding ALS: from genes to mechanism [Research Support, N.I.H., Extramural Research Support, Non-U.S. Gov't Review]. Nature, 539(7628), 197-206. https://doi.org/10.1038/nature20413

291. Tejero, R., Balk, S., Franco-Espin, J., Ojeda, J., Hennlein, L., Drexl, H., Dombert, B., Clausen, J. D., Torres-Benito, L., Saal-Bauernschubert, L., Blum, R., Briese, M., Appenzeller, S., Tabares, L., \& Jablonka, S. (2020). R-Roscovitine improves motoneuron function in mouse models for spinal muscular atrophy. iScience, 23(2), 100826. https://doi.org/10.1016/j. isci.2020.100826

292. Tejero, R., Lopez-Manzaneda, M., Arumugam, S., \& Tabares, L. (2016). Synaptotagmin-2, and -1, linked to neurotransmission impairment and vulnerability in Spinal Muscular Atrophy. Human Molecular Genetics, 25(21), 4703-4716.

293. Torres-Benito, L., Schneider, S., Rombo, R., Ling, K. K., Grysko, V., Upadhyay, A., Kononenko, N. L., Rigo, F., Bennett, C. F., \& Wirth, B. (2019). NCALD antisense oligonucleotide therapy in addition to nusinersen further ameliorates spinal muscular atrophy in mice. American Journal of Human Genetics, 105(1), 221-230. https://doi.org/10.1016/j.ajhg.2019. 05.008

294. Tsai, L. K., Chen, C. L., Ting, C. H., Lin-Chao, S., Hwu, W. L., Dodge, J. C., Passini, M. A., \& Cheng, S. H. (2014). Systemic administration of a recombinant AAV1 vector encoding IGF-1 improves disease manifestations in SMA mice. Molecular Therapy, 22(8), 1450-1459. https://doi.org/10. 1038/mt.2014.84

295. Tseng, Y. T., Chen, C. S., Jong, Y. J., Chang, F. R., \& Lo, Y. C. (2016). Loganin possesses neuroprotective properties, restores SMN protein and activates protein synthesis positive regulator Akt/mTOR in experimental models of spinal muscular atrophy. Pharmacological Research, 111, 58-75. https://doi.org/10.1016/.jphrs.2016.05.023

296. Tsuiji, H., Iguchi, Y., Furuya, A., Kataoka, A., Hatsuta, H., Atsuta, N., Tanaka, F., Hashizume, Y., Akatsu, H., Murayama, S., Sobue, G., \& Yamanaka, K. (2013). Spliceosome integrity is defective in the motor neuron diseases ALS and SMA. EMBO Molecular Medicine, 5(2), 221-234.

297. Udagawa, T., Fujioka, Y., Tanaka, M., Honda, D., Yokoi, S., Riku, Y., Ibi, D., Nagai, T., Yamada, K., Watanabe, H., Katsuno, M., Inada, T., Ohno, K. Sokabe, M., Okado, H., Ishigaki, S., \& Sobue, G. (2015). FUS regulates AMPA receptor function and FTLD/ALS-associated behaviour via GluA1
mRNA stabilization [Research Support, Non-U.S. Gov't]. Nature Communications, 6, 7098. https://doi.org/10.1038/ncomms8098

298. Upadhyay, A., Hosseinibarkooie, S., Schneider, S., Kaczmarek, A., TorresBenito, L., Mendoza-Ferreira, N., Overhoff, M., Rombo, R., Grysko, V., Kye, M. J., Kononenko, N. L., \& Wirth, B. (2019). Neurocalcin delta knockout impairs adult neurogenesis whereas half reduction is not pathological. Frontiers in Molecular Neuroscience, 12, 19. https://doi.org/10.3389/ fnmol.2019.00019

299. Valori, C. F., Ning, K., Wyles, M., Mead, R. J., Grierson, A. J., Shaw, P. J., \& Azzouz, M. (2010). Systemic delivery of scAAV9 expressing SMN prolongs survival in a model of spinal muscular atrophy. Science Translational Medicine, 2(35), 35ra42. https://doi.org/10.1126/scitranslmed. 3000830

300. Van Alstyne, M., Simon, C. M., Sardi, S. P., Shihabuddin, L. S., Mentis, G. Z., \& Pellizzoni, L. (2018). Dysregulation of Mdm2 and Mdm4 alternative splicing underlies motor neuron death in spinal muscular atrophy [Research Support, N.I.H., Extramural Research Support, U.S. Gov't, NonP.H.S.]. Genes \& Development, 32(15-16), 1045-1059. https://doi.org/10. 1101/gad.316059.118

301. Van Alstyne, M., Tattoli, I., Delestree, N., Recinos, Y., Workman, E., Shihabuddin, L. S., Zhang, C., Mentis, G. Z., \& Pellizzoni, L. (2021). Gain of toxic function by long-term AAV9-mediated SMN overexpression in the sensorimotor circuit. Nature Neuroscience. https://doi.org/10.1038/ s41593-021-00827-3

302. van Blitterswijk, M., DeJesus-Hernandez, M., Niemantsverdriet, E., Murray, M. E., Heckman, M. G., Diehl, N. N., Brown, P. H., Baker, M. C., Finch, N. A., Bauer, P. O., Serrano, G., Beach, T. G., Josephs, K. A., Knopman, D. S., Petersen, R. C., Boeve, B. F., Graff-Radford, N. R., Boylan, K. B., Petrucelli, L., ... Rademakers, R. (2013). Association between repeat sizes and clinical and pathological characteristics in carriers of C9ORF72 repeat expansions (Xpansize-72): a cross-sectional cohort study [Comparative Study Research Support, N.I.H., Extramural Research Support, Non-U.S. Gov't]. The Lancet Neurology, 12(10), 978-988. https://doi.org/10.1016/S14744422(13)70210-2

303. Van Langenhove, T., van der Zee, J., Sleegers, K., Engelborghs, S., Vandenberghe, R., Gijselinck, I., Van den Broeck, M., Mattheijssens, M., Peeters, K., De Deyn, P. P., Cruts, M., \& Van Broeckhoven, C. (2010). Genetic contribution of FUS to frontotemporal lobar degeneration [Research Support, Non-U.S. Gov't]. Neurology, 74(5), 366-371. https:// doi.org/10.1212/WNL.0b013e3181ccc732

304. Vance, C., Rogelj, B., Hortobagyi, T., De Vos, K. J., Nishimura, A. L., Sreedharan, J., Hu, X., Smith, B., Ruddy, D., Wright, P., Ganesalingam, J., Williams, K. L., Tripathi, V., Al-Saraj, S., Al-Chalabi, A., Leigh, P. N., Blair, I. P., Nicholson, G., de Belleroche, J., ... Shaw, C. E. (2009). Mutations in FUS, an RNA processing protein, cause familial amyotrophic lateral sclerosis type 6 [Research Support, Non-U.S. Gov't]. Science, 323(5918), 1208-1211. https://doi.org/10.1126/science.1165942

305. Verhaart, I. E. C., Robertson, A., Wilson, I. J., Aartsma-Rus, A., Cameron, S., Jones, C. C., Cook, S. F., \& Lochmuller, H. (2017). Prevalence, incidence and carrier frequency of $5 q$-linked spinal muscular atrophy-A literature review. Orphanet Journal of Rare Diseases, 12(1), 124. https://doi. org/10.1186/s13023-017-0671-8

306. Verhaart, I. E. C., \& Aartsma-Rus, A. (2019). Therapeutic developments for Duchenne muscular dystrophy. Nature Reviews Neurology, 15(7), 373-386. https://doi.org/10.1038/s41582-019-0203-3

307. Villalon, E., Shababi, M., Kline, R., Lorson, Z. C., Florea, K. M., \& Lorson, C. L. (2018). Selective vulnerability in neuronal populations in $\mathrm{nmd} /$ SMARD1 mice. Human Molecular Genetics, 27(4), 679-690. https://doi.org/10. 1093/hmg/ddx434

308. Vrbova, G., \& Slawinska, U. (2018). Critical period of neuromuscular development: Importance for a new treatment of SMA. Neuromuscular Disorders, 28(5), 385-393. https://doi.org/10.1016/j.nmd.2018.03.007

309. Wadman, R. I., Stam, M., Jansen, M. D., van der Weegen, Y., Wijngaarde, C. A., Harschnitz, O., Sodaar, P., Braun, K. P., Dooijes, D., Lemmink, H. H., van den Berg, L. H., \& van der Pol, W. L. (2016). A comparative study of SMN protein and mRNA in blood and fibroblasts in patients with spinal muscular atrophy and healthy controls [Clinical Trial Comparative Study]. PLOS ONE, 11(11), e0167087. https://doi.org/10.1371/journal.pone.01670 87

310. Wadman, R. I., Vrancken, A. F., van den Berg, L. H., \& van der Pol, W. L. (2012). Dysfunction of the neuromuscular junction in spinal muscular 
atrophy types 2 and 3. Neurology, 79(20), 2050-2055. https://doi.org/10. 1212/WNL.0b013e3182749eca

311. Walker, M. P., Rajendra, T. K., Saieva, L., Fuentes, J. L., Pellizzoni, L., \& Matera, A. G. (2008). SMN complex localizes to the sarcomeric Z-disc and is a proteolytic target of calpain. Human Molecular Genetics, 17(21), 3399-3410. https://doi.org/10.1093/hmg/ddn234

312. Wang, D., Tai, P. W. L., \& Gao, G. (2019). Adeno-associated virus vector as a platform for gene therapy delivery. Nature Reviews Drug Discovery, 18(5), 358-378. https://doi.org/10.1038/s41573-019-0012-9

313. Wang, X., Arai, S., Song, X., Reichart, D., Du, K., Pascual, G., Tempst, P., Rosenfeld, M. G., Glass, C. K. \& Kurokawa, R. (2008). Induced ncRNAs allosterically modify RNA-binding proteins in cis to inhibit transcription [Research Support, N.I.H., Extramural]. Nature, 454(7200), 126-130. https://doi.org/10.1038/nature06992

314. Weaver, J. J., Natarajan, N., Shaw, D. W. W., Apkon, S. D., Koo, K. S. H., Shivaram, G. M., \& Monroe, E. J. (2018). Transforaminal intrathecal delivery of nusinersen using cone-beam computed tomography for children with spinal muscular atrophy and extensive surgical instrumentation: Early results of technical success and safety. Pediatric Radiology, 48(3), 392-397. https://doi.org/10.1007/s00247-017-4031-6

315. Wen, X., Tan, W., Westergard, T., Krishnamurthy, K., Markandaiah, S. S., Shi, Y., Lin, S., Shneider, N. A., Monaghan, J., Pandey, U. B., Pasinelli, P., Ichida, J. K., \& Trotti, D. (2014). Antisense proline-arginine RAN dipeptides linked to C9ORF72-ALS/FTD form toxic nuclear aggregates that initiate in vitro and in vivo neuronal death [Research Support, N.I.H., Extramural Research Support, Non-U.S. Gov't]. Neuron, 84(6), 1213-1225. https:// doi.org/10.1016/j.neuron.2014.12.010

316. Werdnig, G. (1891). Zwei frühinfantile hereditäre Fälle von progressiver Muskelatrophie unter dem Bilde der Dystrophie, aber auf neurotischer Grundlage. Archiv für Psychiatrie und Nervenkrankheiten, 22, 437.

317. Winkler, C., Eggert, C., Gradl, D., Meister, G., Giegerich, M., Wedlich, D., Laggerbauer, B., \& Fischer, U. (2005). Reduced U snRNP assembly causes motor axon degeneration in an animal model for spinal muscular atrophy. Genes \& Development, 19(19), 2320-2330.

318. Wirth, B. (2000). An update of the mutation spectrum of the survival motor neuron gene (SMN1) in autosomal recessive spinal muscular atrophy (SMA). Human Mutation, 15(3), 228-237.

319. Wirth, B., Brichta, L., Schrank, B., Lochmuller, H., Blick, S., Baasner, A., \& Heller, R. (2006). Mildly affected patients with spinal muscular atrophy are partially protected by an increased SMN2 copy number. Human Genetics, 119(4), 422-428. (IN FILE).

320. Wirth, B. Herz, M., Wetter, A. Moskau, S., Hahnen, E, Rudnik-Schoneborn, S., Wienker, T., \& Zerres, K. (1999). Quantitative analysis of survival motor neuron copies: Identification of subtle SMN1 mutations in patients with spinal muscular atrophy, genotype-phenotype correlation, and implications for genetic counseling. American Journal of Human Genetics, 64(5), 1340-1356.

321. Wirth, B., Karakaya, M., Kye, M. J., \& Mendoza-Ferreira, N. (2020). Twenty-five years of spinal muscular atrophy research: From phenotype to genotype to therapy, and what comes next. Annual Review of Genomics and Human Genetics. https://doi.org/10.1146/annur ev-genom-102319-103602

322. Wong, V., Arriga, R., Ip, N., \& Lindsay, R. M. (1993). The neurotrophins BDNF, NT-3 and NT-4/5, but not NGF, upregulate the cholinergic phenotype of developing motoneurons. European Journal of Neuroscience, 5, 466-474. (IN FILE).

323. Yamazaki, T., Chen, S., Yu, Y., Yan, B., Haertlein, T. C., Carrasco, M. A., Tapia, J. C., Zhai, B., Das, R., Lalancette-Hebert, M., Sharma, A., Chandran, S., Sullivan, G., Nishimura, A. L., Shaw, C. E., Gygi, S. P., Shneider, N. A., Maniatis, T., \& Reed, R. (2012). FUS-SMN protein interactions link the motor neuron diseases ALS and SMA. Cell Reports, 2(4), 799-806.

324. Yan, Z., Chi, P., Bibb, J. A., Ryan, T. A., \& Greengard, P. (2002). Roscovitine: A novel regulator of P/Q-type calcium channels and transmitter release in central neurons. Journal of Physiology, 540(Pt 3), 761-770.

325. Yasuda, K., Clatterbuck-Soper, S. F., Jackrel, M. E., Shorter, J., \& Mili, S. (2017). FUS inclusions disrupt RNA localization by sequestering kinesin-1 and inhibiting microtubule detyrosination. Journal of Cell Biology, 216(4), 1015-1034. https://doi.org/10.1083/jcb.201608022

326. Yasuda, K., \& Mili, S. (2016). Dysregulated axonal RNA translation in amyotrophic lateral sclerosis. Wiley Interdisciplinary Reviews: RNA, 7(5), 589-603. https://doi.org/10.1002/wrna.1352
327. Yokoi, S., Udagawa, T., Fujioka, Y., Honda, D., Okado, H., Watanabe, H., Katsuno, M., Ishigaki, S., \& Sobue, G. (2017). 3'UTR length-dependent control of SynGAP Isoform alpha2 mRNA by FUS and ELAV-like proteins promotes dendritic spine maturation and cognitive function. Cell Reports, 20(13), 3071-3084. https://doi.org/10.1016/j.celrep.2017.08.100

328. Yoon, J. H., Chandrasekharan, K., Xu, R., Glass, M., Singhal, N., \& Martin, P. T. (2009). The synaptic CT carbohydrate modulates binding and expression of extracellular matrix proteins in skeletal muscle: Partial dependence on utrophin [Research Support, N.I.H., Extramural]. Molecular and Cellular Neuroscience, 41(4), 448-463. https://doi.org/10.1016/j.mcn. 2009.04.013

329. Yoshiyama, Y., Lee, V. M., \& Trojanowski, J. Q. (2013). Therapeutic strategies for tau mediated neurodegeneration [Research Support, Non-U.S. Gov't Review]. Journal of Neurology, Neurosurgery \& Psychiatry, 84(7), 784-795. https://doi.org/10.1136/jnnp-2012-303144

330. Zaworski, P., von Herrmann, K. M., Taylor, S., Sunshine, S. S., McCarthy, K., Risher, N., Newcomb, T., Weetall, M., Prior, T. W., Swoboda, K. J., Chen, K. S., \& Paushkin, S. (2016). SMN protein can be reliably measured in whole blood with an Electrochemiluminescence (ECL) immunoassay: Implications for clinical trials [Research Support, N.I.H., Extramural Research Support, Non-U.S. Gov't]. PLoS ONE, 11(3), 640. https://doi.org/10.1371/ journal.pone.0150640

331. Zhou, H., Meng, J., Malerba, A., Catapano, F., Sintusek, P., Jarmin, S., Feng, L., Lu-Nguyen, N., Sun, L., Mariot, V., Dumonceaux, J., Morgan, J. E., Gissen, P., Dickson, G., \& Muntoni, F. (2020). Myostatin inhibition in combination with antisense oligonucleotide therapy improves outcomes in spinal muscular atrophy. Journal of Cachexia, Sarcopenia and Muscle 11(3), 768-782. https://doi.org/10.1002/jcsm.12542

332. Zhu, X., Hadhazy, M., Wehling, M., Tidball, J. G., \& McNally, E. M. (2000). Dominant negative myostatin produces hypertrophy without hyperplasia in muscle. FEBS Letters, 474(1), 71-75. https://doi.org/10.1016/ s0014-5793(00)01570-2

333. Zinszner, H., Sok, J., Immanuel, D., Yin, Y., \& Ron, D. (1997). TLS (FUS) binds RNA in vivo and engages in nucleo-cytoplasmic shuttling [Research Support, Non-U.S. Gov't Research Support, U.S. Gov't, P.H.S.] Journal of Cell Science, 110(Pt 15), 1741-1750.

334. Zou, Z. Y., Zhou, Z. R., Che, C. H., Liu, C. Y., He, R. L., \& Huang, H. P. (2017). Genetic epidemiology of amyotrophic lateral sclerosis: A systematic review and meta-analysis [Meta-Analysis Review Systematic Review]. Journal of Neurology, Neurosurgery and Psychiatry, 88(7), 540-549. https://doi.org/10.1136/jnnp-2016-315018

335. Zu, T., Liu, Y., Banez-Coronel, M., Reid, T., Pletnikova, O., Lewis, J., Miller, T. M., Harms, M. B., Falchook, A. E., Subramony, S. H., Ostrow, L. W., Rothstein, J. D., Troncoso, J. C., \& Ranum, L. P. (2013). RAN proteins and RNA foci from antisense transcripts in C9ORF72 ALS and frontotemporal dementia [Clinical Trial Research Support, N.I.H., Extramural Research Support, Non-U.S. Gov't]. Proceedings of the National Academy of Sciences USA, 110(51), E4968-4977. https://doi.org/10.1073/pnas.13154 38110

\section{Publisher's Note}

Springer Nature remains neutral with regard to jurisdictional claims in published maps and institutional affiliations.

Ready to submit your research? Choose BMC and benefit from:

- fast, convenient online submission

- thorough peer review by experienced researchers in your field

- rapid publication on acceptance

- support for research data, including large and complex data types

- gold Open Access which fosters wider collaboration and increased citations

- maximum visibility for your research: over $100 \mathrm{M}$ website views per year

At BMC, research is always in progress.

Learn more biomedcentral.com/submissions 